\title{
Modelo preditivo para perda de crédito e sua aplicação em
} decisão de spread

João Fernando Serrajordia Rocha de Mello

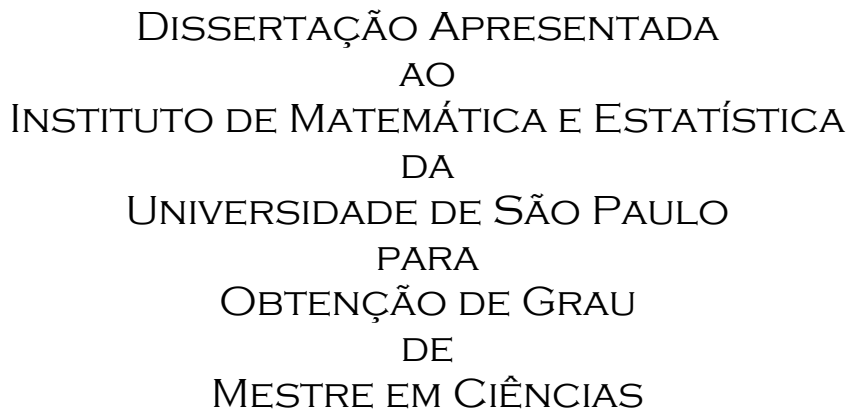

Programa: Estatística

Orientador: Prof. Dr. Carlos Alberto de Bragança Pereira 


\title{
Modelo preditivo para perda de crédito e sua aplicação em \\ decisão de spread
}

\author{
Este exemplar corresponde à redação da dissertação \\ devidamente corrigida e apresentada por \\ João Fernando Serrajordia Rocha de Mello, \\ e avaliada pela Comissão Julgadora.
}

Banca examinadora:

- Prof. Dr. Carlos Alberto de Bragança Pereira (orientador) - IME-USP

- Prof. Dr. Marco Dimas Gubitoso - IME-USP

- Prof. Carlos Alberto Ribeiro Diniz - DEs-UFSCar 


\section{Inspiração}

"Eu me enganei apenas uma vez, quando pensei estar enganado" Rubén Aguirre, o Professor Girafales

Parafraseando Julio Cesar: "Alea jacta erat, alea agnosco est nunc" ou "A sorte era lançada, ela agora é compreendida". 


\section{Dedicatória}

A conclusão deste trabalho dedico aos meus pais, Samuel Rocha de Mello e Ana Maria Serrajordia Ros de Mello e aos meus irmãos Pedro Paulo Serrajordia Rocha de Mello e Mariana Serrajordia Lopes.

O Conteúdo deste trabalho dedico ao desenvolvimento da minha pessoa, em benefício de toda a Sociedade e da Ciência, nesta ordem. 


\section{Agradecimentos}

Agradeço primeiramente ao Carlos Alberto de Bragança Pereira, meu orientador, pela convivência, incentivo, aprendizado, orientação e também pela amizade durante estes anos todos que estive no IME.

Agradeço ao meu pai, Samuel Rocha de Mello, que apesar de me tentar ao ócio durante alguns dos escassos momentos disponíveis para a realização deste trabalho, me deu apoio fundamental para o termino deste trabalho. Também à minha mãe, Ana Maria Serrajordia Ros de Mello, por todo o carinho e apoio que sempre me deram forças para o alcance dos meus objetivos, este trabalho inclusive.

Agradeço ao meu irmão mais velho, Pedro Paulo Serrajordia Rocha de Mello, pelos conselhos, pelos exemplos, pelas conversas e pelo apoio fornecido mesmo que de outro continente. À minha irmã, Mariana Rocha de Mello Serrajordia Lopes, pelo companheirismo, carinho e tudo de bom que me ensina. Ao meu irmão mais novo a quem eu aprendi a amar sem esperar nada em troca, Guilherme Serrajordia Rocha de Mello, por tudo que ele nem imagina que me ensina.

Aos integrantes de círculo de que me orgulho de pertencer: Renan Caron, André Yoshizumi Gomes, Camila Tiemi de Oliveira, Dalila de Moraes, Everton Gustavo Moura, Felipe Domingues Araujo, Fernando Lemonje Westrupp, Guilherme Barreto Fernandes, Josué Tzan Hsin Ma, Mateus Rodrigues Iritani, Melissa Brandão Figueiroa de Sousa, Michelle Schuindt do Carmo, Nilton Tsuchiya, Patricia Naomi Uehara, Sergio Leopoldino Barbosa Leite, Tiago Silva Mendonça, não esquecendo de Sarah Helena Moya, Debora Sotovia Medeiros, Luanna D’Maschio Vargas, Camilo Albertini Viggiani e Danilo Clemente Coelho, pelas discussões, incentivo, amizade, momentos de descontração e companheirismo. Menciono também Alexandre Ryuzo Shinzato e Evana Rafaela Minatel, pelo apredizado, convivência e pela amizade viva até hoje! A todos estes, em memória aos tantos momentos que passamos, das tantas conquistas que tiveram por mérito próprio que me fazem orgulhar-me deles, das que tiveram também com minha ajuda, apoio e amizade - que me dão um orgulho com sabor especial, eis aqui, uma conquista, agora minha, para que vocês possam também compartilhar da minha realização! 


\section{Resumo}

Métodos analíticos para concessão de crédito vêm apresentando enormes avanços nas últimas décadas, particularmente no que se refere a métodos estatísticos de classificação para identificar grupos de indivíduos com diferentes taxas de inadimplência. A maioria dos trabalhos existentes sugere decisões do tipo conceder o crédito ou não, considerando apenas de forma marginal o resultado esperado da operação.

O presente trabalho tem o objetivo de propor um modelo de avaliação de risco de crédito mais complexo que os tradicionais modelos de "Credit Scoring", que forneça uma perspectiva mais detalhada acerca do desempenho futuro de um contrato de crédito, e que vá além da classificação entre bom e mau pagador. Aliado a este ganho de informação na previsibilidade oferecida pelo modelo, também é objetivo ampliar o espaço de decisões do problema, saindo de uma resposta binária (como aceitar/rejeitar o crédito) para algo que responda à seguinte pergunta: "qual é a taxa justa para cobrir determinado risco?".

Palavras-chave: Risco de crédito, Análise de sobrevivência, Regressão logística.

\section{Abstract}

Analytical methods for granting credit are presenting enormous advances in recent decades, particularly in the field of statistical methods of classification to identify groups of individuals with different rates of default. Most of the existing work suggests decisions of the type granting credit or not, regarding just marginally the expected outcome of the operation.

This work aims to propose a model to evaluate credit risk with more complexity than the traditional "Credit Scoring" models, providing a more detailed view about the future performance of a credit agreement, which goes beyond the classification of good and bad payers. Coupled with this improvement of information offered by the model, it is also this work's aim to expand the decision space of the problem, leaving a binary response (such as accept/reject the claim) to something that answers the following question: "what is the fair rate to cover a given risk ".

Key-words: Credit risk, Survival Analysis, Logistic Regression. 


\section{SUMÁRIO}

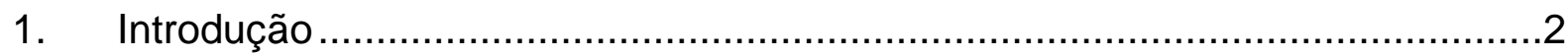

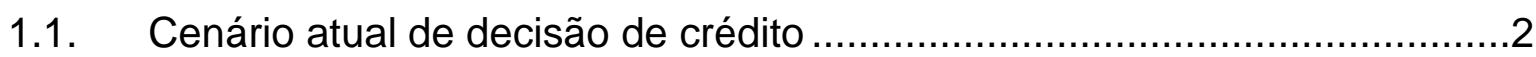

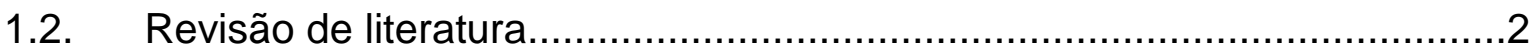

1.3. Decisão de crédito baseada em perda .......................................................

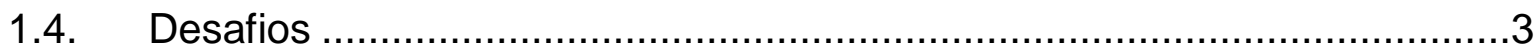

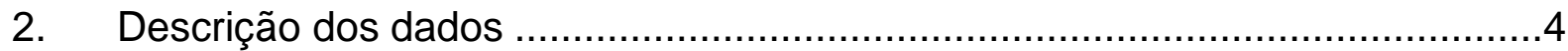

2.1. Desenho da simulação ........................................................................

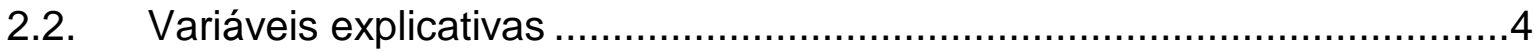

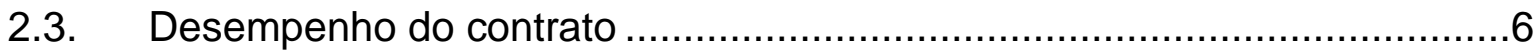

2.4. Simulação das informações de desempenho da operação ...........................7

2.5. Cálculo do resultado da operação .......................................................

2.6. Definição das variáveis resposta...........................................................13

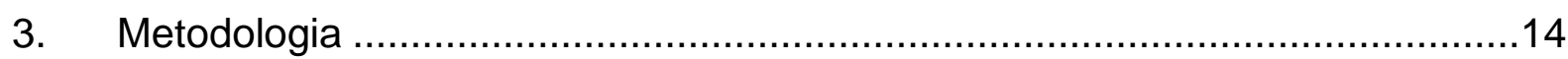

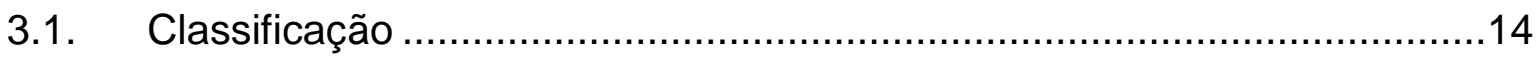

3.2. Avaliação dos modelos de classificação ……….................................17

3.2.1. Análise das estimativas condicionais................................................17

3.2.2. Análise das estimativas conjuntas .................................................19

3.3. Previsão da parcela de encerramento .......................................................21

3.3.1. Variáveis dependentes do tempo ………......................................27

3.3.2. Avaliação dos modelos de tempo até evento ......................................28

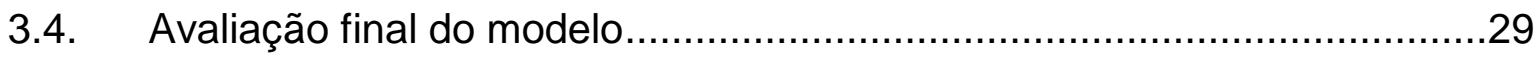

3.5. Cálculo do resultado esperado da operação ...........................................30

3.6. Definição da taxa mínima ........................................................................ 


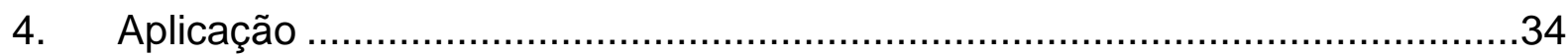

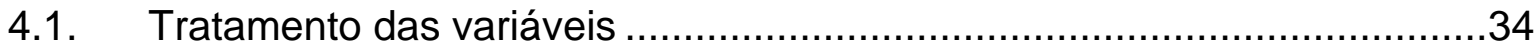

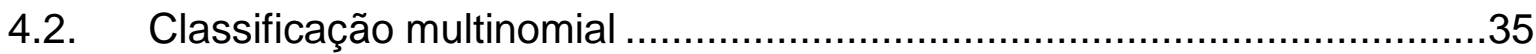

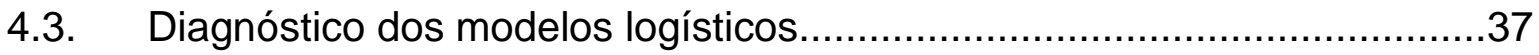

4.4. Parcela de encerramento ….............................................................

4.5. Diagnóstico do tempo até evento ……………...................................42

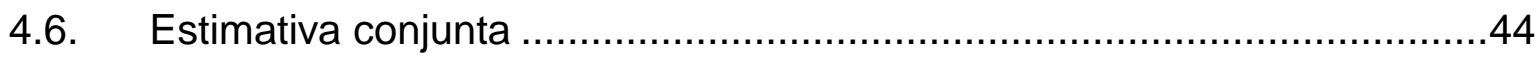

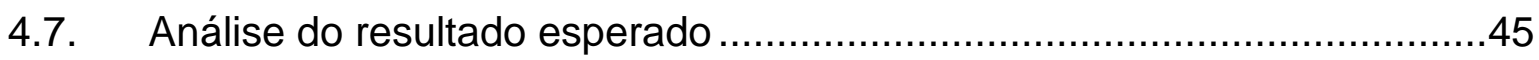

4.8. Otimização do spread mínimo da operação ………………......................48

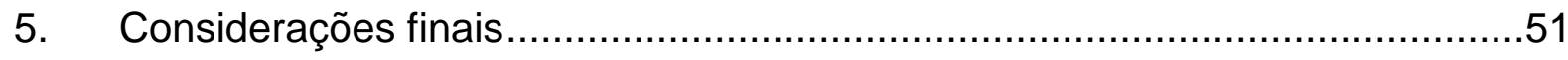

5.1. Utilização de contratos não finalizados ..................................................51

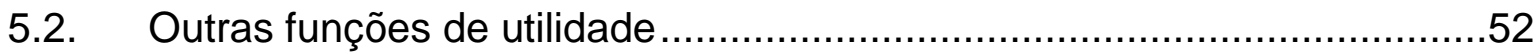

5.3. Parâmetros para alocação de capital ..........................................................53

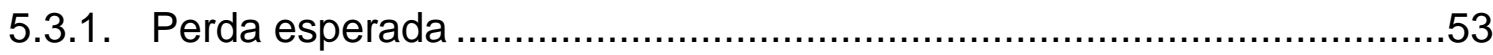

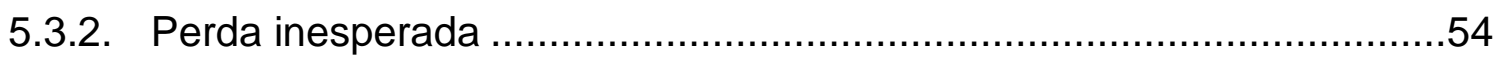

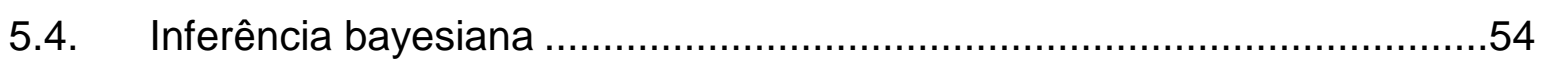

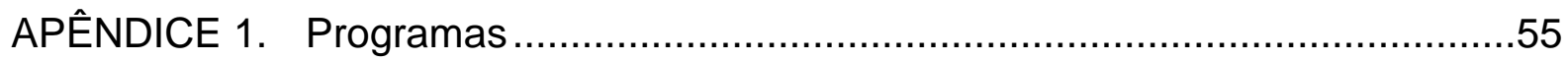

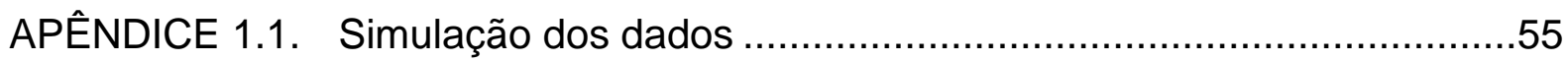

APÊNDICE 1.2. Simulação da situação de encerramento.....................................56

APÊNDICE 1.3. Simulação do tempo até evento ...............................................57

APÊNDICE 1.4. Macro para categorizar variáveis por quantís..............................59

APÊNDICE 1.5. Estimação dos parâmetros de classificação..................................61

APÊNDICE 1.6. Estimação dos parâmetros de tempo até evento ..........................62

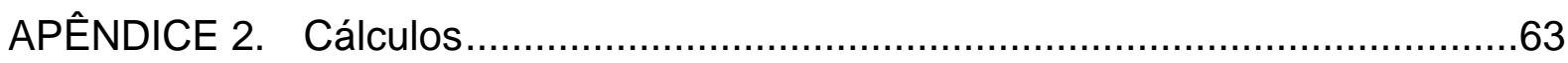

APÊNDICE 2.1. Modelo multinomial condicionado..............................................63

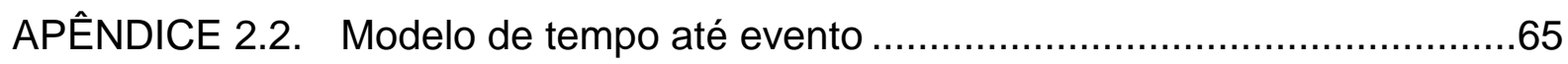

APÊNDICE 2.3. Modelo de tempo até evento com riscos competitivos .................68 


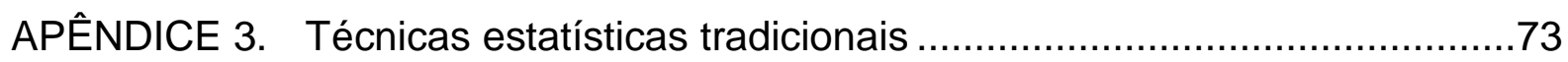

APÊNDICE 3.1. Teste de Hosmer \& Lemeshow ...................................................73

APÊNDICE 3.2. Estatística de Kolmogorov \& Smirnov ..........................................74

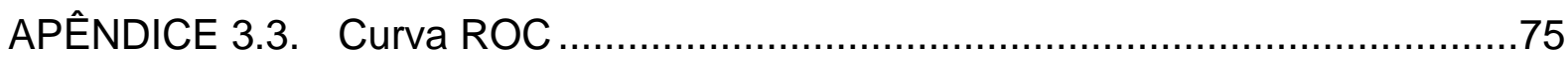




\section{Índice de tabelas}

TABELA 2.1. Exemplo para cálculo de resultado de operação de crédito ................10

TABELA 2.2. Exemplo de resultado para operações quitadas sem sinistro ..............11

TABELA 2.3. Exemplo de resultado para operações quitadas com sinistro ..............12

TABELA 2.4. Exemplo de resultado para operações lançadas a prejuízo .................12

TABELA 3.1. Exemplo da tabela original de contratos do Grupo 1.........................24

TABELA 3.2. Exemplo da tabela modificada de contratos do Grupo 1 ....................24

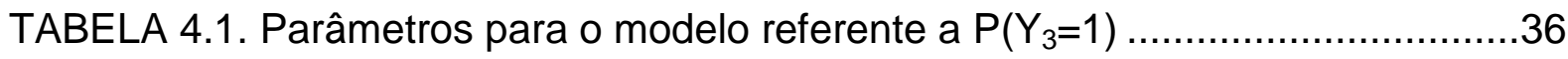

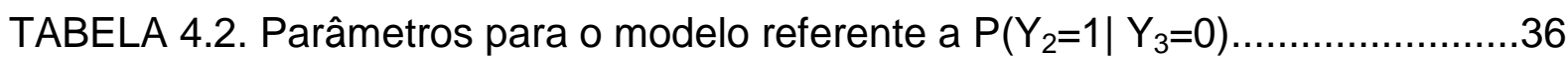

TABELA 4.3. Teste de Hosmer e Lemeshow do modelo de classificação 1 ...............37

TABELA 4.4. Poder de classificação do modelo 1 ................................................

TABELA 4.5. Teste de Hosmer e Lemeshow do modelo de classificação 2 ...............38

TABELA 4.6. Poder de classificação do modelo 2 ….............................................39

TABELA 4.7. Diagnóstico da classificação multinomial ...........................................39

TABELA 4.8. Estimativas do modelo de parcela de encerramento no Grupo 1 .........41

TABELA 4.9. Estimativas do modelo de parcela de encerramento no Grupo 2........41

TABELA 4.10. Estimativas do modelo de parcela de encerramento no Grupo 3 ......42

TABELA 4.11. Resultado total das operações: observado versus esperado .............46 


\section{Índice de figuras}

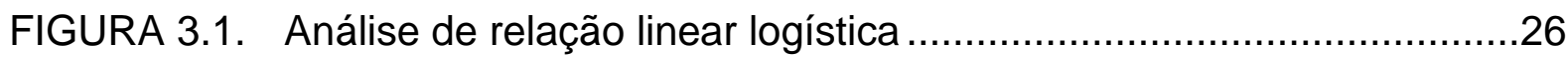

FIGURA 4.1. Curva ROC do modelo de classificação 1 .......................................38

FIGURA 4.2. Curva ROC do modelo de classificação 2 ..........................................39

FIGURA 4.3. Diagnóstico de curvas de sobrevida por prazo para o Grupo 1 ........43

FIGURA 4.4. Diagnóstico de curvas de sobrevida por prazo para o Grupo 2 ........43

FIGURA 4.5. Diagnóstico de curvas de sobrevida por prazo para o Grupo 3 ........44

FIGURA 4.6. Utilidades acumuladas, esperada e observada..............................47

FIGURA 4.7. Distribuição do Spread observado por decil de Spread sugerido.....48

FIGURA 4.8. Resultado esperado e observado por decil de spread sugerido ......49 


\section{Dissertação}

\section{Introdução}

\subsection{Cenário atual de decisão de crédito}

Atualmente, decisões de concessão ou não de crédito são tomadas por instituições bancárias baseando-se em modelos estatísticos construídos para prever contratos inadimplentes, no momento da concessão de crédito, buscando classificar seus clientes como bons e maus pagadores (Rosa, 2000). As definições mais observadas de mau pagador são funções dos dias em atraso (ex: atraso superior a 60 dias em um período de 12 meses após o início do contrato). As decisões de concessão ou não de crédito a um dado contrato são então realizadas com base na proporção de mau pagadores do perfil correspondente a que o contrato pertence. Em alguns casos, a instituição estima a perda média de um contrato "mau pagador" e a receita média de um "bom pagador", tornando mais objetiva a definição da taxa máxima de inadimplência tolerável.

Esta abordagem proporcionou um grande avanço no cenário de concessão de crédito, mas não considera que a perda dos "maus pagadores" pode ainda sofrer variações conforme as características do proponente ${ }^{1}$ e do contrato. Além disso, a perda de crédito pode sofrer variações com a taxa cobrada do cliente, fator que pode ser importante na precificação de contratos de crédito.

\subsection{Revisão de literatura}

No problema de avaliação do risco de operações de crédito, no momento de sua contratação (Credit Scoring), para dar suporte à decisão de aceitar ou rejeitar determinado crédito solicitado, Rosa discutiu o uso de três metodologias distintas para a discriminação entre bons e maus clientes (Rosa, 2000); Alves discutiu modelos semelhantes, mas propondo estratégias para a consideração de propostas de crédito rejeitadas (Alves, 2008), Moraes discutiu o uso de uma metodologia semelhante, para a detecção de eventos raros, no caso, fraude em cartões de crédito (Moraes, 2008); Tomazela utilizou um modelo de Credit Scoring baseado em Análise de Sobrevivência, discutindo medidas de desempenho,

\footnotetext{
${ }^{1}$ No contexto de crédito, proponente é aquele que solicita empréstimo a uma instituição bancária, realizando, para isto, uma proposta, que será aceita ou rejeitada, conforme análise a ser realizada.
} 
e comparou seu desempenho com os modelos baseados em regressão logística (Tomazela, 2007).

\subsection{Decisão de crédito baseada em perda}

Ao tomar decisões de crédito com base em uma previsão eficiente da perda de crédito, a instituição consegue estabelecer os critérios de risco com que deseja trabalhar com maior objetividade, estabelecer as taxas de seus contratos com melhores critérios e até prever de forma mais eficiente as despesas com perda que um determinado conjunto de contratos deverá representar no futuro.

\subsection{Desafios}

Existem diversos desafios para se obter uma boa opinião acerca da previsão da perda de uma carteira de contratos de crédito. Dentre estes desafios, podemos listar alguns importantes:

Informações confiáveis: A instituição deve possuir fontes de informação confiáveis e com um histórico bastante longo. Para contratos de longo prazo, este histórico passa a ser especialmente longo. As informações necessárias envolvem informações do contrato e do contratante, desempenho do contrato, custos operacionais, custos com cobrança, descontos, impostos e tudo o mais que estiver relacionado com o resultado da operação. Estas informações podem estar em sistemas distintos, não centralizadas e disponíveis com históricos diferentes, o que pode dificultar a tarefa.

Metodologia estatística: De posse das informações mencionadas, se faz necessária uma metodologia estatística para prever a perda de crédito. O desenvolvimento desta metodologia é o objetivo deste trabalho.

Definição da taxa de juros: Uma instituição de crédito tem um determinado objetivo com relação à lucratividade que deseja em uma operação de crédito, que é função da taxa de juros. Fator importante do resultado dessa operação é o risco de crédito, de modo que quanto maior o risco, maior a taxa que a instituição deve cobrar para assegurar o seu objetivo. Perfis de operações/clientes com diferentes riscos podem, portanto, obter taxas de juros diferentes. Parte do objetivo deste trabalho é obter uma metodologia que forneça essa taxa. 


\section{Descrição dos dados}

Devido à dificuldade em se obter dados reais, este trabalho foi desenvolvido com dados que simulam uma situação real. De acordo com a experiência dos autores, os dados foram simulados seguindo aproximadamente a associação original entre as variáveis, com pequenas modificações. Dados reais, dentro da mesma estrutura, terão eventualmente mais variáveis, o que não é considerado um problema, pois os algoritmos de estimação de parâmetros da metodologia que será apresentada já são utilizados com grandes quantidades de dados, tanto em número de observações quanto em número de variáveis.

No APÊNDICE 1 encontram-se os códigos em linguagem SAS para a geração destes dados.

\subsection{Desenho da simulação}

Os dados foram gerados de modo a simular uma situação de uma carteira de crédito em que contratos são iniciados todos os meses e permanecem na carteira até serem quitados ou lançados a prejuízo, por motivo de inadimplência.

O estudo realizado com estes dados simulados consiste em observar, dentro do histórico de contratos disponível, todos os contratos iniciados em um determinado período de tempo.

O período selecionado deve ser antigo o suficiente para permitir a observação do desempenho do contrato e recente o suficiente para refletir a realidade em que o modelo será aplicado.

\subsection{Variáveis explicativas}

O momento em que o modelo será aplicado é exatamente o momento da decisão de concessão ou não do crédito proposto. Assim, as variáveis explicativas candidatas a serem consideradas na equação final do modelo serão todas aquelas que podem ter alguma associação com o desempenho do contrato e são observáveis no momento da aplicação.

As variáveis explicativas foram simuladas com uma estrutura de associação entre elas, procurando refletir a associação existente em dados reais. Destes contratos, observam-se todas as informações que estavam disponíveis no momento de suas 
contratações. É essencial que estas informações estejam disponíveis também para os contratos futuros, para que a metodologia possa ser aplicada.

llustraremos o problema com uma pequena seleção de variáveis. Uma instituição bem organizada certamente dispõe de uma lista mais extensa. Abaixo seguem as variáveis que serão consideradas neste trabalho:

- Prazo - é o próprio prazo da operação, medido em meses, sendo que ao final de cada mês ocorre também o vencimento de uma das parcelas;

- Idade da empresa - indica há quanto tempo a empresa proponente foi fundada;

- Endividamento - é o valor da operação de crédito dividida pelo faturamento mensal do cliente;

- Histórico negativo - Definida de forma ordinal em três níveis: 2 indica que o contratante possui apontamentos de dívidas vencidas com outras instituições financeiras, 1 indica que o contratante apresenta apontamentos de dívidas com instituições de crédito vencidas mas regularizadas, nos últimos 6 meses. Por último, 0 indica que o cliente não possui dívidas vencidas nem histórico de dívidas nos últimos 6 meses. Esta informação pode ser obtida através de órgãos de proteção ao crédito;

- Histórico positivo - Definida de forma ordinal em três níveis: 0 indica que o contratante não possui histórico de contratos finalizados com a instituição; 1 indica que o contratante apresenta um contrato quitado em 12 meses e 2 indica que o contratante apresenta dois ou mais contratos com a instituição quitados nos últimos 12 meses.

Para auxiliar na construção do modelo, definimos algumas variáveis indicadoras construídas com base nas variáveis descritas acima:

- $\operatorname{PRAZO6}=1$ se Prazo=6 e 0 caso contrário;

- PRAZO12=1 se Prazo=12 e 0 caso contrário;

- PRAZO18=1 se Prazo=18 e 0 caso contrário;

- PRAZO24=1 se Prazo=24 e 0 caso contrário. 


\subsection{Desempenho do contrato}

O resultado monetário final do contrato pode ser difícil de se medir diretamente devido ao fato de que alguns fatores como custos relacionados à cobrança normalmente não são atribuídos ao contrato diretamente. Além disso, não se aconselha construir um modelo sobre o resultado final, pois este varia de acordo com parâmetros externos à instituição, como a inflação e o custo de captação, por exemplo. Ao se construir um modelo sobre o resultado final, estes parâmetros poderiam tornar o modelo específico demais para um determinado ciclo econômico, não sendo capaz de se adaptar às mudanças dos parâmetros mencionados.

A solução proposta baseia-se, portanto, em prever o comportamento de pagamentos dos contratos, considerando-se, em seguida, as expectativas dos valores para os fatores relevantes durante o período de desempenho do contrato no cálculo do resultado final.

Para melhor estimar o resultado final do contrato, dividiremos os contratos finalizados em três grupos, definidos de acordo com a forma de finalização do contrato. Os grupos possuem uma hierarquia natural entre si, de modo que um será preferível ao outro. A definição dos grupos será útil no cálculo do resultado final, que será diferenciado para cada grupo, como será mostrado adiante.

Os grupos serão definidos com base no contrato sendo quitado com ou sem uma ação de cobrança (que se faça necessária em decorrência de atraso) ou no contrato sendo considerado prejuízo (definição também baseada no atraso de pagamentos). A definição do grupo que sofre intervenção de cobrança pode estar alinhada com a definição de sinistro (ou default), que pode variar para cada instituição, mas já é muito utilizada pelas instituições de crédito, também consideradas normativamente nos documentos do acordo da Basiléia².

- Grupo 1: Contratos encerrados sem ocorrência de sinistro:

São contratos quitados normalmente, sem a necessidade de uma intervenção mais drástica de cobrança (renegociação de dívida ou intervenção jurídica).

${ }^{2}$ O Acordo da Basiléia é um conjunto de recomendações internacionais sobre leis e regulamentações bancárias, definidas pelo Comitê de Supervisão Bancária da Basiléia, na expectativa de que as várias nações mundiais as adotem, e que teêm o objetivo de reduzir os riscos de insolvência dos bancos. Para mais detalhes sobre 0 acordo da Basiléia, referenciar www.bis.org ou 0 Banco Central do Brasil http://www.bcb.gov.br/?BASILEIA2. 


\section{- Grupo 2: contratos encerrados com intervenção de cobrança:}

São contratos também quitados, porém com a ocorrência de atraso superior a 60 dias, de modo que se fazem necessárias ações de cobrança mais enérgicas, envolvendo custos operacionais extras e políticas de saída de risco como descontos, de modo a incentivar a quitação antecipada do contrato e minimizar o risco de crédito da operação. Suponhamos que esta definição seja coincidente com a definição de sinistro da instituição de crédito em que a metodologia esteja sendo aplicada.

\section{- Grupo 3: Contratos lançados a prejuízo:}

São contratos cujos atrasos atingiram patamares muito elevados, resistindo aos esforços de cobrança e tentativas de saída de risco. Neste trabalho consideraremos como prejuízo contratos com 180 dias de atraso ou mais. Estes contratos apresentam baixa expectativa de recebimento e são lançados contabilmente a prejuízo no balanço das instituições. São normalmente elegíveis a cessão de crédito, operação em que a dívida é vendida para uma instituição de securitização ${ }^{3}$ de crédito por um percentual do seu saldo devedor. Estes contratos serão considerados encerrados, e eventuais recebimentos destes contratos são contabilizados como receitas apartadas, e neste trabalho não vão compor o resultado da operação.

Note que, em qualquer situação, o contrato pode ser encerrado antes da última parcela. No caso de contratos encerrados sem ocorrência de sinistro, os juros pagos são menores do que o esperado no início do contrato.

\subsection{Simullação das informações de desempenho da operação}

As simulações das variáveis de desempenho do contrato foram realizadas através da construção artificial de um modelo probabilístico semelhante ao descrito no capítulo 3 , com parâmetros de perturbação para que o modelo estimado não se ajuste de forma exageradamente adequada.

${ }^{3}$ No caso de crédito, securitização é uma operação em que o banco vende uma dívida a uma empresa securitizadora, a um valor abaixo da expectativa de recebimentos, de modo a torná-la liquida. Em troca, a empresa securitizadora espera obter um recebimento com estes ativos maior que o valor da venda. O responsável pela cobrança e pelos riscos de não recebimento passa a ser, então, a empresa securitizadora. 
O programa em SAS com a simulação das situações de encerramento do contrato encontra-se no APÊNDICE 1.1 e o programa em SAS com as simulações do tempo até o encerramento encontra-se no APÊNDICE 1.2.

\subsection{Cálcullo do resultadlo da operação}

O resultado das operações de crédito será calculado conforme o sistema de amortizações. Normalmente, contratos de crédito parcelados são regidos pelo sistema PRICE de amortizações, em que o valor da parcela é constante durante todo o contrato, mas o valor amortizado do saldo varia conforme a parcela. Atualmente no Brasil, alguns contratos, como no caso de crédito imobiliário, são regidos pelo sistema SAC (sigla para sistema de amortizações constantes), em que a parcela é decrescente, mas o valor da amortização é constante.

Este trabalho trata apenas de contratos regidos pelo sistema PRICE, mas a metodologia é facilmente adaptável para outros sistemas. A parcela do sistema PRICE é calculada de forma iterativa. Dado o valor da parcela, ela pode ser decomposta em juros e amortizações (Pompeu \& Hazzan, 2007) (Vieira Sobrinho, 2006).

Ressaltando o fato de que o contrato pode ser encerrado em qualquer uma das parcelas definidas no momento da concessão de crédito, por qualquer um dos motivos descritos que caracterizam os três grupos definidos, teremos uma forma distinta de calcular o resultado do contrato para cada um destes grupos, que dependerá também da parcela em que o contrato foi encerrado.

Assim, o resultado da operação será calculado como função da situação em que o contrato é encerrado, da primeira parcela não paga no encerramento do contrato e de outros parâmetros considerados constantes no momento da aplicação (o custo de capital e parâmetros relacionados a custos de cobrança):

Seja $t=1, \ldots t_{i}$ indexando as parcelas dos contratos, com $t_{i}$ representando a primeira não paga no instante do encerramento do contrato. Por exemplo, se o contrato $i$ teve três parcelas pagas e foi quitado em seguida, temos $t_{l}=4$. Note que nos grupos 1 e 2 , a parcela $t_{i}$ é paga no ato de encerramento do contrato (juntamente com todas as seguintes), e no grupo 3, todas as parcelas anteriores a $t_{i}$ são pagas. Definimos então: 
- $S p(t)$ é o Spread total pago até o encerramento do contrato, que é a taxa de Spread multiplicada pelo saldo devedor no período;

- $\operatorname{Sd}(t)$ é o saldo devedor no momento da inadimplência;

- $\mathrm{C}(t)$ é o custo em cobrança até o encerramento do contrato.

Os valores de $\mathrm{Sp}(t), \mathrm{Sd}(t)$ e $\mathrm{C}(t)$ devem ser considerados a valor presente na data da contratação, à taxa do custo de captação ${ }^{4}$.

Os resultados das operações são calculados, por grupo de desempenho, como:

- Grupo 1, Contratos encerrados sem ocorrência de sinistro:

$\mathrm{R}=\mathrm{Sp}(t)$

- Grupo 2, Contratos quitados com ocorrência de sinistro:

$\mathrm{R}=\mathrm{Sp}(t)-\mathrm{C}(t)$

- Grupo 3, Contratos lançados a prejuízo:

$R=S p(t-1)-S d(t)-C(t)$ se $j>1$ e $R=S d(1)-C(1)$ se $j=1$.

llustraremos o resultado de uma operação, em diferentes situações, com um exemplo.

Seja um contrato efetuado com as seguintes condições:

\begin{tabular}{|l|r|}
\hline valor presente (VP) & $100.000,00$ \\
\hline parcelas (NP) & 6 \\
\hline taxa (i) & $1,9 \%$ \\
\hline custo (c) & $1,0000 \%$ \\
\hline
\end{tabular}

No sistema PRICE, o valor da parcela é obtido dados a taxa de juros, o valor presente do empréstimo e o prazo, de forma iterativa, segundo a restrição de que as parcelas devem ser constantes. O Spread e a parcela dos juros subtraído da parcela referente ao custo de captação. No nosso exemplo, teremos:

\begin{tabular}{|l|r|}
\hline Valor Parcela (PMT) & $17.792,38$ \\
\cline { 1 - 2 } valor futuro (VF) & $106.754,28$ \\
\cline { 1 - 2 } Taxa Spread (spr) & $0,8911 \%$ \\
\hline
\end{tabular}

${ }^{4}$ A taxa utilizada para atualização do capital utilizada neste trabalho é de $1 \%$. Uma taxa mais precisa pode ser a CDI ou outro valor derivado de algum estudo, que reflita com maior precisão o custo exato de captação a instituição. 
O valor da parcela pode ser dividida em amortização e juros. Os juros podem ser subdivididos em dois valores: custos de captação e o Spread nominal, que é o resultado de fato para a instituição financeira, em caso de pagamento.

O exemplo abaixo ilustra, para cada $t_{i}$ as seguintes quantidades:

- Saldo principal: é o saldo principal remanescente logo após o pagamento da parcela correspondente;

- Saldo atualizado: é o saldo principal atualizado ao final do período, ou seja, logo antes do pagamento da parcela seguinte;

- Amortização: é o valor a ser amortizado da dívida devido ao pagamento da parcela em questão;

- Juros pagos: é o valor referente aos juros pagos pela parcela correspondente;

- Custo de captação: é a fração dos juros correspondente ao pagamento do custo de captação;

- Valor Spread: é a fração dos juros correspondente ao Spread da parcela.

TABELA 2.1. Exemplo para cálculo de resultado de operação de crédito

\begin{tabular}{|l|c|r|r|r|r|r|r|}
$\mathbf{t}_{\mathbf{i}}$ & PMT & Valor Principal & $\begin{array}{c}\text { Saldo } \\
\text { Atualizado }\end{array}$ & Amortização & Juros Pagos & $\begin{array}{c}\text { Custo de } \\
\text { Captação }\end{array}$ & $\begin{array}{c}\text { Valor } \\
\text { Spread }\end{array}$ \\
\hline 1 & $17.792,38$ & $100.000,00$ & $101.000,00$ & $15.892,38$ & $1.900,00$ & $1.000,00$ & 900,00 \\
\hline 2 & $17.792,38$ & $84.107,62$ & $84.948,70$ & $16.194,34$ & $1.598,04$ & 841,08 & 756,97 \\
\hline 3 & $17.792,38$ & $67.913,28$ & $68.592,42$ & $16.502,03$ & $1.290,35$ & 679,13 & 611,22 \\
\hline 4 & $17.792,38$ & $51.411,26$ & $51.925,37$ & $16.815,57$ & 976,81 & 514,11 & 462,70 \\
\hline 5 & $17.792,38$ & $34.595,69$ & $34.941,65$ & $17.135,06$ & 657,32 & 345,96 & 311,36 \\
\hline 6 & $17.792,38$ & $17.460,63$ & $17.635,23$ & $17.460,63$ & 331,75 & 174,61 & 157,15 \\
\hline
\end{tabular}

\section{- Resultado para operações quitadas sem sinistro}

No mesmo exemplo de contrato, ilustramos a seguir o resultado do contrato quitado ao vencimento de cada uma das parcelas pré-estabelecidas. Lembrando que $t_{i}$ representa a primeira que deveria ser paga quando do encerramento do contrato, observe que, nesta 
situação de encerramento, o spread referente à parcela $t_{i}$ é pago, mas os referentes às parcelas seguintes não.

Na tabela a seguir são mostradas as quantidades:

- Spread Corrigido: é o valor do spread pago, atualizado para valor presente na data da contratação pela taxa do custo de captação;

- Spread acumulado: é a somatória dos spreads pagos em valor presente na data da contratação;

- Resultado da operação: é o saldo final da operação ao se quitar o contrato sem ocorrência de sinistro na parcela indicada. Neste caso, é simplesmente o Spread acumulado.

TABELA 2.2. Exemplo de resultado para operações quitadas sem sinistro

\begin{tabular}{|c|c|c|c|c} 
t & $\begin{array}{c}\text { Valor } \\
\text { Spread }\end{array}$ & $\begin{array}{c}\text { Spread } \\
\text { Corrigido }\end{array}$ & $\begin{array}{c}\text { Spread } \\
\text { Acumulado }\end{array}$ & $\begin{array}{c}\text { Resultado da } \\
\text { Operação (1) }\end{array}$ \\
\hline 1 & 900,00 & 891,09 & 891,09 & 891,09 \\
\hline 2 & 756,97 & 742,05 & $1.633,14$ & $1.633,14$ \\
\hline 3 & 611,22 & 593,24 & $2.226,39$ & $2.226,39$ \\
\hline 4 & 462,70 & 444,65 & $2.671,03$ & $2.671,03$ \\
\hline 5 & 311,36 & 296,25 & $2.967,28$ & $2.967,28$ \\
\hline 6 & 157,15 & 148,04 & $3.115,32$ & $3.115,32$ \\
\hline
\end{tabular}

\section{- Resultado para operações quitadas com sinistro}

Para as mesmas condições de contrato, ilustramos agora o resultado da operação quitada com ocorrência de sinistro. Neste caso, o resultado será o Spread subtraído do custo de cobrança devido à ocorrência do sinistro, cujo cálculo será explicado adiante.

Vale ressaltar, o custo de cobrança varia para cada instituição. O modelo de custo utilizado aqui é bastante simples, mas bem ilustrativo: um valor fixo, refletindo a distribuição dos custos envolvendo processos permanentes de cobrança (salários, cartas, telefonemas, visitas, etc.) e um custo proporcional ao saldo devedor no instante da quitação, refletindo eventuais remunerações variáveis aos cobradores e negociações de descontos. Segundo este modelo, o custo referente ao contrato terá então a forma:

Custo total $(\mathrm{i})=\mathrm{C}_{1}+\mathrm{C}_{2} \times$ Saldo Principal(i) 


\section{Mês Valor Spread}

\begin{tabular}{lr}
$\mathrm{C}_{1}$ & $\mathrm{R} \$ 1000,00$ \\
\hline $\mathrm{C}_{2}$ & $2 \%$
\end{tabular}

O resultado é calculado então como o Spread acumulado até a última parcela paga, atualizado ao valor presente no momento da contratação pela taxa do custo de captação, subtraído do custo total conforme a equação (2.4). A tabela abaixo mostra o resultado da operação nas condições descritas:

TABELA 2.3. Exemplo de resultado para operações quitadas com sinistro

\begin{tabular}{|l|r|r|r|rr|r|r|}
\hline t & Valor Principal & $\begin{array}{c}\text { Saldo } \\
\text { Atualizado }\end{array}$ & \multicolumn{1}{c|}{$\begin{array}{c}\text { Spread } \\
\text { Acumulado }\end{array}$} & $\begin{array}{c}\text { Custo fixo de } \\
\text { cobrança (C1) }\end{array}$ & $\begin{array}{c}\text { Custo proporcional } \\
\text { de cobrança (C2) }\end{array}$ & $\begin{array}{c}\text { Resultado da } \\
\text { Operação (3) }\end{array}$ \\
\hline 1 & $100.000,00$ & $101.000,00$ & 891,09 & $1.000,00$ & $2.020,00$ & $-103.911,09$ \\
\hline 2 & $84.107,62$ & $84.948,70$ & $1.633,14$ & $1.000,00$ & $1.698,97$ & $-88.280,81$ \\
\hline 3 & $67.913,28$ & $68.592,42$ & $2.226,39$ & $1.000,00$ & $1.371,85$ & $-72.190,65$ \\
\hline 4 & $51.411,26$ & $51.925,37$ & $2.671,03$ & $1.000,00$ & $1.038,51$ & $-55.634,91$ \\
\hline 5 & $34.595,69$ & $34.941,65$ & $2.967,28$ & $1.000,00$ & 698,83 & $-38.607,76$ \\
\hline 6 & $17.460,63$ & $17.635,23$ & $3.115,32$ & $1.000,00$ & 352,70 & $-21.103,26$ \\
\hline
\end{tabular}

\section{- Resultado para operações lançadas a prejuízo}

As operações lançadas a prejuízo podem ter algumas de suas parcelas pagas ao serem lançadas a prejuízo. O resultado final de operações nessa situação é um saldo negativo no valor do saldo principal remanescente na parcela correspondente, somado com os spreads acumulados até o momento da quitação, subtraindo do custo de cobrança devido conforme o caso anterior.

TABELA 2.4. Exemplo de resultado para operações lançadas a prejuízo

\begin{tabular}{|l|c|r|r|r|r|l|}
\hline t & $\begin{array}{c}\text { Valor } \\
\text { Spread }\end{array}$ & $\begin{array}{c}\text { Spread } \\
\text { Corrigido }\end{array}$ & $\begin{array}{c}\text { Spread } \\
\text { Acumulado }\end{array}$ & $\begin{array}{c}\text { Custo fixo de } \\
\text { cobrança (C1) }\end{array}$ & $\begin{array}{c}\text { Custo proporcional } \\
\text { de cobrança (C2) }\end{array}$ & $\begin{array}{l}\text { Resultado da } \\
\text { Operação (3) }\end{array}$ \\
\hline 1 & 900,00 & 891,09 & 891,09 & $1.000,00$ & $2.020,00$ & $-103.911,09$ \\
\hline 2 & 756,97 & 742,05 & $1.633,14$ & $1.000,00$ & $1.698,97$ & $-88.280,81$ \\
\hline 3 & 611,22 & 593,24 & $2.226,39$ & $1.000,00$ & $1.371,85$ & $-72.190,65$ \\
\hline 4 & 462,70 & 444,65 & $2.671,03$ & $1.000,00$ & $1.038,51$ & $-55.634,91$ \\
\hline 5 & 311,36 & 296,25 & $2.967,28$ & $1.000,00$ & 698,83 & $-38.607,76$ \\
\hline 6 & 157,15 & 148,04 & $3.115,32$ & $1.000,00$ & 352,70 & $-21.103,26$ \\
\hline
\end{tabular}




\subsection{Definição das variáveis resposta}

As variáveis resposta são aquelas necessárias para o cálculo da perda do contrato:

- $Y_{i}$ - indica em que situação o contrato foi encerrado:

$Y_{i}=0$ indica que o contrato não foi encerrado até 0 momento da coleta dos dados;

$Y_{i}=1$ indica que o contrato foi quitado sem ocorrência de sinistro;

$Y_{i}=2$ indica que o contrato foi quitado com ocorrência de sinistro;

$Y_{i}=3$ indica que o contrato foi encerrado por cessão de inadimplência.

- $\mathrm{T}_{\mathrm{i}}$ - indica o número de parcelas pagas até a coleta dos dados.

Observe que dependendo do período em que os contratos se iniciam e dos prazos estabelecidos, podem haver contratos que permanecem com parcelas em aberto, de modo que não se pode observar qual é o grupo de desempenho a que pertencem. 


\section{Metodologia}

A metodologia proposta busca prever o desempenho de um contrato de crédito, de modo a obter, no momento da contratação, uma estimativa do seu resultado futuro. Esta estimativa é feita com base nas variáveis observáveis relevantes do modelo e como função dos parâmetros de custo de cobrança e custo de captação, bem como da taxa de spread propriamente dita.

Com isto, a instituição poderá conhecer o resultado esperado de um contrato de crédito dada uma taxa de spread negociada, ou, obter a taxa de spread mínima que garante o resultado esperado desejado.

Resumidamente, os objetivos da metodologia são:

- Classificação: estimar a proporção de contratos que será classificada em cada um dos três grupos já descritos, para cada perfil definido pelas variáveis explicativas.

- Parcelas pagas: obter uma estimativa da proporção de contratos encerrados em cada uma das possíveis parcelas.

- Resultado esperado: conhecer o resultado esperado de um contrato de crédito, dada a taxa negociada;

- Determinação da taxa: determinar a taxa de spread mínimo que garante o lucro mínimo desejado pela instituição, considerando o risco de crédito.

\subsection{Classificação}

Esta etapa é uma generalização do já conhecido modelo de "Credit Scoring". Ao invés de classificar os contratos em duas classes de acordo com o perfil definido pelas variáveis explicativas, o objetivo é classificá-los em 1 de 3 grupos:

- Grupo 1: Contratos quitados sem ocorrência de sinistro;

- Grupo 2: Contratos quitados com ocorrência de sinistro;

- Grupo 3: Contratos encerrados por cessão de crédito.

A idéia geral é construir um modelo logístico que indique a proporção esperada de contratos que pertencerá ao Grupo 3, e em seguida, outro modelo logístico, separado, 
indicando a proporção esperada de contratos que pertencerá ao Grupo 2, condicionado a não pertencerem ao Grupo 3. Em seguida, com um cálculo simples de probabilidades, transformaremos essas proporções condicionais encontradas nas proporções de contratos que pertencem ao Grupo 1, Grupo2 e Grupo 3.

Sejam $X_{1}, X_{2}, \ldots, X_{p}$ variáveis explicativas, cujas observações em cada contrato i da amostra $(i=1, \ldots N)$ são denotadas pelos $N$ vetores $\mathbf{X}_{i}=\left(x_{i 1}, x_{i 2}, \ldots, x_{i p}\right)$. Definimos:

$$
\begin{gathered}
\mathbf{Y}_{\mathbf{i}}=\left(Y_{i 1}, Y_{i 2}, Y_{i 3}\right) \text { com } Y_{i 1}+Y_{i 2}+Y_{i 3}=1 \text { e sendo } \\
Y_{i j}=\left\{\begin{array}{l}
1 \text { se o contrato } i \text { pertence ao grupo } j \\
0 \text { caso contrário }
\end{array}\right. \\
\pi_{i j}=P\left(Y_{i j}=1\right)
\end{gathered}
$$

$N_{j}=\sum_{i=1}^{N} Y_{i j}$ é o número de contratos pertencentes ao grupo $\mathrm{j}(\mathrm{j}=1,2,3)$.

Com $\mathrm{i}=1, \ldots \mathrm{N}$ e $\mathrm{j}=1,2$, 3 e $\pi_{i 1}+\pi_{i 2}+\pi_{i 3}=1$, de modo que:

$$
\mathbf{Y}_{\mathbf{i}}=\left(Y_{i 1}, Y_{i 1}, Y_{i 1}\right) \sim M\left(\pi_{i 1}, \pi_{i 2}, \pi_{i 3}, 1\right) .
$$

Em que $\mathrm{M}(\mathrm{a}, \mathrm{b}, \mathrm{c}, \mathrm{n})$ representa a multinomial de parâmetros $a, b$ e $c$, e tamanho amostral $n$. Observe o vetor $\mathbf{Y}_{\mathbf{i}}$ assume apenas três possíveis valores, os quais podemos representar como:

$$
\mathbf{Y}_{1}=(1,0,0) ; \mathbf{Y}_{2}=(0,1,0) ; \mathbf{Y}_{3}=(0,0,1)
$$

Definimos também:

$$
\theta_{i 2}=P\left(Y_{i 2}=1 \mid Y_{i 3}=0\right)
$$

Note que $\left(\pi_{i 1}, \pi_{i 2}, \pi_{i 3}\right)=\left(\left(1-\pi_{i 3}\right)\left(1-\theta_{i 2}\right),\left(1-\pi_{i 3}\right) \theta_{i 2}, \pi_{i 3}\right)$, além disso, $\pi_{i 3}$ e $\theta_{i 2}$ são de variação independente.

Temos então:

$$
\begin{aligned}
& Y_{\mathrm{i} 3} \sim \operatorname{Bernoulli}\left(\pi_{\mathrm{i} 3}\right) \\
& \mathrm{Y}_{\mathrm{i} 2} \mid \mathrm{Y}_{\mathrm{i} 3}=0 \sim \operatorname{Bernoulli}\left(\theta_{\mathrm{i} 2}\right)
\end{aligned}
$$


Se observarmos uma amostra de tamanho $\mathrm{N}$ de uma população de contratos, teremos a função de verossimilhança em termos de seus parâmetros $\left(\pi_{i 1}, \pi_{i 2}, \pi_{i 3}\right)$. Podemos, porém, reescrever esta verossimilhança em termos dos parâmetros $\pi_{i 3}$ e $\theta_{\mathrm{i} 2}$. No APÊNDICE 2.1 mostramos com detalhes que esta verossimilhança pode ser fatorada como uma parte dependendo apenas de $\pi_{\mathrm{i} 3}$ e outra de $\theta_{\mathrm{i} 2}$. Além disso, como $\pi_{\mathrm{i} 3}$ e $\theta_{\mathrm{i} 2}$ variam dentro do mesmo espaço paramétrico $[0,1]$ e são de campo de variação independente, podemos estimar o vetor $\left(\pi_{i 1}, \pi_{i 2}, \pi_{i 3}\right)$ com duas regressões logísticas: uma para $\pi_{i 3}$ e outra para $\theta_{i 2}$, de forma independente.

Dessa forma, podemos descrever as probabilidades de $\left(Y_{i 1}, Y_{i 2}, Y_{i 3}\right)$ através de modelos logísticos separados para $\pi_{\mathrm{i} 3}$ e $\theta_{\mathrm{i} 2}$.

$$
\begin{aligned}
& \operatorname{Ln}\left(\frac{\pi_{i 3}}{1-\pi_{i 3}}\right)=\alpha_{1}+X_{i 1} \beta_{11}+\cdots+X_{i n} \beta_{1 n} \\
& \operatorname{Ln}\left(\frac{\theta_{i 2}}{1-\theta_{i 2}}\right)=\alpha_{2}+X_{i 1} \beta_{21}+\cdots+X_{i n} \beta_{2 n}
\end{aligned}
$$

Ou, de uma forma mais direta,

$$
\begin{aligned}
& \pi_{i 3}=\frac{1}{1+e^{-\left(\alpha_{1}+X_{i 1} \beta_{11}+\cdots+X_{i n} \beta_{1 n}\right)}} \\
& \theta_{i 2}=\frac{1}{1+e^{-\left(\alpha_{2}+X_{i 1} \beta_{21}+\cdots+X_{i n} \beta_{2 n}\right)}}
\end{aligned}
$$

Interpretação dos parâmetros:

$e^{\beta_{j 1}}$ é a razão de chances para 0 evento $Y_{i 3}=1$ devida ao aumento da variável explicativa $X_{j}$ em uma unidade, mantidas as outras constantes.

$e^{\beta_{j 2}}$ é a razão de chances para o evento $Y_{i 2}=1$ condicional a $Y_{i 3}=0$, devida ao aumento da variável explicativa $X_{j}$ em uma unidade, mantidas as outras constantes.

$\alpha_{1}$ é o intercepto para $\pi_{i 3}$ : é o $\ln \left(\pi_{i 3} /\left(1-\pi_{i 3}\right)\right)$ quando $X_{i 1}=X_{i 2}=\ldots, X_{i p}=0$

$\alpha_{2}$ é o intercepto para $\theta_{\mathrm{i} 2}$ : é o $\ln \left(\theta_{\mathrm{i} 2} /\left(1-\theta_{\mathrm{i} 2}\right)\right)$ quando $\mathrm{X}_{\mathrm{i} 1}=\mathrm{X}_{\mathrm{i} 2}=\ldots, \mathrm{X}_{\mathrm{ip}}=0$. 


\subsection{Avaliação dos modelos de classificação}

Para verificar o ajuste do modelo multinomial, pode-se inicialmente realizar as mesmas análises utilizadas em modelos logísticos para os modelos construídos separadamente.

Em seguida, analisaremos o ajuste das estimativas da multinomial conjuntamente.

\subsubsection{Análise das estimativas condicionais}

A seguir, discutiremos algumas metodologias para verificar o ajuste dos modelos condicionais, de forma independente do restante do modelo. A estimativa conjunta será discutida mais adiante.

Os modelos condicionais têm como objetivo discriminar perfis definidos pelas variáveis $\mathrm{X}$ que apresentem proporções diferentes de clientes nos dois grupos considerados pelo modelo, e também tem o objetivo de fornecer estas proporções de forma coerente com o que ocorre na população.

Para verificar estes dois objetivos, discutiremos a seguir o teste de Hosmer \& Lemeshow, a curva de Lorenz (ou curva ROC) e a estatística do teste de Kolmogorov \& Smirnov.

\section{Teste de Hosmer \& Lemeshow}

Um dos principais objetivos deste trabalho é obter, para cada perfil definido pelas variáveis explicativas, uma previsão acertada sobre a proporção de contratos em cada um dos grupos. O Teste de Hosmer \& Lemeshow (Hosmer \& Lemeshow, 1997) busca verificar, em um modelo com resposta binária, exatamente se as probabilidades preditas estão próximas das observadas.

O Teste de Hosmer \& Lemeshow é construído ao se classificar as probabilidades estimadas dadas pelo modelo em dez grupos (decis). Para cada um destes dez grupos, calcular o número de ocorrências observadas de eventos e não eventos e compará-las com as respectivas quantidades esperadas dadas pelo modelo.

A hipótese testada pelo Teste de Hosmer \& Lemeshow é: 
$\mathrm{H}_{0}$ : As probabilidades esperadas são iguais às observadas para cada decil. contra

$H_{a}$ : As probabilidades esperadas são diferentes às observadas para cada decil.

Para maiores explicações sobre o Teste de Hosmer \& Lemeshow, ver o APÊNDICE 3.1, metodologias.

\section{Estatística de Kolmogorov \& Smirnov}

Kolmogorov \& Smirnov propuseram um teste não paramétrico no qual uma das finalidades é testar a hipótese de que duas populações apresentam a mesma distribuição para uma determinada variável aleatória (Conover, 1999). No contexto de crédito, porém, é muito comum se utilizar da estatística do teste como medida da capacidade discriminativa do modelo logístico, sendo conhecido simplesmente como KS (Alves, 2008).

Além de obter previsões acuradas, é interessante também que os perfis identificados tenham distribuições bastante distintas com relação à distribuição multinomial de interesse. Assim, se cada um dos modelos logísticos tiver bom poder de discriminação, isto é uma evidência de que o modelo conjunto terá bom poder de discriminação.

Para melhores explicações sobre a estatística KS, referenciar o APÊNDICE 3.2, metodologias.

\section{Curva ROC (Curva de Lorenz)}

Uma excelente forma de analisar a capacidade de discriminação de um modelo com resposta binária é a curva de Lorenz, ou curva ROC (Martinez, Neto, \& Pereira, 2003).

Para um modelo que classifique, digamos, clientes pertencentes ao Grupo 3, a curva ROC fornecerá um gráfico com todas as possibilidades de especificidade (proporção de contratos classificados corretamente, dado que pertencem ao grupo 3) e de 1sensibilidade (proporção de contratos classificados erroneamente, dado que não pertencem ao grupo 3). Para maiores detalhes, referenciar ao APÊNDICE 3.3. A área sob a curva ROC é também uma medida interessante de avaliação do modelo, tendo seu campo de variação entre 0,5 e 1 , sendo que 0,5 indica um modelo sem poder de discriminação algum e 1 indica um modelo que discrimina perfeitamente as duas populações. 


\subsubsection{Análise das estimativas conjuntas}

Boas estimativas das probabilidades da multinomial particionada não necessariamente levam a boas estimativas da multinomial completa.

A avaliação da adequação da distribuição multinomial estimada para cada perfil pode ser realizada através da construção de uma tabela parecida com a que serve como base para o Teste de Hosmer \& Lemeshow, porém, teremos, para cada um dos decis, números esperados e observados para as quantidades de ocorrências de 3 eventos (e não apenas de 2).

A tabela construída no caso das probabilidades condicionais é construída com base em categorizações das proporções estimadas em decis. Como temos aqui três proporções, podemos construir três tabelas, cada uma com base na categorização de uma das proporções. No entanto, cada uma destas tabelas será construída por um critério que favorece a análise de apenas uma das três quantidades. Gostaríamos de construir uma única tabela, que quebrasse as linhas de acordo com uma quantidade que leve em consideração todas as três estimativas.

Poderíamos construir a distância euclidiana entre uma observação com estimativas $\left(p_{1} ; p_{2} ; p_{3}\right)$ e o ponto $(0 ; 0 ; 1)$, que seria o pior caso, de modo que, quanto maior essa distância, melhor é o ponto correspondente, e com isto, construir a tabela quebrando as linhas de acordo com os decis desta distância. Porém, o problema com esta medida é que poderíamos obter um ponto $\left(p_{1} ; p_{2} ; p_{3}\right)$ com distância igual a outro $\left(p_{1}{ }^{*} ; p_{2}{ }^{*} ; p_{3}{ }^{*}\right)$, mas com o primeiro ponto claramente pior que o segundo. Por exemplo, os pontos $\left(p_{1} ; p_{2} ; p_{3}\right)=(0,75$; $0,25 ; 0)$ e $\left(p_{1}{ }^{*} ; p_{2}{ }^{*} ; p_{3}{ }^{*}\right)=(0,25 ; 0,75 ; 0)$ apresentam mesma distância euclidiana ao ponto $(0 ; 0 ; 1)$, mas o primeiro ponto é preferível ao segundo, observada a hierarquia existente entre os eventos.

Dessa forma, precisamos definir um índice que expressa uma distância de cada trio estimado $\left(p_{1} ; p_{2} ; p_{3}\right)$ ao pior caso $(0 ; 0 ; 1)$, de modo que um ponto com o valor do índice maior que outro indicará sempre que o primeiro ponto é preferível ao segundo.

Definiremos então o Índice de Dissimilaridade ao Pior Caso: 
A idéia do índice é obter o comprimento da do caminho obtido entre o ponto $\left(\mathrm{p}_{1} ; \mathrm{p}_{2}\right.$; $\mathrm{p}_{3}$ ) ao pior ponto, que é o $(0 ; 0 ; 1)$, passando por todos os pontos que sejam piores que ele.

Seja então $D_{1}$ a distância entre $\left(p_{1} ; p_{2} ; p_{3}\right)$ ao pior ponto dentro do conjunto formado por $\left(P_{1} ; P_{2} ; p_{3}\right)$, mantendo $p_{3}$ constante. Este ponto é o $\left(0 ; p_{1}+p_{2} ; p_{3}\right) . D_{2}$ será a distância entre este segundo ponto e o pior ponto do espaço $\left(P_{1} ; P_{2} ; P_{3}\right)$, que é o $(0 ; 0 ; 1) .0$ nosso índice será baseado em $D_{1}+D_{2}$.

Dado um ponto $\left(p_{1} ; p_{2} ; p_{3}\right)$ temos então:

$$
\begin{gathered}
D_{1}=D\left[\left(p_{1} ; p_{2} ; p_{3}\right) ;\left(0 ; p_{1}+p_{2} ; p_{3}\right)\right]=\sqrt{\left(-p_{1}\right)^{2}+\left(p_{1}\right)^{2}+(0)^{2}}=\sqrt{2} p_{1} \\
D_{2}=D\left[\left(0 ; p_{1}+p_{2} ; p_{3}\right) ;\left(0 ; 0 ; p_{1}+p_{2}+p_{3}\right)\right] \\
\left.=\sqrt{(0)^{2}+\left(-p_{1}-p_{2}\right)^{2}+\left(p_{1}+p_{2}\right)^{2}}=\sqrt{2}\left(p_{1}+p_{2}\right)\right) \\
D=D_{1}+D_{2}=\sqrt{2}\left(2 p_{1}+p_{2}\right)
\end{gathered}
$$

Podemos ainda utilizar uma transformação linear em D, de forma que a ordem proporcionada seja mantida e seu campo de variação passe a ser no intervalo [0;1]. Essa transformação pode ser obtida dividindo (3.1) por seu valor máximo, que é obtido inserindo em (3.1) o ponto de maior distância, o $(1 ; 0 ; 0)$, obtemos um índice que ordena as estimativas das proporções $\left(\mathrm{P}_{\mathrm{i} 1} ; \mathrm{P}_{\mathrm{i} 2} ; \mathrm{P}_{\mathrm{i} 3}\right)$ da pior para a melhor e varia no intervalo [0;1].

Temos então o Índice de Dissimilaridade ao Pior Caso:

$$
I=\frac{\sqrt{2}\left(2 P_{1}+P_{2}\right)}{2 \sqrt{2}}
$$

Assim, podemos considerar na análise as três dimensões $p_{1}, p_{2}$ e $p_{3}$, simultaneamente, de forma semelhante à proposta por Hosmer \& Lemeshow, expandida para a trinomial. Dividimos a população observada em decis de acordo com o Índice de Dissimilaridade ao Pior Caso e comparamos a distribuição multinomial esperada dada pelo modelo com a observada, em cada um dos grupos formados pelos decis. Este resultado estará exposto na TABELA 4.7, na Seção 0. 


\subsection{Previsão da parcela de encerramento}

Conhecida a proporção de contratos que se encerra em cada uma das três situações para cada perfil, resta ainda conhecer, dentro dessas situações, a proporção de contratos que se encerra em cada uma das possíveis parcelas para podermos calcular 0 resultado da operação, conforme descrito na Seção 3.5.

Além de conhecer o resultado médio da carteira, é interessante discriminar o resultado dos diferentes perfis de contrato da carteira que podem ser reconhecidos através das variáveis explicativas.

A distribuição do número de parcelas pagas até a ocorrência de um destes eventos pode ser estudada com abordagem de análise de sobrevivência em tempo discreto, com o número de parcelas pagas no lugar do tempo.

Seja $T_{i}$ indicando, em ordem pela data dos vencimentos, a primeira parcela não paga no instante em que o contrato i foi encerrado. Definimos a função de riscos dada a situação de encerramento do contrato como:

$$
h_{i t k}=P\left(T_{i}=t \mid T_{i}>t-1 ; X_{i} ; Y_{i k}=1\right)
$$

Lembrando que $Y_{i k}=1$ indica que o contrato $i$ foi encerrado no grupo $k$, definido na Seção 2.3, e se $Y_{i k}=1$, então $Y_{i k^{\prime}}=0$, para $k^{\prime}=1,2$, 3 e $k^{\prime} \neq k$.

Seja $T=\operatorname{Max}\left(\mathrm{t}_{\mathrm{i}}\right), \mathrm{i}=1, \ldots \mathrm{N}$ o número máximo de parcelas observadas de qualquer contrato. Definimos:

$$
D_{i t l} \text { são } T \text { indicadoras de observação no tempo } j . D_{i t l}=\left\{\begin{array}{c}
1 \text { se } t=l \\
0 \text { caso contrário }
\end{array}\right.
$$

De modo a estudar $h_{\text {itk }}$ segundo os diferentes perfis dados pelas variáveis explicativas $\mathbf{X}_{\mathbf{i}}$, podemos escrever $\boldsymbol{h}_{\text {itk }}$ segundo um modelo logístico da seguinte forma:

$$
\operatorname{Ln}\left(\frac{h_{i t k}}{1-h_{i t k}}\right)=D_{i t 1} \alpha_{k 1}^{\prime}+\cdots+D_{i t T} \alpha_{k T}^{\prime}+X_{i 1} \beta^{\prime}{ }_{k 1}+\cdots+X_{i p} \beta^{\prime}{ }_{k p}
$$

Ou ainda,

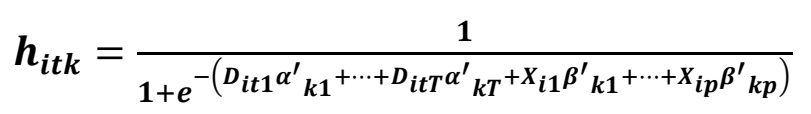


Temos assim, três modelos lineares sobre $\mathrm{G}\left(\mathrm{h}_{\mathrm{itk}}\right)$, um para cada valor de $\mathrm{k}, \mathrm{k}=1,2,3$ em que, dado o encerramento na situação k, de (3.2), $h_{\text {itk }}$ representa a proporção esperada de contratos do perfil i não encerrados na parcela $t-1$ que se encerram na parcela t, e de (3.5) $\mathrm{G}($.$) é a função logística.$

Dessa forma, através das estimativas por máxima verossimilhança de $\alpha_{1}, \ldots, \alpha_{\jmath}$ e $\beta_{l}$, podemos obter a estimativa de máxima verossimilhança de $h_{\text {itk. }}$ Esta estimativa será usada adiante para obter a estimativa da proporção esperada de contratos, dado perfil i e a situação de encerramento $k$, que se encerram com $T_{i}=t$, para t entre 1 e o prazo do contrato i.

\section{Interpretação dos parâmetros:}

$\alpha_{1}, \ldots, \alpha_{\lrcorner}$são os parâmetros da função de risco de referência (baseline). Cada um destes parâmetros é um intercepto permitindo um valor diferente para o risco em cada tempo.

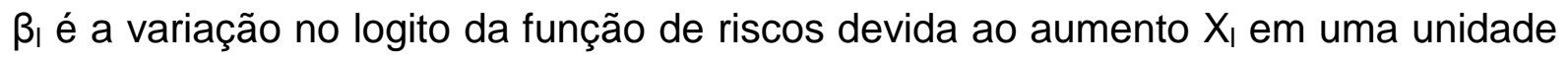
$(\operatorname{com~} \mathrm{l}=1, \ldots, \mathrm{p})$.

Observe que se o evento ocorreu para o indivíduo i no instante $t, y_{i j}=1$ para $\mathrm{j}=\mathrm{t}$ e $\mathrm{y}_{\mathrm{ij}}=0$ para $j=1,2, \ldots t-1$.

Que é equivalente à função de verossimilhança da regressão logística convencional.

\section{Estimação dos parâmetros}

Os parâmetros mencionados podem ser estimados maximizando-se em $\Theta$ a verossimilhança:

$$
L(T ; \beta \mid X)=\prod_{i=1}^{N} P\left(T_{i}=t_{i} \mid X ; \Theta\right)=\prod_{i=1}^{N}\left[h_{i t_{i}} \prod_{j=1}^{t_{i}-1}\left(1-h_{i t}\right)\right]
$$

No APÊNDICE 2.2 está uma demonstração completa de que estes parâmetros podem ser estimados pelos mesmos algoritmos que resolvem uma regressão logística convencional, tendo como unidades observacionais as parcelas j de cada contrato i, com $Y_{\text {itk }}$ sendo a variável resposta (para um k dado entre 1, 2 ou 3), indicando se o contrato foi 
encerrado na parcela t ou não. Mais adiante essa estrutura com visão-parcela é explicada com maiores detalhes.

Note que para cada indivíduo teremos tantas variáveis resposta quantos forem os períodos em que o indivíduo é observado, até a ocorrência do evento. Além disso, existe uma estrutura de correlação entre as probabilidades de o evento ocorrer a cada tempo, que é capturada por este modelo na medida em que estamos tratando das probabilidades condicionais através da função de riscos.

O resultado prático é que, com uma pequena adaptação na base de dados, este modelo pode ser estimado por uma regressão logística convencional, disponível nos pacotes estatísticos mais importantes.

O modelo aqui proposto é baseado no artigo de (Singer \& Willet, 1993), que propõem este modelo para observações no tempo, em que os dados são coletados a cada final de período. Entretanto, em situações em que a variável resposta (usualmente o tempo) é medida de forma contínua, (Hosmer \& Lemeshow, 1999) recomendam que se considere a variável resposta contínua nestes casos, pois o modelo com dados grupados em tempo discreto fornece estimativas ruins para os parâmetros, na medida em que todas as ocorrências de evento dentro de um intervalo de tempo serão acumuladas ao final do período. Este problema não se aplica para a situação em questão, pois o evento ocorre de forma discreta, em uma das parcelas contratadas.

\section{Preparação da tabela para a estimação dos parâmetros}

Estas estimativas podem ser obtidas pelos mesmos procedimentos computacionais que resolvem regressão logística, mas para isto, é necessário realizar uma preparação na tabela de dados.

Cada uma das $\mathrm{N}$ linha tabela original que representa um contrato $i$ deverá ser replicada $t_{i}$ vezes. Agora cada linha da nova tabela representará a parcela $t$ do contrato $i$, da primeira parcela até a parcela em que o contrato se encerra. Devem ser criadas as $T$ variáveis $D_{i t l}$ (com I variando entre 1 e $T$ ), que indicarão se a linha em questão representa a parcela $t$ do contrato $i$. Devemos construir uma nova variável resposta para cada evento: $Y_{i t 1}, Y_{i t 2}$ e $Y_{i t 3}$, definidas como: 


$$
Y_{i t k}=\left\{\begin{array}{c}
1 \text { se contrato } i \text { se encerrou pelo evento } k \text { na parcela } t \\
0 \text { caso contrário. }
\end{array}\right.
$$

Assim, dado um contrato encerrado no evento $\mathrm{k}, \mathrm{Y}_{\text {itk }}$ valerá 0 para todo $t<t i$ e 1 para $t=t_{i}$. Dessa forma, cada $Y_{i t k}$ será observado $t_{i}$ vezes (em $t_{i}$ linhas da tabela) para o contrato i. As tabelas abaixo ilustram um exemplo de uma tabela original de contratos pertencentes ao Grupo 1 e em seguida um exemplo da tabela modificada para se estimar os parâmetros pelo mesmo algoritmo que resolve a regressão logística:

\section{TABELA 3.1. Exemplo da tabela original de contratos do Grupo 1}

\begin{tabular}{|cccc|}
\hline Contrato(i) & Parcela $(\mathbf{t})$ & $\mathbf{t}$ & $\mathbf{Y}_{1}$ \\
\hline 1 & 12 & 1 & 1 \\
\hline 2 & 6 & 3 & 1 \\
\hline 3 & 24 & 2 & 1 \\
\hline
\end{tabular}

TABELA 3.2. Exemplo da tabela modificada de contratos do Grupo 1

\begin{tabular}{|ccccccccc|}
\hline Contrato(i) & prazo & Parcela (t) & $\mathrm{E}_{1}$ & $\mathrm{D}_{1}$ & $\mathrm{D}_{2}$ & $\mathrm{D}_{3}$ & $\ldots$ & $\mathrm{D}_{24}$ \\
\hline 1 & 12 & 1 & 1 & 1 & 0 & 0 & $\ldots$ & 0 \\
\hline 2 & 6 & 3 & 0 & 1 & 0 & 0 & $\ldots$ & 0 \\
\hline 2 & 6 & 3 & 0 & 0 & 1 & 0 & $\ldots$ & 0 \\
\hline 2 & 6 & 3 & 1 & 0 & 0 & 1 & $\ldots$ & 0 \\
\hline 3 & 24 & 2 & 0 & 1 & 0 & 0 & $\ldots$ & 0 \\
\hline 3 & 24 & 2 & 1 & 0 & 1 & 0 & $\ldots$ & 0 \\
\hline
\end{tabular}

Observe que na TABELA 3.2, o contrato $i=1$ aparece em apenas uma linha, pois foi encerrado na primeira parcela, ao passo que o contrato $\mathrm{i}=2$ aparece em 3 linhas e 0 contrato $\mathrm{i}=3$ aparece em 2 linhas, pois foram encerrados na terceira e na segunda parcelas, respectivamente.

\section{Função de sobrevivência e probabilidade de evento na parcela t}

A função de riscos tem importância central na análise de sobrevivência. Outro elemento importante é a função de sobrevivência $S\left(t_{i}\right)$, que fornece a proporção esperada de contratos do perfil i que permanece ativa até a parcela t. A função de sobrevivência terá um papel importante em análises intermediárias do modelo, permitindo a avaliação da importância de alguns fatores, a observação clara da distribuição do tempo até evento dos diferentes perfis e auxiliará também no diagnóstico do modelo, discutido mais adiante. 
A função de sobrevivência é definida como:

$$
S_{i t k}=\mathrm{P}\left(T_{i j k}>t_{i j k} \mid Y_{i j}=\mathrm{k}\right)
$$

Estimados os parâmetros do modelo descrito acima, a função de sobrevivência pode ser estimada como:

$$
\widehat{\boldsymbol{S}}_{i t k}= \begin{cases}\mathbf{1} & \text { se } t=\mathbf{0} \\ \widehat{\boldsymbol{S}}_{i(t-1) k}\left(\mathbf{1}-\widehat{\boldsymbol{h}}_{t j k}\right) & \text { se } 0<t \leq \text { prazo }_{i} \\ \mathbf{0} & \text { se } t>\text { prazo }_{i}\end{cases}
$$

A estimativa da proporção esperada $p\left(\mathrm{~T}_{\mathrm{i}}=\mathrm{t}_{\mathrm{i}} \mid \mathrm{X}_{\mathrm{i}}=\mathrm{X}_{\mathrm{i}}\right)$ decontratos do perfil i que incorrem no evento após pagar a parcela i é de fundamental importância no cálculo do resultado esperado dos contratos, como será discutido na Seção 3.5. Os parâmetros obtidos com a maximização da verossimilhança (3.6) aplicados à equação (3.3) oferecem estimativas

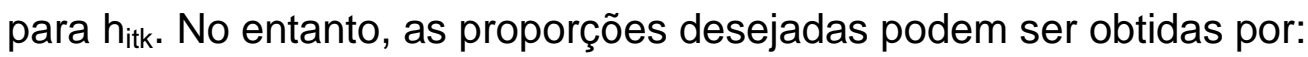

$$
\hat{p}\left(T_{i}=t_{i} \mid \boldsymbol{Y}_{\boldsymbol{i}}=\boldsymbol{y}_{\boldsymbol{i}}\right)=\widehat{\boldsymbol{S}}_{i(t-1) k} \hat{h}_{i t k}
$$

Observe que, se $\mathrm{t}=$ prazo $_{i}$, então $h_{\text {itk }}=1$, pois $t_{i}$ só pode assumir valores entre $1 \mathrm{e}$ prazo

\section{Redução do número de parâmetros da função de riscos base}

Como em um problema de modelagem linear, podemos querer testar se determinado par $\alpha_{t}$ e $\alpha_{t+1}$ são iguais. Em caso positivo, pode-se construir um modelo simplificado utilizando apenas um parâmetro para estas duas parcelas. Existem diversas formas de simplificar este modelo quanto ao seu número de parâmetros.

Uma forma eficiente de reduzir o número de parâmetros é colocar nos $\alpha_{t}^{\prime}$ s uma estrutura mais rígida, como por exemplo, $\alpha_{t}=\theta_{0}+\theta_{1} t$. Esta estrutura assume que os alfas tenham uma relação linear com o tempo.

Outras funções com forma mais livre podem ser utilizadas. Vamos propor agora uma análise que auxilie a decidir qual é a função mais adequada.

\section{Escolha da função de riscos base}


A relação entre os alfas e o número da parcela pode ser observada com o auxílio de um gráfico muito útil, que tem nas ordenadas o número da parcela e nas abscissas o logito do risco de ocorrência do evento na parcela respectiva. Estes valores podem ser obtidos pela estimativa direta de um modelo que possui somente os parâmetros $\alpha_{j}$.

Para ajudar na escolha da estrutura que desejamos colocar, podemos inserir no mesmo gráfico um intervalo de confiança para cada parâmetro. O intuito desse intervalo é meramente descritivo, por esse motivo não há a necessidade de controlar o erro global dos intervalos.

Podemos inserir também, no mesmo gráfico, a curva que segue a estrutura desejada para verificar se esta estrutura é adequada.

A FIGURA 3.1 ilustra um exemplo dessa análise.

FIGURA 3.1. Análise de relação linear logística

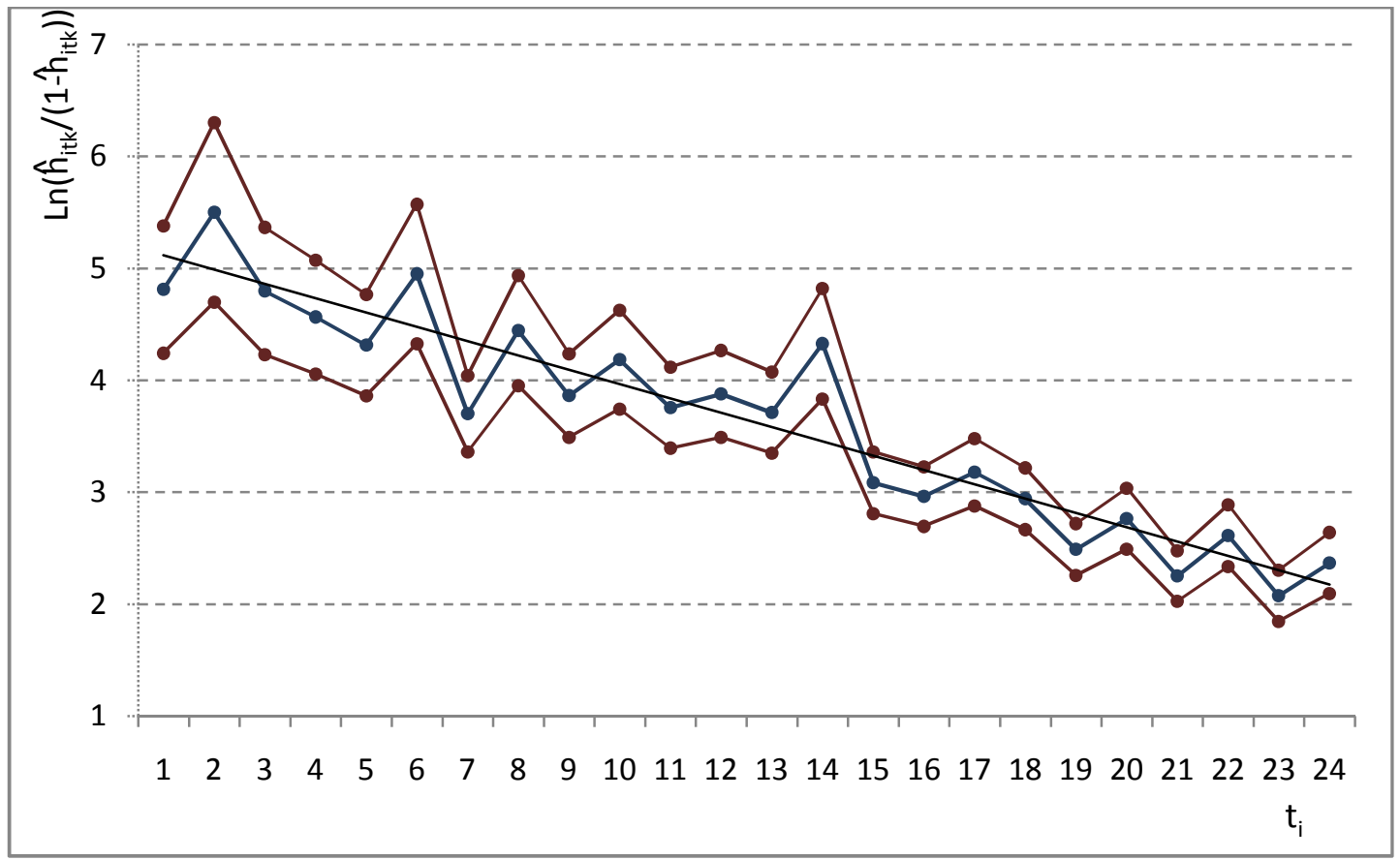

A observação do gráfico ilustrado na FIGURA 3.1 pode sugerir a forma da função de riscos base (reta, quadrática, cúbica, log, etc.). No exemplo ilustrado na FIGURA 3.1, verificamos que a reta é uma estrutura que se ajusta bem ao logito do risco em função do tempo, sendo uma boa candidata a função de riscos base. 
Um cuidado especial deve ser tomado com variáveis diretamente relacionadas ao tempo de observação do contrato. A variável prazo, por exemplo, além de ser candidata a fonte de variação dos $h_{\mathrm{ijk}}$ 's, define o tempo máximo de exposição de um contrato. Dessa forma, contratos com prazo de seis meses só aparecerão no gráfico até o sexto mês, de modo que o efeito devido ao contrato ser de seis meses não estará presente do sétimo mês em diante.

Sugerimos, assim, que esta análise seja estratificada pelas variáveis mais importantes. No exemplo citado acima, sugerimos construir um gráfico para cada valor do prazo.

\section{Suposições do modelo:}

Independência: As variáveis aleatórias $Y_{i j k}$ têm distribuição bernoulli( $\left.h_{i j k}\right)$ e são condicionalmente independentes, dadas as observações do vetor $X_{i}$ de características e dado $\mathrm{k}=1,2$ ou 3 .

Riscos com Logitos aditivos: Variando a parcela j, o logito dos riscos deve ser sempre igual à função de risco dada pela função de referência (baseline), a menos de uma constante dada pela combinação linear entre os parâmetros $(\boldsymbol{\beta})$ do modelo e as variáveis explicativas $\mathbf{X}_{\mathbf{i}}$ do contrato. De forma análoga à suposição de riscos proporcionais no modelo de Cox (Hosmer \& Lemeshow, 1999), esta suposição é equivalente à proporcionalidade na quantidade $\frac{h_{i t k}}{1-h_{i t k}}$ (analogamente à proporcionalidade da quantidade $h_{\mathrm{ijk}}$ observada no modelo de Cox).

\subsubsection{Variáveis dependentes do tempo}

A suposição de Riscos com Logitos Aditivos mencionada acima pode ser aliviada com a introdução de variáveis dependentes do tempo, o que permite que a função $h_{i j k}$ possa assumir uma forma distinta em j, dependendo do perfil do contrato i.

Uma forma de inserir variáveis dependentes do tempo é utilizar a seguinte estrutura:

$$
\operatorname{Ln}\left(\frac{h_{i t k}}{1-h_{i t k}}\right)=D_{i t 1} \alpha_{01}+\cdots+D_{i t T} \alpha_{0 T}+\cdots+D_{i t 1} \alpha_{w 1} X_{i w}+\cdots+D_{i t T} \alpha_{w T} X_{i w}
$$


Com $w \in\{1,2, \ldots, p\}$. Sendo $X_{w}$ uma variável dummy (binária, valendo 1 na presença de determinada característica e zero caso contrário), este modelo permite uma função de riscos totalmente livre para o grupo determinado por ela.

Uma estrutura bastante semelhante pode ser construída ao se utilizar a interação entre $X_{w}$ e um subconjunto dos $D_{i t l}$. Isso permite que o risco varie com $X_{w}$ apenas em determinadas parcelas.

A estrutura que utilizaremos aqui mescla a estrutura descrita na seção 3.3 com a já descrita nesta seção. Ela se baseia em uma curva estruturada diferente para cada perfil, utilizando o próprio índice $t$ no lugar das variáveis $D_{\text {itt. }}$ Traduzindo em uma equação, o logito do risco $h_{\text {itk }}$ do indivíduo $i$, na parcela t para o evento $k$ tem a forma:

$$
\operatorname{Ln}\left(\frac{h_{i t}}{1-h_{i t}}\right)=\theta_{00}+\theta_{01} t+\theta_{10} X_{i w 1}+\cdots+\theta_{p 0} X_{i p}+\theta_{p 1} t X_{i p}+X_{i 1} \beta_{1}+\cdots+X_{i p} \beta_{p}
$$

Dessa forma, teremos, para cada perfil determinado por uma configuração fixa de $X_{i 1}=x_{i 1}, \ldots, X_{i p}=x_{i p}$, uma reta com intercepto e inclinação diferentes. Na análise que se segue, utilizaremos como variáveis dependentes do tempo somente variáveis categorizadas, o que torna o modelo mais simples.

\subsubsection{Avaliação dos modelos de tempo até evento}

É importante que o modelo de sobrevivência forneça com precisão, para cada perfil definido pelas variáveis observáveis $X$, o percentual de contratos que incorre no evento $k$ em cada parcela.

Observe que o resultado do contrato é uma função monótona com a parcela em que ele foi encerrado, dado o evento, de modo que erros na estimação das proporções de ocorrência que se compensem em parcelas consecutivas têm importância menor na estimação final do resultado.

Assim, uma boa maneira de avaliar o desempenho dos modelos de tempo é comparar a curva de sobrevivência estimada com a curva de sobrevivência empírica obtida através do estimador de Kaplan Meyer (Hosmer \& Lemeshow, 1999). Esta comparação indicará se as estimativas das distribuições de tempo até evento esperadas estão próximas das observadas. 
Esta análise pode também ser estratificada pelos níveis das variáveis explicativas discretas, ou por categorizações das variáveis quantitativas contínuas. Uma variável com importância especial, como já mencionado, é o prazo do contrato.

\subsection{Avaliação final do modelo}

Esta análise procura verificar a qualidade da resposta final do modelo. Ou seja, por melhores que sejam os modelos construídos separadamente, desejamos verificar o quão útil é o modelo final para decisão de crédito e quão bem o resultado esperado final se ajusta ao resultado observado.

O gráfico descrito a seguir é uma adaptação do "lift chart" descrito por (Vuk \& Curk, 2006), porém com variável resposta contínua, ao invés do gráfico com resposta binária.

O objetivo final do modelo proposto é a obtenção de uma avaliação do resultado esperado da operação de crédito, no momento da contratação. Desejamos agora verificar para este resultado esperado as seguintes características:

- Aderência: Desejamos verificar se o resultado esperado fornecido pelo modelo é próximo do resultado observado.

- Discriminação: Desejamos verificar se o modelo tem a capacidade de discriminar operações que fornecerão resultados diferentes.

Para verificar estas duas características, observaremos o Gráfico de Utilidade Acumulada. Descrevemos a seguir os passos para a construção deste gráfico:

1) Ordenar os dados de acordo com o resultado esperado da operação, em ordem decrescente;

2) Para cada observação ordenada, calcular, para todas as observações com resultado esperado igual ou pior que o da observação:

a. O percentual de observações;

b. A soma dos resultados observados;

c. A soma dos resultados esperados.

3) Construir um gráfico com quatro linhas, sempre com o percentual das observações com melhores resultados esperados no eixo das abscissas, colocando no eixo das ordenadas: 
a. Os resultados observados acumulados das observações com melhores resultados esperados (2.b).

b. Os resultados esperados acumulados das observações com melhores resultados esperados (2.c).

c. Linha de referência da curva observada: seja $C_{0}$ o resultado observado de todos os contratos da amostra, a linha de referência da curva observada é a reta que liga o ponto $(0,0)$ ao ponto $\left(1, \mathrm{C}_{0}\right)$.

d. Linha de referência da curva esperada: seja $C_{e}$ o resultado esperado de todos os contratos da amostra, a linha de referência da curva esperada é a reta que liga o ponto $(0,0)$ ao ponto $\left(1, C_{e}\right)$.

O gráfico resultante está disposto na Seção 4.7, na FIGURA 4.6

\subsection{Cálcullo do resultado esperado da operação}

Na Seção 2.5 definimos o cálculo do resultado de uma operação de crédito com observação encerrada, já classificada em um dos três grupos. Dada uma proposta de crédito i, com suas variáveis explicativas $\mathbf{x}_{\mathbf{i}}$ já observadas, e estabelecidos os valores para os custos de cobrança e captação, definido o spread, temos que o seu resultado esperado $E\left(R_{i}\right)$ é calculado da seguinte forma:

$$
E\left(R_{i} \mid \boldsymbol{X}_{\boldsymbol{i}}=\boldsymbol{x}_{\boldsymbol{i}}\right)=\sum_{j=1}^{3} E\left(R_{i} \mid \boldsymbol{Y}_{\boldsymbol{i}}=\boldsymbol{y}_{\boldsymbol{j}} ; \boldsymbol{X}_{\boldsymbol{i}}=\boldsymbol{x}_{\boldsymbol{i}}\right)
$$

Seja $R_{i}\left(\mathbf{y}_{\mathbf{j}}, t_{i}, s, \mathbf{C}\right)=E\left(R_{i} \mid \mathbf{Y}_{\mathbf{i}}=\mathbf{y}_{\mathbf{j}} ; T_{i}=t_{i} ; s ; \mathbf{C}\right)$, em que $s$ é o valor da taxa Spread, $\mathbf{C}$ é um vetor de constantes referentes aos custos de captação e de cobrança. A quantidade $R_{i}\left(\mathbf{y}_{\mathbf{j}}, t_{i}, s, \mathbf{C}\right)$ é considerada constante, e é calculada conforme mostrado na Seção 2.5. Dessa forma, podemos estimar $E\left(R_{i} \mid \mathbf{x}_{i}\right)$ como:

$$
\widehat{E}\left(R_{i} \mid \mathbf{x}_{\mathbf{i}}\right)=\sum_{t=1}^{\operatorname{prazo}_{i}} \sum_{g=1}^{3} R_{i}\left(\mathbf{y}_{\mathbf{j}}, t_{i}, s, \mathbf{C}\right) \hat{P}\left(\mathbf{Y}_{\mathbf{i}}=\mathbf{y}_{\mathbf{j}} ; T_{i}=t_{i} \mid \mathbf{X}_{\mathbf{i}}=\mathbf{x}_{\mathbf{i}}\right)
$$

Ou seja,

$$
\begin{aligned}
& \hat{E}\left(R_{i} \mid \boldsymbol{X}_{\boldsymbol{i}}=\boldsymbol{x}_{\boldsymbol{i}}\right)= \\
& \quad=\sum_{t=1}^{\operatorname{prazo}_{i}} \sum_{g=1}^{3} R_{i}\left(\boldsymbol{y}_{\boldsymbol{j}}, t_{i}, s, \boldsymbol{C}\right) \hat{P}\left(\boldsymbol{Y}_{\boldsymbol{i}}=\boldsymbol{y}_{\boldsymbol{i}} \mid \boldsymbol{X}_{\boldsymbol{i}}=\boldsymbol{x}_{\boldsymbol{i}}\right) \hat{P}\left(T_{i}=t_{i} \mid \boldsymbol{Y}_{\boldsymbol{i}}=\boldsymbol{y}_{\boldsymbol{j}} ; \boldsymbol{X}_{\boldsymbol{i}}=\boldsymbol{x}_{\boldsymbol{i}}\right)
\end{aligned}
$$


Em que $\hat{P}\left(\mathbf{Y}_{\mathbf{i}}=\mathbf{y}_{\mathbf{i}} \mid \mathbf{X}_{\mathbf{i}}=\mathbf{x}_{\mathbf{i}}\right)$ é estimada pelos modelos logísticos da Seção $3.1 \mathrm{e}$ $\hat{P}\left(T_{i}=t_{i} \mid \mathbf{Y}_{\mathbf{i}}=\mathbf{y}_{\mathbf{j}} ; \mathbf{X}_{\mathbf{i}}=\mathbf{x}_{\mathbf{i}}\right)$ é dada pela análise de sobrevivência descrita na Seção 3.3.

\subsection{Definição da taxa mínima}

Conforme discutido anteriormente, a instituição financeira deseja conhecer qual a taxa mínima de crédito que deve cobrar sobre determinadas condições para determinado perfil de cliente de modo que, em média, obtenha o lucro desejado.

A taxa cobrada pode interferir de duas formas diferentes na utilidade esperada. A primeira forma é uma possível relação de causa-efeito entre a taxa do contrato e a inadimplência, refletindo a hipótese de que: quanto maior a taxa do contrato, maior (ou menor) é o risco de crédito. A segunda forma é pelo aumento direto do valor das parcelas, aumentando juntamente a amortização e o spread, melhorando, portanto, o resultado do ponto de vista da instituição.

A primeira forma de relação entre a taxa e o risco é muito difícil de ser medida, pois para estimar este efeito existe um confundimento com outros fatores relacionados ao cliente de maior risco ter maior propensão a aceitar um contrato de taxa mais elevada (ou menos elevada).

Já o segundo efeito está perfeitamente considerado no modelo em questão. Assim, uma vez estimadas as proporções esperadas dos eventos de interesse (classificações, parcelas pagas até quitação antecipada e parcelas pagas até prejuízo), a utilidade ainda varia conforme a taxa de spread.

A instituição financeira é quem deve definir qual é o resultado mínimo aceitável para um contrato de crédito. Normalmente essa definição é feita com o auxílio de conceitos econômico-financeiros como o RAROC $^{5}$ (Risk Adjusted Return on Capital) ou EVA ${ }^{6}$ (Economic Value Added). Estes conceitos se baseiam no Capital Econômico ${ }^{7}$, que é a quantidade de capital próprio que a instituição deve manter alocado pela operação de crédito. Como não é escopo desse estudo discutir conceitos econômico-financeiros,

\footnotetext{
${ }^{5}$ RAROC é uma medida do resultado líquido da operação, considerando todo o tipo de custos, impostos e perda de crédito dividido pelo capital econômico (Glantz, 2003).

${ }^{6}$ EVA é uma medida do resultado da operação semelhante ao RAROC, mas o capital econômico é considerado pelo seu custo de oportunidade, de forma aditiva. (Stern \& Shieli, 2001).

${ }^{7}$ Capital Econômico é um percentual do saldo de um contrato que uma instituição de crédito deve manter de capital próprio alocado, regulatoriamente, de modo a evitar insolvência. (Porteous \& Tapadar, 2006)
} 
definimos simplesmente como alvo mínimo um resultado de $4 \%$ do valor presente do contrato, mas tais conceitos podem facilmente ser incorporados a este trabalho.

Estabelecida a receita desejada pela instituição financeira e estimados os parâmetros necessários, descrevemos a seguir um algorítmo para determinar a taxa mínima para atingir a receita desejada pela instituição financeira.

Este algoritmo tem como entrada:

Spr_a e Spr_b: São os valores iniciais máximo e mínimo, respectivamente, entre os quais o algoritmo iniciará a busca pelo valor ótimo da taxa. Valores sugeridos para estes parâmetros são Spr_a=0 e Spr_b=spread máximo dentre todos os observados na amostra;

Precisão: É a diferença máxima tolerável entre a taxa ótima e a taxa dada como resposta pelo algoritmo. Utilizaremos como precisão 0,00001 .

Max_iter: Número máximo de iterações que o algoritmo irá realizar na busca pela taxa ótima. Utilizamos $30^{8}$ como número máximo de iterações.

Alvo: é o valor do resultado mínimo desejado para a operação. O valor alvo utilizado será $4 \%$ do valor da operação.

Terá também as variáveis:

Spr_c: variável auxiliar que armazenará o ponto médio entre os valores de Spr_a e Spr_b.

Res_a, Res_b e Res_c: Resultado do contrato calculado com todas as características observadas do contrato, mas utilizando como spread o valor armazenado em Spr_a, Spr_b e Spr_c, respectivamente.

i) Atribuir a Res_b o resultado esperado da operação (calculado conforme Capítulo 3.7) considerando Spr_b como o spread da operação;

ii) Enquanto Res_b for menor que o alvo, atribuir a Res_b o dobro de Res_b e repetir (i);

${ }^{8}$ Todas as simulações atingiram o alvo com menos de 30 iterações. 
iii) Atribuir a Spr_c o ponto médio entre Res_a e Res_b;

iv) Atribuir a Res_c o resultado esperado da operação (calculado conforme Capítulo 3.7) considerando como spread Spr_c.

v) Se Res_c for menor que o alvo, Atribuir a Spr_b o valor de Spr_c. Caso contrário, atribuir a Spr_a o valor de Spr_c;

vi) Enquanto o módulo da diferença entre Res_c e o alvo for menor que a precisão e o número de iterações for menor que Max_iter, repetir os passos (iii), (iv) e (v);

vii) Atribuir a Spr_final o valor de Spr_c. 


\section{Aplicação}

Neste capítulo são mostrados os resultados da aplicação da metodologia descrita no Capítulo 3, utilizando os dados simulados descritos no Capítulo 2.

As Seções 4.1 e 4.2 mostram os resultados dos modelos discutidos no Capítulo 3, de classificação multinomial e de tempo até evento, respectivamente.

A Seção 4.3 e 4.4 mostram os resultados das análises de qualidade dos modelos.

Serão mostrados aqui os resultados das estimativas dos parâmetros do modelo para a classificação multinomial e dos modelos de sobrevivência em tempo discreto, condicional à situação de encerramento no contrato. Em seguida, serão mostrados os resultados do ganho esperado de cada contrato e da estimativa de taxa mínima que se deve cobrar para um contrato para garantir a rentabilidade da carteira.

\subsection{Tratamento das variáveis}

A regressão logística, assim como os modelos lineares generalizados, permite o uso de variáveis quantitativas e qualitativas. Alguns autores categorizam as variáveis contínuas e trabalham com elas como qualitativas (Neter, Kutner, Nachtsheim, \& li, 2004). Esta metodologia facilita o ajuste de funções mais complexas nas variáveis explicativas e traz robustez ao modelo, no sentido de minimizar problemas com valores discrepantes. Porém, traz a desvantagem de tratar como diferentes valores muito próximos do ponto de corte entre uma classe e outra e utilizar parâmetros demais no ajuste de uma única variável.

Neste trabalho a abordagem será a de ajustar as variáveis contínuas linearmente sempre que possível, utilizando, se necessário, uma função contínua que melhore o ajuste dessa variável.

Sugerimos aqui uma análise para verificar se a variável pode ser utilizada como contínua, e que fornece uma pista de qual função utilizar. A seguir, descrevemos os passos para esta análise:

- Categorizar a variável explicativa em percentís. O número de percentís pode depender do tamanho da amostra. Em amostras especialmente grandes, pode-se utilizar um número maior de percentis, dependendo do tamanho da amostra. Em amostras muito pequenas, este número pode ser reduzido para 5; 
- Calcular, para cada percentil, a média da variável explicativa em questão;

- Calcular o percentual de eventos da variável resposta para cada quantil da explicativa;

- Calcular a transformação logito para estes percentuais;

- Pode-se também calcular o intervalo de confiança de máxima verossimilhança para o logito do percentual de eventos;

- Construir um gráfico com o logito do percentual de eventos com respectivo intervalo de confiança, no eixo das ordenadas, por percentil, com o ponto médio do percentil no eixo das abscissas.

Dependendo da forma da curva que o gráfico mostrar, pode ser indício de uma transformação diferente necessária para a variável. Por exemplo, se uma reta puder ser traçada sem que nenhum ponto fique fora do intervalo de confiança, é um indício de que a variável pode ser utilizada como contínua sem qualquer função.

\subsection{Classificação multinomial}

Conforme descrito no capítulo 3, a classificação multinomial que faremos se baseia em dois modelos de regressão logística separados para obter a estimação dos três parâmetros da distribuição. O primeiro modelo será construído para discriminar uma classe arbitrária das demais. O segundo modelo será construído para discriminar uma segunda classe arbitrária da classe restante, condicionado à não ocorrência da classe identificada pelo modelo anterior.

Construiremos o primeiro modelo para identificar a classe menos freqüente, de modo que o segundo modelo será estimado com mais observações, fornecendo melhores estimativas.

Cada um destes modelos, separadamente, é muito semelhante aos modelos de "Credit Scoring" baseados em regressão logística para classificação binomial (Rosa, 2000).

Os modelos, conjuntamente, porém, configuram uma expansão da regressão logística tradicional. Assim, as medidas de qualidade do modelo servem para verificação isolada de cada um. 
Os parâmetros descritos para o modelo referente a $P\left(Y_{3}=1\right)$ foram estimados por máxima verossimilhança. Na TABELA 4.1 estão mostrados, para cada variável, a estimativa do seu parâmetro correspondente, seu erro padrão, a estatística de Wald e o nível descritivo para o teste de Wald, cuja hipótese nula é a de que o parâmetro é igual a zero.

TABELA 4.1. Parâmetros para o modelo referente a $P\left(Y_{3}=1\right)$

\begin{tabular}{|c|c|c|c|c|c|}
\hline Parâmetro & $\boldsymbol{G L}$ & Estimativa & $\begin{array}{r}\text { Erro } \\
\text { adrão }\end{array}$ & $\frac{\text { Estatística de }}{\text { Wald }}$ & $\begin{array}{r}\text { Nível } \\
\text { Descritivo }\end{array}$ \\
\hline PRAZO6 & 1 & $-2,523$ & 0,159 & 251,2 & $<0,0001$ \\
\hline PRAZO12 & 1 & $-2,265$ & 0,152 & 223,0 & $<0,0001$ \\
\hline PRAZ018 & 1 & $-1,567$ & 0,151 & 107,4 & $<0,0001$ \\
\hline PRAZO24 & 1 & $-0,465$ & 0,147 & 9,979 & 0,0020 \\
\hline Histórico positivo & 1 & $-1,334$ & 0,083 & 260,2 & $<0,0001$ \\
\hline Idade da empresa & 1 & $-0,084$ & 0,005 & 292,4 & $<0,0001$ \\
\hline Endividamento & 1 & $-0,457$ & 0,218 & 4,399 & 0,0360 \\
\hline Histórico Negativo & 1 & 1,565 & 0,064 & 598,0 & $<0,0001$ \\
\hline
\end{tabular}

TABELA 4.2. Parâmetros para o modelo referente a $P\left(Y_{2}=1 \mid Y_{3}=0\right)$

\begin{tabular}{l|rrrrr}
\hline Parâmetro & GL & Estimativa & Erro & Estatística de & \begin{tabular}{r} 
Nível \\
\cline { 3 - 6 }
\end{tabular} \\
\cline { 3 - 6 } & 1 & -1.964 & 0.1151 & 291.1 & $<.0001$ \\
PRAZO6 & 1 & -1.604 & 0.1073 & 223.6 & $<.0001$ \\
PRAZ012 & 1 & -1.215 & 0.1088 & 124.7 & $<.0001$ \\
PRAZ018 & 1 & -0.550 & 0.1104 & 24.9 & $<.0001$ \\
PRAZ024 & 1 & -0.725 & 0.0468 & 239.3 & $<.0001$ \\
Histórico Positivo & 1 & -0.030 & 0.0040 & 53.8 & $<.0001$ \\
Idade da empresa & 1 & 0.001 & 0.0037 & 6.9 & 0.0085 \\
Idade*Hist. Neg & 1 & 0.558 & 0.0870 & 41.1 & $<.0001$ \\
Histórico Negativo & 1 & & & & Wald \\
\hline
\end{tabular}




\subsection{Diagnóstico dos modelos logísticos}

Nesta seção mostraremos os resultados das análises de diagnóstico para 0 modelo1: $\mathrm{P}\left(\mathrm{Y}_{3}=1\right)$ e modelo 2: $\mathrm{P}\left(\mathrm{Y}_{2}=1 \mid \mathrm{Y}_{3}=0\right)$. As análises realizadas são: teste de Hosmer \& Lemeshow para adequabilidade de ajuste, estatística de Kolmogorov \& Smirnov e a curva ROC para a qualidade da discriminação entre os dois públicos.

TABELA 4.3. Teste de Hosmer e Lemeshow do modelo de classificação 1

\begin{tabular}{|c|c|c|c|c|c|c|}
\hline & Tatal & $Y_{1}$ & & $\mathrm{Y}_{1}=$ & & Qui-quadrado \\
\hline DeclI & Iotal & Observado & Esperado & Observado & Esperado & \\
\hline 1 & 1000 & 0 & 0,5 & 1000 & 999,5 & 0,470221 \\
\hline 2 & 1000 & 1 & 1,6 & 999 & 998,4 & 0,225361 \\
\hline 3 & 1000 & 3 & 3,3 & 997 & 996,8 & 0,019293 \\
\hline 4 & 1000 & 8 & 6,3 & 992 & 993,7 & 0,474060 \\
\hline 5 & 1000 & 7 & 12,5 & 993 & 987,5 & 2,464595 \\
\hline 6 & 1000 & 22 & 23,7 & 978 & 976,3 & 0,129189 \\
\hline 7 & 1000 & 38 & 44,2 & 962 & 955,8 & 0,912641 \\
\hline 8 & 1000 & 92 & 83,7 & 908 & 916,3 & 0,905041 \\
\hline 9 & 1000 & 171 & 170,5 & 829 & 829,5 & 0,001768 \\
\hline 10 & 1000 & 461 & 456,8 & 539 & 543,2 & 0,072452 \\
\hline & & & & $\begin{array}{l}\text { Qui-q } \\
\text { Graus } \\
\text { Ní }\end{array}$ & $\begin{array}{l}\text { drado total } \\
\text { e liberdade } \\
\text { l descritivo }\end{array}$ & $\begin{array}{r}5,6734 \\
8 \\
0,6838 \\
\end{array}$ \\
\hline
\end{tabular}


FIGURA 4.1. Curva ROC do modelo de classificação 1

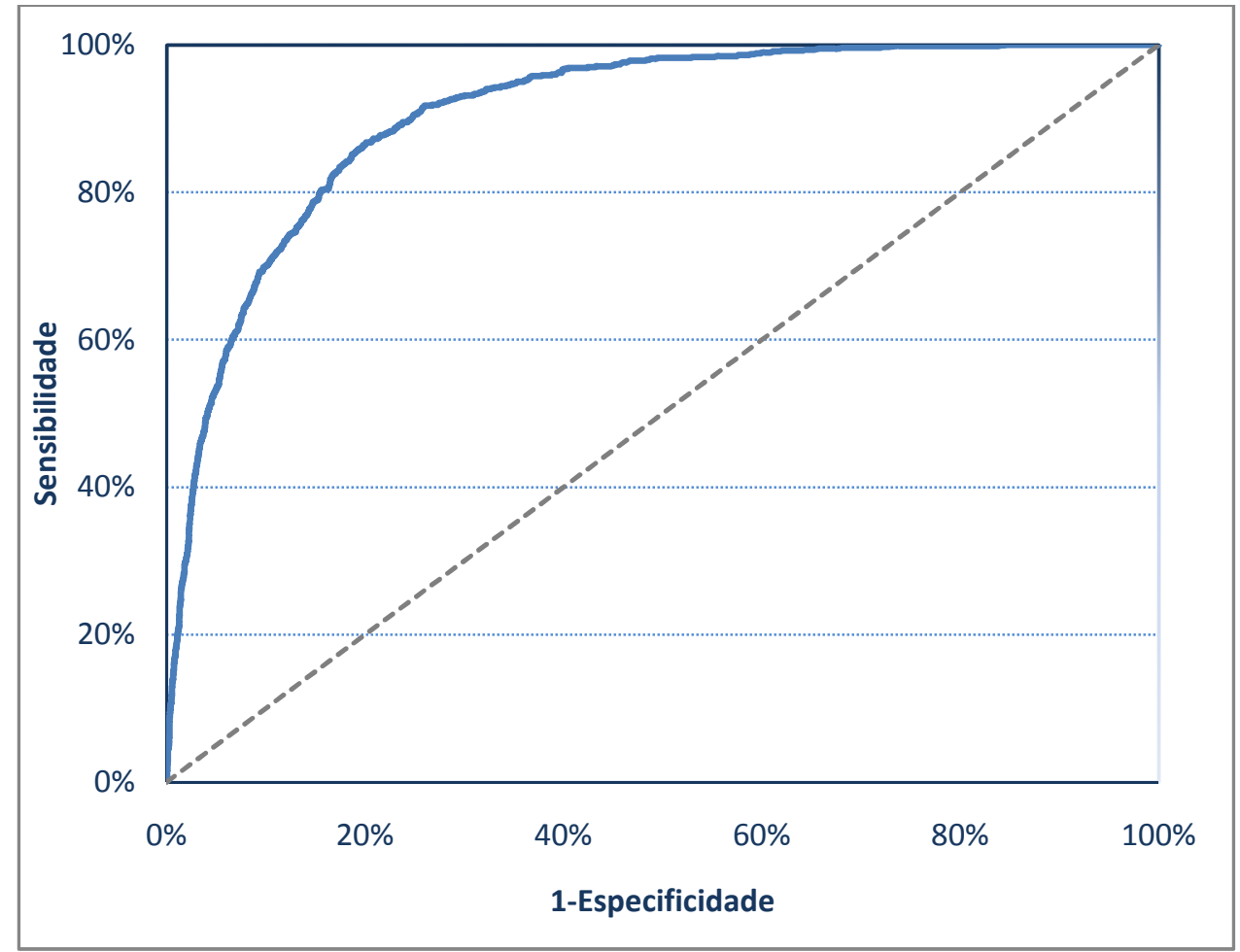

TABELA 4.4. Poder de classificação do modelo 1

\begin{tabular}{r|c}
\hline KS & 0,67 \\
\hline Área sob curva ROC & 0,91 \\
\hline
\end{tabular}

TABELA 4.5. Teste de Hosmer e Lemeshow do modelo de classificação 2

\begin{tabular}{rrrrrrr}
\hline \multicolumn{7}{c|}{ Partições para o teste de Hosmer e Lemeshow } \\
Decíl & Total & \multicolumn{2}{c}{$\mathbf{Y}_{\mathbf{2}}=\mathbf{1}$} & \multicolumn{2}{c|}{$\mathbf{Y}_{\mathbf{2}}=\mathbf{0}$} & $\begin{array}{c}\text { Qui-quadrado } \\
\text { Parcial }\end{array}$ \\
\hline $\mathbf{1}$ & 921 & 9 & 14,81 & 912 & 906,19 & 2,3165 \\
$\mathbf{2}$ & 920 & 23 & 25,21 & 897 & 894,79 & 0,1992 \\
$\mathbf{3}$ & 917 & 34 & 35,85 & 883 & 881,15 & 0,0994 \\
$\mathbf{4}$ & 920 & 40 & 50,46 & 880 & 869,54 & 2,2941 \\
$\mathbf{5}$ & 922 & 77 & 70,36 & 845 & 851,64 & 0,6784 \\
$\mathbf{6}$ & 915 & 101 & 90,55 & 814 & 824,45 & 1,3384 \\
$\mathbf{7}$ & 918 & 123 & 118,06 & 795 & 799,94 & 0,2372 \\
$\mathbf{8}$ & 923 & 161 & 153,66 & 762 & 769,34 & 0,4206 \\
$\mathbf{9}$ & 915 & 214 & 202,73 & 701 & 712,27 & 0,8048 \\
$\mathbf{1 0}$ & 926 & 306 & 326,31 & 620 & 599,69 & 1,9520 \\
\hline
\end{tabular}


FIGURA 4.2. Curva ROC do modelo de classificação 2

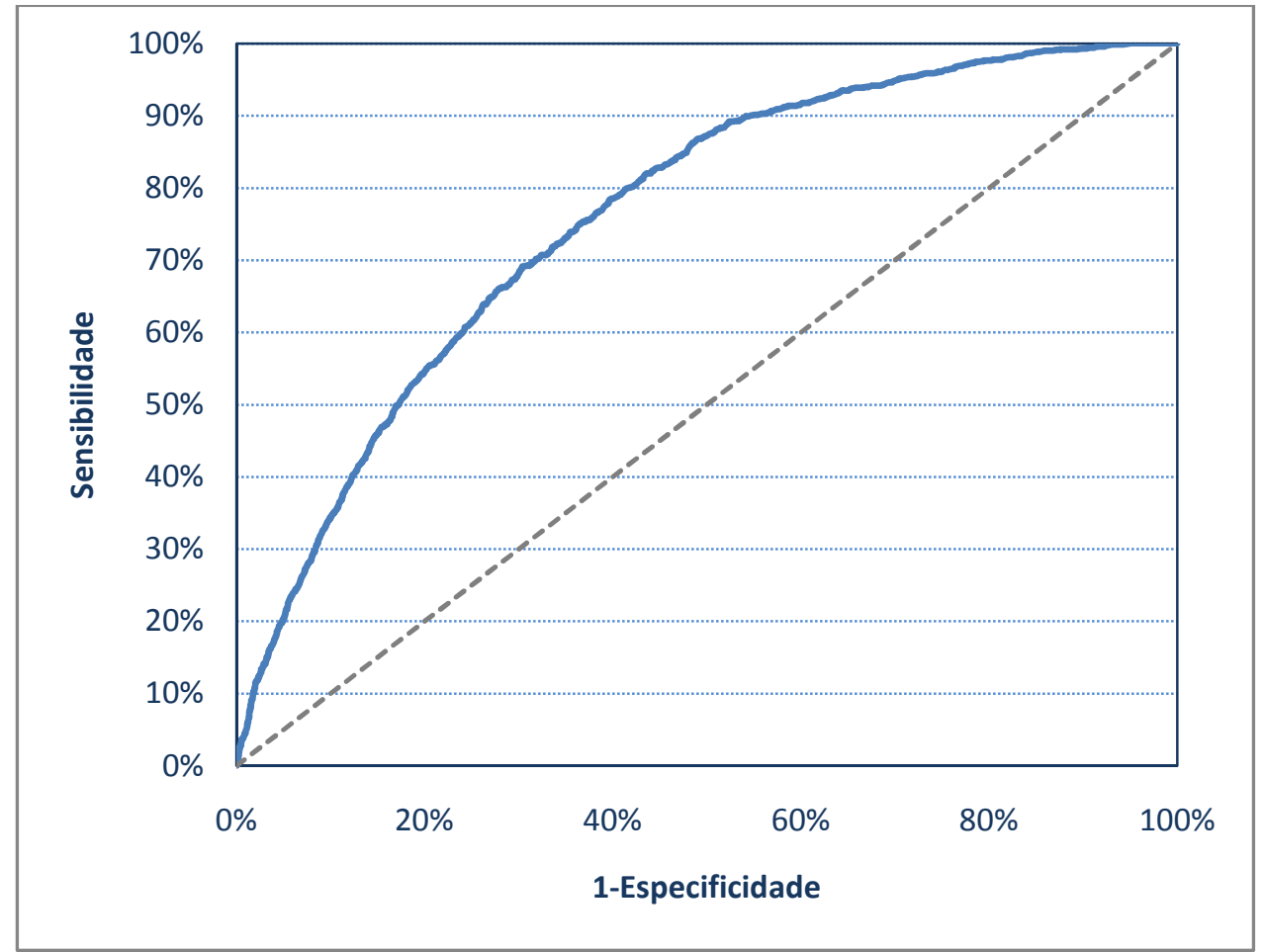

TABELA 4.6. Poder de classificação do modelo 2

\begin{tabular}{r|r}
\hline KS & 0,39 \\
\hline Área sob curva ROC & 0,76 \\
\hline
\end{tabular}

TABELA 4.7. Diagnóstico da classificação multinomial

\begin{tabular}{l|rrr|rrr}
\hline \multirow{2}{*}{$\begin{array}{c}\text { Índice de Distância } \\
\text { ao Pior Caso }\end{array}$} & \multicolumn{3}{|c|}{ Observado } & \multicolumn{3}{c}{ Esperado } \\
\cline { 2 - 7 } & $\mathbf{Y}_{\mathbf{1}}$ & \multicolumn{1}{c}{$\mathbf{Y}_{\mathbf{2}}$} & \multicolumn{1}{c}{$\mathbf{Y}_{\mathbf{3}}$} & \multicolumn{1}{|c}{$\mathbf{Y}_{\mathbf{1}}$} & \multicolumn{1}{c}{$\mathbf{Y}_{\mathbf{2}}$} & \multicolumn{1}{|}{$\mathbf{Y}_{\mathbf{3}}$} \\
\hline $\mathbf{0 , 0 0 0 - | 0 , 6 3 9}$ & 353 & 189 & 458 & 337.0 & 207.5 & 455.5 \\
$\mathbf{0 , 6 3 9 - | 0 , 7 8 8}$ & 604 & 217 & 179 & 616.5 & 213.5 & 170.0 \\
$\mathbf{0 , 7 8 8 - | 0 , 8 6 3}$ & 726 & 191 & 83 & 736.0 & 180.9 & 83.2 \\
$\mathbf{0 , 8 6 3 - | 0 , 9 0 6}$ & 813 & 145 & 42 & 813.5 & 142.1 & 44.4 \\
$\mathbf{0 , 9 0 6 - | 0 , 9 3 4}$ & 852 & 132 & 16 & 865.4 & 110.1 & 24.6 \\
$\mathbf{0 , 9 3 4 - | 0 , 9 5 4}$ & 893 & 94 & 13 & 902.0 & 85.0 & 13.0 \\
$\mathbf{0 , 9 5 4 - | 0 , 9 7 0}$ & 950 & 44 & 6 & 932.6 & 60.6 & 6.7 \\
$\mathbf{0 , 9 7 0 - | 0 , 9 8 0}$ & 958 & 37 & 5 & 954.5 & 42.1 & 3.4 \\
$\mathbf{0 , 9 8 0 - | 0 , 9 8 7}$ & 971 & 28 & 1 & 969.5 & 28.7 & 1.8 \\
$\mathbf{0 , 9 8 7 - | 1 , 0 0 0}$ & 989 & 11 & 0 & 982.8 & 16.7 & 0.6 \\
\hline
\end{tabular}

Observamos que os valores esperados e observados são bastante similares, indicando que o modelo está bem ajustado a estes dados. 


\subsection{Parcela de encerramento}

De acordo com a metodologia descrita no Capítulo 3, o tempo até evento é estimado através de um algoritmo que maximiza a verossimilhança de uma regressão logística. Teremos uma equação por grupo, pois o modelo probabilístico proposto é condicional ao grupo em que o contrato desempenha.

Na TABELA 4.8, TABELA 4.9 e TABELA 4.10 mostramos os parâmetros estimados por máxima verossimilhança dos modelos de tempo até evento condicionais aos grupos de desempenho 1, 2 e 3, respectivamente. 
TABELA 4.8. Estimativas do modelo de parcela de encerramento no Grupo 1

\begin{tabular}{l|rrrrr}
\hline \multicolumn{1}{c|}{ Parâmetro } & GL & Estimativa & $\begin{array}{c}\text { Erro } \\
\text { Padrão }\end{array}$ & $\begin{array}{c}\text { Estatística } \\
\text { de Wald }\end{array}$ & $\begin{array}{c}\text { Nível } \\
\text { Descritivo }\end{array}$ \\
\hline Intercepto & 1 & $-2,2694$ & 0,0982 & 533,52 & $<, 0001$ \\
PRAZ012 & 1 & $-0,5943$ & 0,1128 & 27,77 & $<, 0001$ \\
PRAZ018 & 1 & $-1,5731$ & 0,1207 & 169,75 & $<, 0001$ \\
PRAZ024 & 1 & $-1,972$ & 0,1350 & 213,26 & $<, 0001$ \\
T & 1 & 0,3346 & 0,0261 & 164,03 & $<, 0001$ \\
T*PRAZ012 & 1 & $-0,1114$ & 0,0277 & 16,18 & $<, 0001$ \\
T*PRAZO18 & 1 & $-0,0865$ & 0,0269 & 10,33 & 0,0013 \\
T*PRAZO24 & 1 & $-0,1597$ & 0,0268 & 35,60 & $<, 0001$ \\
Histórico Positivo & 1 & $-0,6239$ & 0,0201 & 962,94 & $<, 0001$ \\
Idade da empresa & 1 & $-0,0495$ & 0,0014 & 1217,36 & $<, 0001$ \\
Endividamento & 1 & 0,3071 & 0,0720 & 18,20 & $<, 0001$ \\
Histórico Negativo & 1 & 0,6478 & 0,0264 & 602,69 & $<, 0001$ \\
\hline
\end{tabular}

TABELA 4.9. Estimativas do modelo de parcela de encerramento no Grupo 2

\begin{tabular}{l|rrrrr}
\hline \multicolumn{1}{c|}{ Parâmetro } & GL & Estimativa & $\begin{array}{c}\text { Erro } \\
\text { Padrão }\end{array}$ & $\begin{array}{c}\text { Estatística } \\
\text { de Wald }\end{array}$ & $\begin{array}{c}\text { Nível } \\
\text { Descritivo }\end{array}$ \\
\hline Intercepto & 1 & $-5,1982$ & 0,1950 & 710,60 & $<, 0001$ \\
PRAZO24 & 1 & 0,5366 & 0,2567 & 4,37 & 0,0366 \\
T & 1 & 1,1301 & 0,0485 & 543,36 & $<, 0001$ \\
T*PRAZO12 & 1 & $-0,5695$ & 0,0345 & 271,72 & $<, 0001$ \\
T*PRAZO18 & 1 & $-0,8012$ & 0,0384 & 434,34 & $<, 0001$ \\
T*PRAZO24 & 1 & $-0,9479$ & 0,0497 & 363,73 & $<, 0001$ \\
Histórico Positivo & 1 & $-0,6096$ & 0,0576 & 111,89 & $<, 0001$ \\
Idade da empresa & 1 & $-0,0134$ & 0,0034 & 15,32 & $<, 0001$ \\
Endividamento & 1 & 0,6192 & 0,1923 & 10,37 & 0,0013 \\
Histórico Negativo & 1 & $-0,4499$ & 0,0575 & 61,13 & $<, 0001$ \\
\hline
\end{tabular}


TABELA 4.10. Estimativas do modelo de parcela de encerramento no Grupo 3

\begin{tabular}{l|rrrrr}
\hline \multicolumn{1}{c|}{ Parâmetro } & GL Estimativa & $\begin{array}{c}\text { Erro } \\
\text { Padrão }\end{array}$ & $\begin{array}{c}\text { Estatística } \\
\text { de Wald }\end{array}$ & $\begin{array}{c}\text { Nível } \\
\text { Descritivo }\end{array}$ \\
\hline Intercept & 1 & $-1,7662$ & 0,1431 & 152,2415 & $<, 0001$ \\
PRAZ06 & 1 & 0,2772 & 0,1386 & 4,0007 & 0,0455 \\
T & 1 & $-0,0682$ & 0,0142 & 23,0465 & $<, 0001$ \\
Endividamento & 1 & 1,2768 & 0,2417 & 27,9029 & $<, 0001$ \\
Histórico Negativo & 1 & 0,5611 & 0,0656 & 73,2183 & $<, 0001$ \\
\hline
\end{tabular}

\subsection{Diagnóstico do tempo até evento}

A verificação do tempo até evento será realizada pela comparação das curvas de sobrevivência obtidas pela metodologia proposta com a curva de sobrevivência obtida através do estimador de Kaplan-Meyer (Hosmer \& Lemeshow, 1999), que será o nosso sucedâneo da curva de sobrevida observada.

A FIGURA 4.3, a FIGURA 4.4 e a FIGURA 4.5 mostram as curvas de sobrevivência esperadas e observadas por classe de prazo para os grupos 1, 2 e 3, respectivamente.

Curvas de sobrevida esperadas e observadas para o grupo 1: operações quitadas sem sinistro. 
FIGURA 4.3. Diagnóstico de curvas de sobrevida por prazo para o Grupo 1

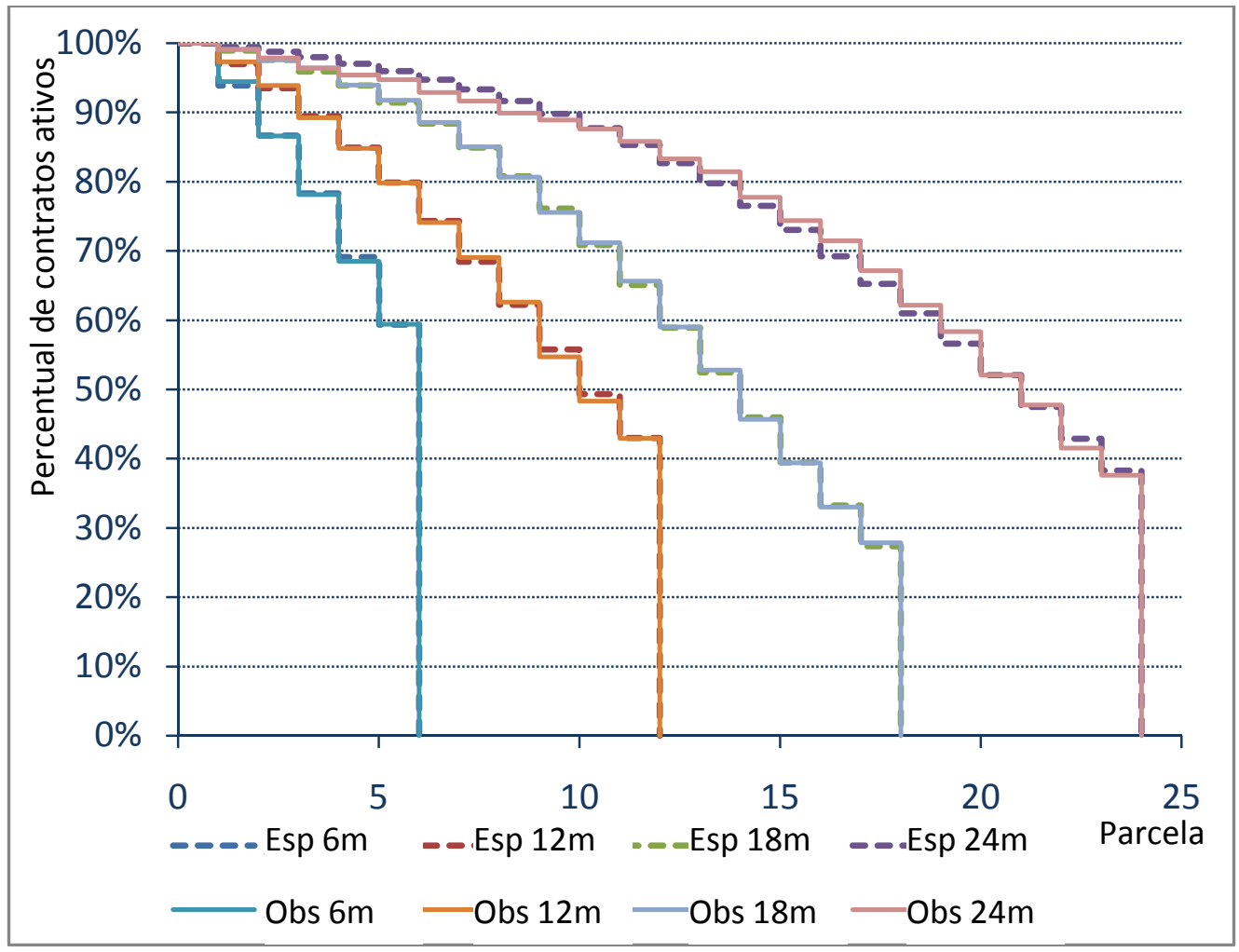

FIGURA 4.4. Diagnóstico de curvas de sobrevida por prazo para o Grupo 2

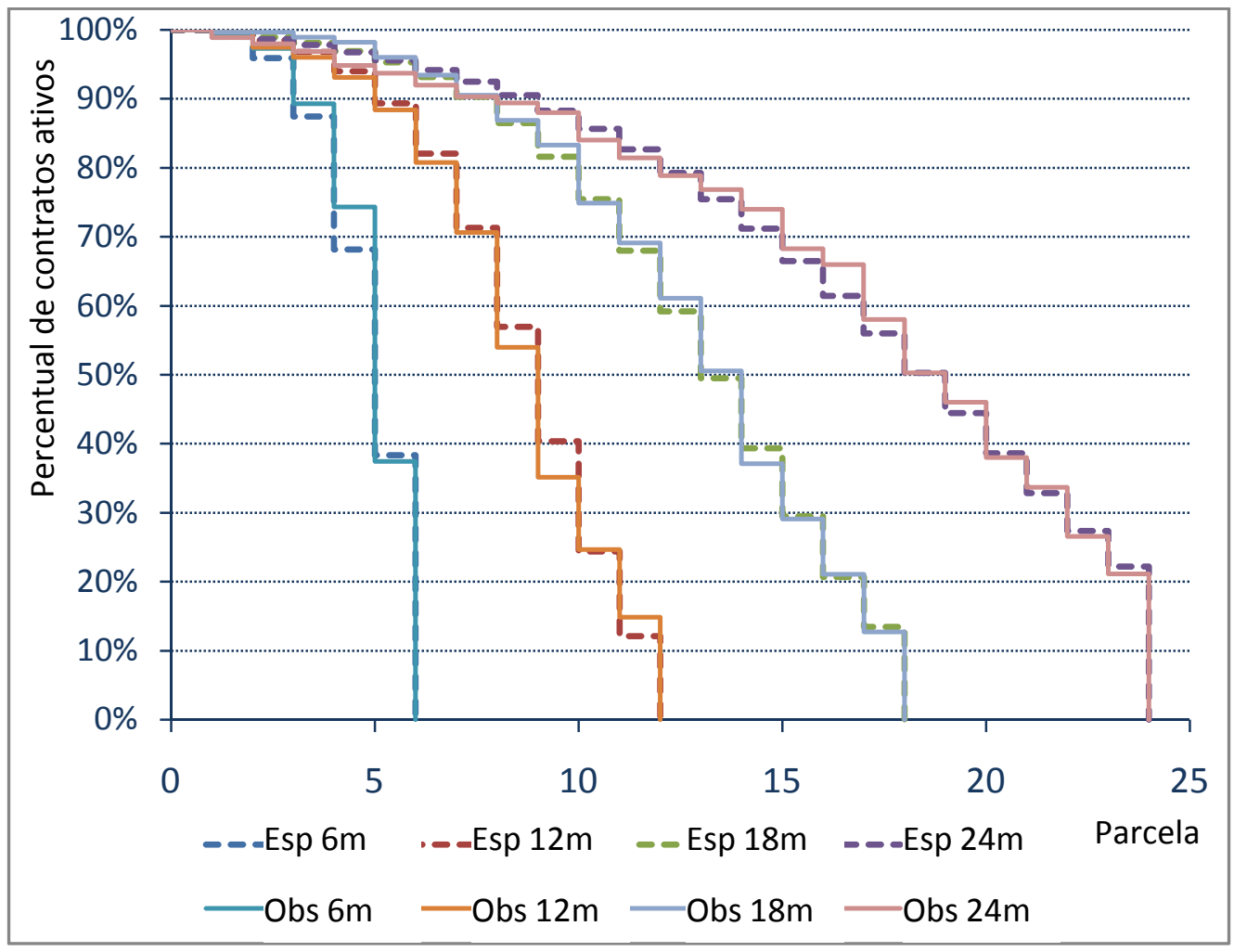


FIGURA 4.5. Diagnóstico de curvas de sobrevida por prazo para o Grupo 3

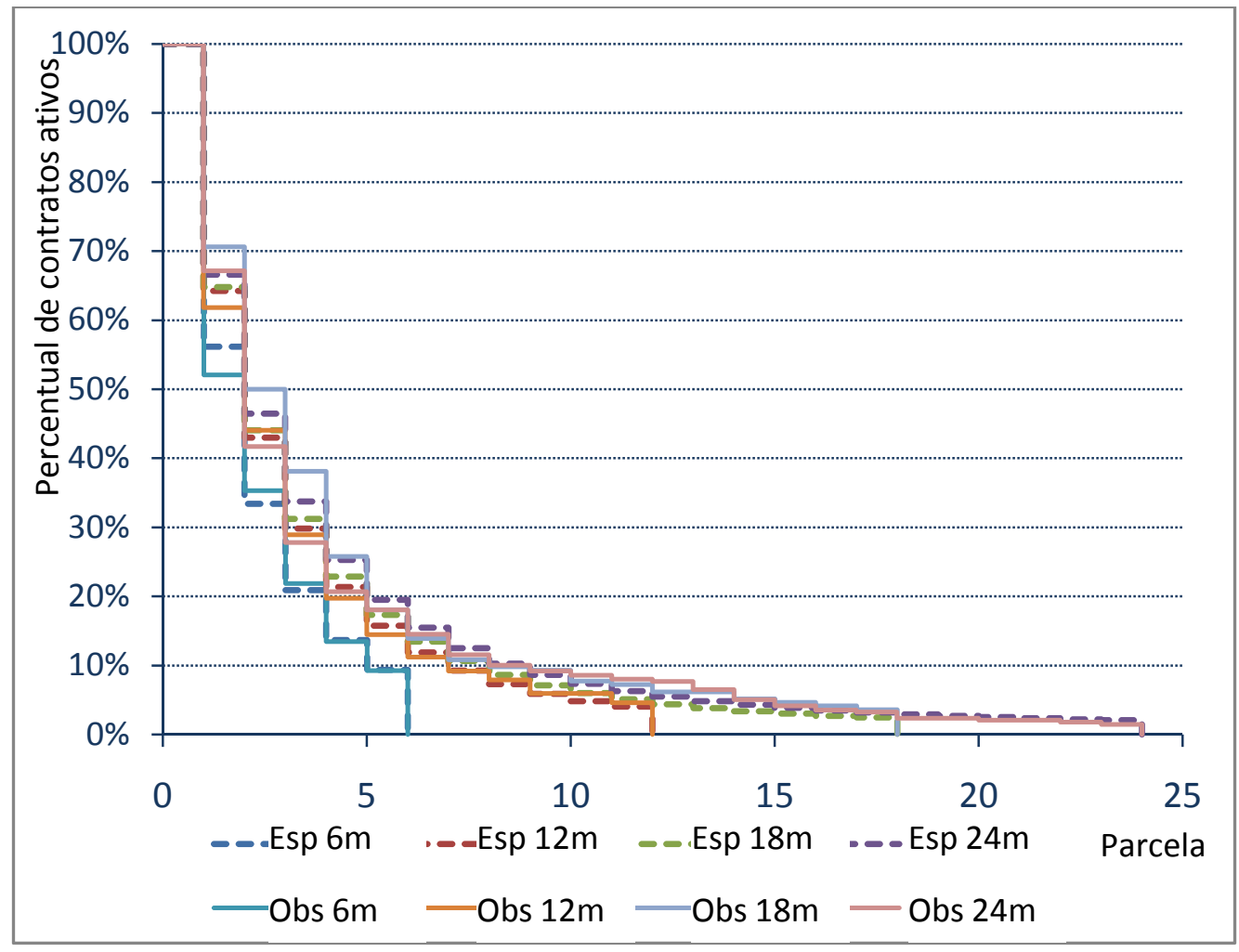

Observamos nas figuras acima que as curvas de sobrevida obtidas pelo modelo estão muito próximas às curvas obtidas pelo Kaplan Meyer, evidência de que o modelo proposto forneceu estimativas coerentes às observações fornecidas pelos dados.

\subsection{Estimativa conjunta}

Para estimar o resultado final de uma carteira de operações com um mesmo perfil $\mathbf{X}=\mathbf{x}$, e a taxa mínima aceitável pela instituição dentro deste perfil, precisamos estimar a proporção de ocorrências do evento $\mathbf{Y}_{\mathbf{i}}$ na parcela $\mathrm{T}$ (com $\mathrm{i}=1$, 2, 3 e $\mathrm{T}=0,1, \ldots$ prazo $\mathrm{i}_{\mathrm{i}}$ ).

A proporção esperada de ocorrências do evento $k$ já foi estimada para cada perfil $\mathbf{X}=\mathbf{x}$ na Seção 4.2 bem como a proporção de ocorrências do evento no tempo $t$, dado $K=k$ foi descrita na Seção 4.3. A proporção esperada conjunta é então:

$$
P\left(T_{i}=t_{i} ; \boldsymbol{Y}_{\boldsymbol{i}}=\boldsymbol{y}_{\boldsymbol{i}} \mid \boldsymbol{X}_{\boldsymbol{i}}=\boldsymbol{x}_{\boldsymbol{i}}\right)=P\left(\boldsymbol{Y}_{\boldsymbol{i}}=\boldsymbol{y}_{\boldsymbol{i}} \mid \boldsymbol{X}_{\boldsymbol{i}}=\boldsymbol{x}_{\boldsymbol{i}}\right) P\left(T_{i}=t_{i} \mid \boldsymbol{Y}_{\boldsymbol{i}}=\boldsymbol{y}_{\boldsymbol{i}} ; \boldsymbol{X}_{\boldsymbol{i}}=\boldsymbol{x}_{\boldsymbol{i}}\right)
$$

Assim, substituindo os valores do lado direito por seus estimadores de máxima verossimilhança, temos do lado esquerdo o estimador de máxima verossimilhança da proporção de ocorrências de $T=t$ e $\mathbf{Y}_{\mathbf{i}}=\mathbf{y}_{\mathbf{i}}$ : 
$\hat{P}\left(T_{i}=t_{i} ; \mathbf{Y}_{\mathbf{i}}=\mathbf{y}_{\mathbf{i}} \mid \mathbf{X}_{\mathbf{i}}=\mathbf{x}_{\mathbf{i}}\right)=\hat{P}\left(\mathbf{Y}_{\mathbf{i}}=\mathbf{y}_{\mathbf{i}} \mid \mathbf{X}_{\mathbf{i}}=\mathbf{x}_{\mathbf{i}}\right) \hat{P}\left(T_{i}=t_{i} \mid \mathbf{Y}_{\mathbf{i}}=\mathbf{y}_{\mathbf{i}} ; \mathbf{X}_{\mathbf{i}}=\mathbf{x}_{\mathbf{i}}\right)$

\subsection{Análise do resultado esperado}

Esta análise pode ser vista da perspectiva de Teoria das Decisões, tendo como função de utilidades a função identidade aplicada ao resultado monetário. A função de Utilidade que gostaríamos de maximizar é, portanto, o resultado da carteira de operações. A comparação da utilidade esperada ${ }^{9}$ com a observada, do ponto de vista prático, é a avaliação última da qualidade do modelo. Esta comparação avalia dois pontos importantes:

1) Se o modelo discrimina os contratos quanto ao seu resultado final;

Esta característica já está presente nos modelos de Credit Scoring tradicionais, porém, o modelo proposto considera maior nível de detalhes na medida em que classifica os contratos em três (e não apenas em dois), e também considera o número de parcelas pagas até a quitação ou inadimplência confirmada.

2) Se o resultado observado é próximo do esperado.

Esta característica é fundamental, pois um modelo que forneça valores viesados pode levar a uma precificação inadequada, levando a uma perda de crédito maior que a esperada, ou a uma redução na margem de negociações da área comercial, portanto, em redução de quantidade de operações contratadas.

Calculamos o resultado esperado de cada contrato considerando a taxa que seria a taxa real de contratação. Dividimos os contratos em dez grupos, de acordo com os decis dos respectivos resultados e comparamos com os resultados observados. A TABELA 4.11 mostra os resultados desta análise:

${ }^{9}$ Para cálculo da utilidade esperada, nesta seção, utilizamos o Spread realizado da operação, e não o sugerido pelo modelo. 
TABELA 4.11. Resultado total das operações: observado versus esperado

\begin{tabular}{|c|r|r|}
\hline $\begin{array}{c}\text { Decil } \\
\text { esperado }\end{array}$ & \multicolumn{1}{|c|}{$\begin{array}{c}\text { Total } \\
\text { observado }\end{array}$} & Total esperado \\
\hline $\mathbf{1}$ & $-17,245,548$ & $-16,648,573$ \\
\hline $\mathbf{2}$ & $-840,821$ & $-257,418$ \\
\hline $\mathbf{3}$ & 728,513 & 798,670 \\
\hline $\mathbf{4}$ & $1,533,691$ & $1,473,809$ \\
\hline $\mathbf{5}$ & $2,336,596$ & $2,435,412$ \\
\hline $\mathbf{6}$ & $3,638,757$ & $3,828,795$ \\
\hline $\mathbf{7}$ & $6,279,451$ & $6,097,883$ \\
\hline $\mathbf{8}$ & $10,407,163$ & $9,990,923$ \\
\hline $\mathbf{9}$ & $17,560,354$ & $18,019,601$ \\
\hline $\mathbf{1 0}$ & $55,398,858$ & $52,705,521$ \\
\hline Total & $79,797,014$ & $78,444,624$ \\
\hline
\end{tabular}

Observamos nesta tabela que o modelo proposto apresenta ambas as características desejadas: discriminação dos resultados e resultados esperados próximos dos observados.

Uma avaliação mais completa é realizada através do gráfico descrito no Capítulo 3.4, mostrado na FIGURA 4.6: 
FIGURA 4.6. Utilidades acumuladas, esperada e observada

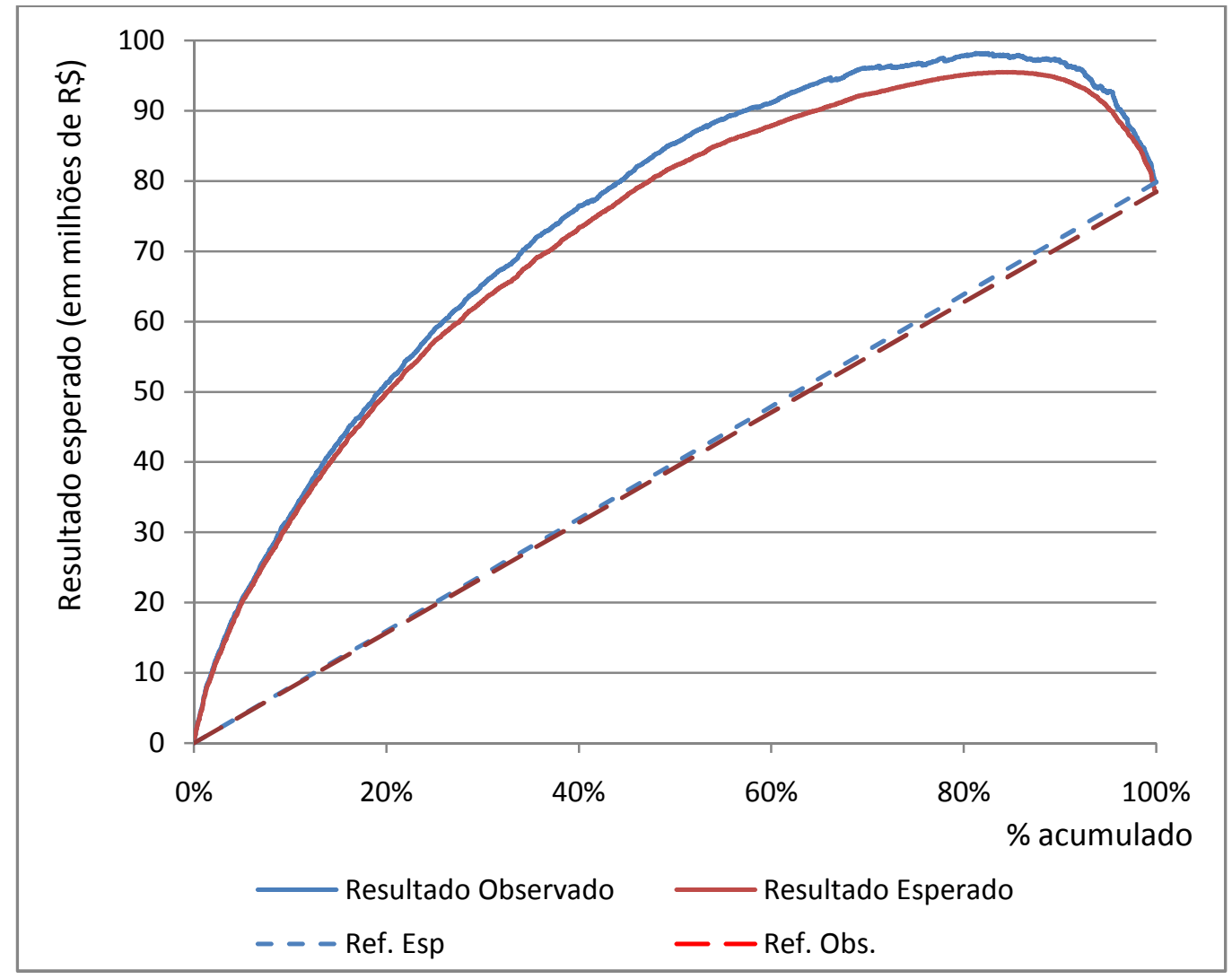

Na FIGURA 4.6 observamos uma boa proximidade entre as curvas esperada e observada, indicando uma boa aderência do modelo, e uma boa distância entre a utilidade dada pelo modelo e a curva de referência, que é o retorno esperado da mesma proporção de contratos quando não existe modelo disponível.

Observamos que a utilidade esperada cresce no início da curva, e em seguida decresce até atingir a utilidade esperada total da carteira de clientes. Este decréscimo final ocorre porque as piores operações têm utilidade esperada negativa, ou seja, o resultado esperado é um prejuízo.

Se na situação descrita este modelo tivesse sido utilizado, estes contratos teriam sido aceitos somente com a taxa de juros sugerida pelo modelo, de modo a garantir 0 resultado esperado da operação de crédito. Como conseqüência esperada, algumas destas operações poderiam não ter sido contratadas. No pior cenário, contratando apenas as operações com resultado positivo, teríamos como resultado mais de 90 milhões (com um valor observado um pouco menor) em aproximadamente $80 \%$ destes contratos realizados. Seria esperado que este resultado ainda aumentasse na medida em que 
alguns contratos fossem aceitos a taxas que produzissem o resultado esperado mínimo desejado pela instituição.

\subsection{Otimização do spread mínimo da operação}

Do ponto de vista financeiro da instituição de crédito, quanto maior o Spread, melhor. Porém, o proponente deste crédito dará preferência, provavelmente, a uma instituição de crédito com taxa mais competitiva.

A instituição de crédito, tendo um objetivo de rentabilidade com a operação, deve definir o spread de uma determinada carteira de modo a cobrir a perda de crédito e pagar a rentabilidade estabelecida. Dessa forma, a carteira de crédito da instituição pode ser segmentada de acordo com perfis de operação e cliente, e o spread mínimo para operações muito semelhantes pode variar para clientes diferentes.

O Capítulo 3.8 explica como é feito o cálculo do Spread mínimo. Esta metodologia foi aplicada aos dados simulados. Iremos agora analisar os contratos realizados no histórico simulado e comparar os resultados sugeridos pelo modelo com os resultados realizados nestes contratos.

Dividimos os contratos em dez grupos, de acordo com os decis da taxa de juros sugerida pelo modelo. A FIGURA 4.7 mostra a distribuição da taxa de juros realizada para cada um destes grupos:

FIGURA 4.7. Distribuição do spread observado por decil de spread sugerido

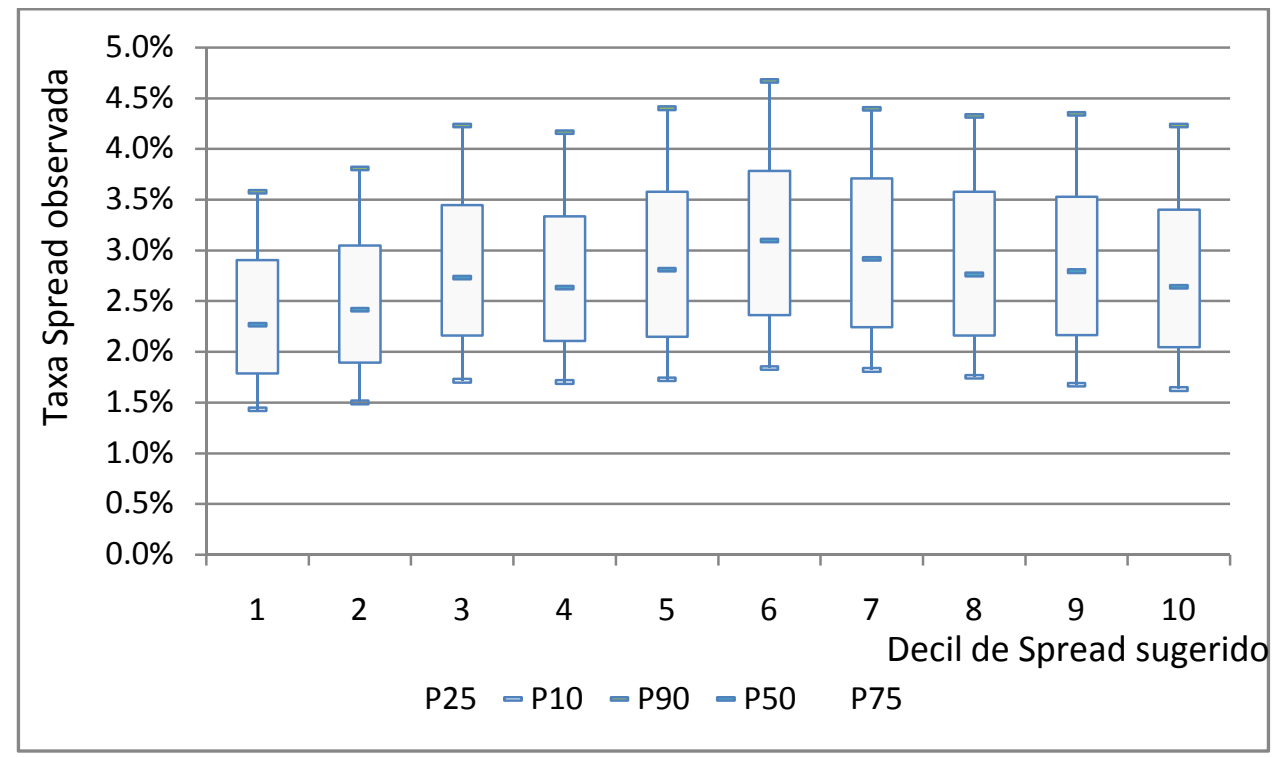


A FIGURA 4.7 mostra que as operações contratadas não levavam em conta o risco no estabelecimento do Spread na situação simulada. Esta pode ser uma situação provável em uma instituição de crédito que não utilize alguma metodologia que considere o risco ao estabelecer o Spread. Nesta situação, grupos de operações de menor risco fornecem um maior resultado ao passo que operações de maior risco fornecem menores resultados, possivelmente até resultados negativos.

Outra característica interessante dos contratos por decil de Spread sugerido é o resultado efetivo da operação e o resultado esperado sob a taxa contratada.

A FIGURA 4.8 mostra os resultados observados e esperados sob a taxa contratada por cada grupo formado pelos decis do Spread sugerido pelo modelo.

FIGURA 4.8. Resultado esperado e observado por decil de spread sugerido

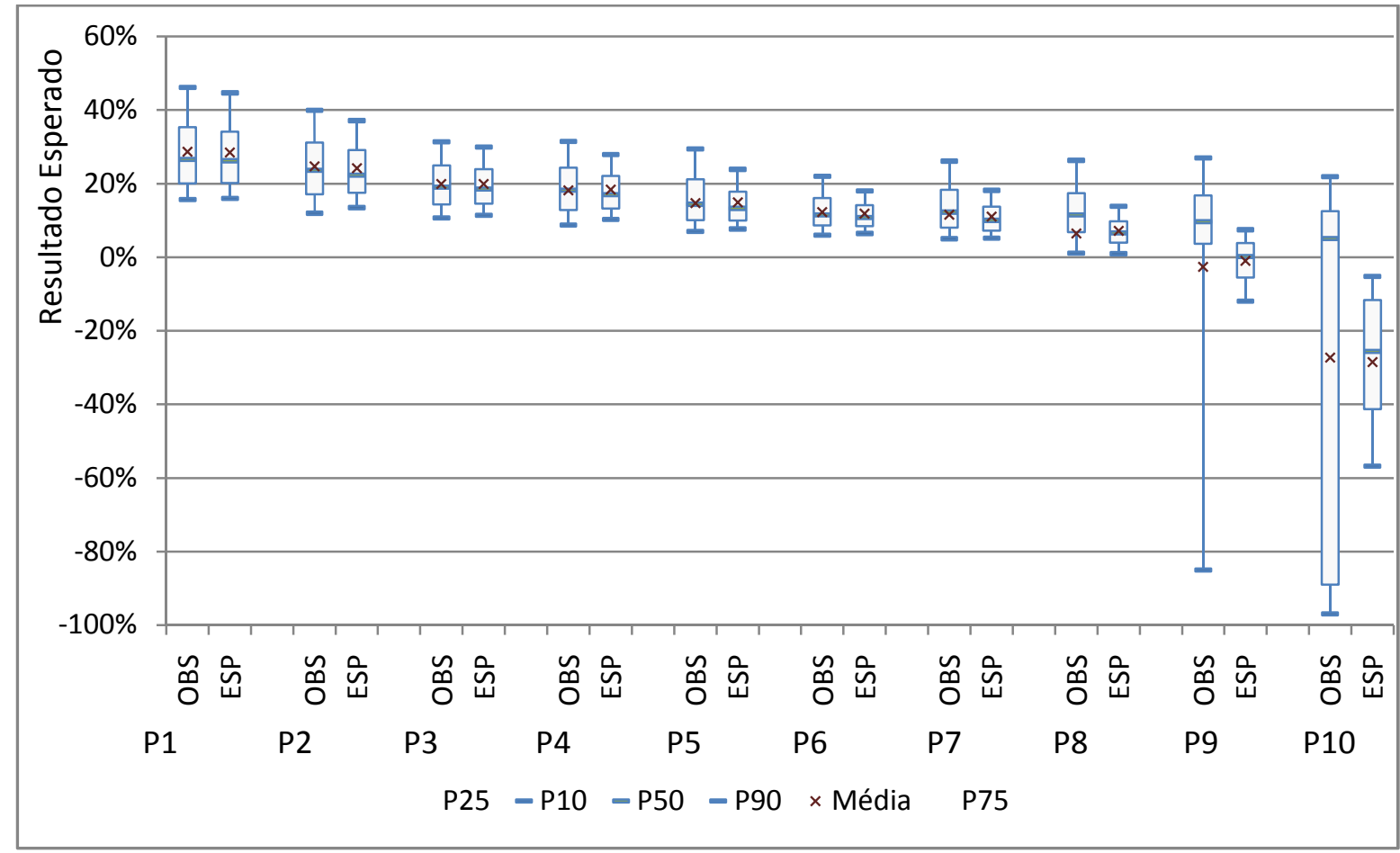

Vemos neste gráfico que o resultado esperado cai conforme a operação apresenta um spread sugerido superior. Este resultado chega a se mostrar negativo para grande para grande parte do grupo de maior Spread sugerido.

Supondo que o fato de alterar o Spread não interfira no desempenho do contrato, se estes contratos tivessem sido realizados com um Spread maior ou igual ao mínimo sugerido pelo modelo, o resultado esperado teria sido de no mínimo o alvo (4\% do valor da 
operação). Ou seja, os grupos com resultados médios negativos teriam atingido a meta estabelecida - ou os clientes não teriam aceito o contrato por um Spread mais elevado, tendo evitado assim, o prejuízo gerado pelos grupos de contratos referentes aos maiores decis de Spread sugerido.

Por outro lado, os contratos com menor Spread sugerido apresentam uma oportunidade comercial para ganho em escala, pois se espera que, com a oferta de Spreads menores, as chances de contratação aumentem, atraindo assim, um maior número de clientes com estes perfis. 


\section{Considerações finais}

Encerramos este trabalho com uma síntese acerca da nossa contribuição para a resolução do problema de precificação em crédito considerando o risco de crédito e apresentando possibilidades para a continuação e aprimoramento deste trabalho.

Na Seção 5.1 discutiremos o próprio modelo utilizado, suas limitações e propostas de desenvolvimento futuro para supri-las. Na Seção 5.2 discutiremos a metodologia de precificação, sugerindo estudos futuros para alterá-la, tanto com a introdução de novos fatores relevantes quanto na consideração de funções de utilidade diferentes. Na Seção 5.3 mencionaremos outras possibilidades de uso para o modelo proposto que envolvem uma possibilidade de estimativa para a perda não-esperada. Na Seção 5.4 discutiremos o uso de inferência bayesiana na resolução deste problema.

\subsection{Utilização de contratos não finalizados}

Da mesma forma como em modelos tradicionais de Credit Scoring, a metodologia apresentada se baseia na premissa de que a distribuição das variáveis resposta observadas na construção do modelo se manterão de forma parecida quando da aplicação da metodologia. Com o passar do tempo, pequenas alterações são naturais e esperadas, de modo que o modelo estimado venha se degradando com o tempo, a ponto de precisar ser substituído.

Assim, é interessante que se usem dados recentes, tanto quanto possível, de modo a refletir um cenário macro-econômico semelhante ao da aplicação da metodologia. O modelo apresentado no Capítulo 3 necessita que todos os contratos utilizados na estimação de seus parâmetros tenham sido observados por completo. Isso faz com que os dados utilizados sejam relativamente antigos, pois deve ser possível observar o contrato por todo o seu prazo contratual mais seis meses (que é o período necessário para se constatar o prejuízo).

Uma forma de se considerar contratos com data de início mais recentes é a utilização de uma metodologia que acomode contratos não encerrados no momento da coleta dos dados. A análise sobrevivência em tempo discreto com riscos competitivos tem essa característica. Essa análise é muito semelhante à apresentada no Capítulo 3, mas se baseia na modelagem de cada parcela do contrato como uma multinomial com apenas um 
ensaio (ou Bernoulli multivariada). As funções de riscos estimadas neste modelo são semelhantes às já apresentadas, mas são estimadas conjuntamente, de modo que observações de contratos não finalizados contribuem com a verossimilhança apenas indicando que o contrato permanece ativo até determinada parcela - assim como no modelo de Cox.

Este modelo se baseia em quatro funções de riscos, semelhantes às do Capítulo 3, mas que são estimadas simultaneamente, definidas como:

1) $\mathrm{H}_{0}(\mathrm{j})$ - Probabilidade de que o contrato permaneça ativo na parcela $\mathrm{j}$, dado que $o$ contrato está ativo na parcela j-i;

2) $H_{1}(j)$ - Probabilidade o contrato seja quitado na parcela $j$, sem despesas com cobrança, dado que o contrato está ativo na parcela j-i;

3) $\mathrm{H}_{2}(\mathrm{j})$ - Probabilidade o contrato seja quitado na parcela $\mathrm{j}$, com ocorrência de despesas com cobrança, dado que o contrato está ativo na parcela j-i;

4) $\mathrm{H}_{3}(\mathrm{j})$ - Probabilidade de que a parcela j não seja paga a ponto de o restante do contrato ser lançado a prejuízo, dado que o contrato está ativo na parcela j-i;

Em que a função $H_{0}(j)$ é combinação linear das outras: $H_{0}(j)=1-H_{1}(j)-H_{2}(j)-H_{3}(j)$.

O APÊNDICE 2.3 apresenta a verossimilhança de um modelo que pode ser utilizado em substituição ao modelo apresentado no Capítulo 3, cuja estrutura admite observações de contratos censurados.

Pretendemos utilizar este modelo em trabalhos futuros.

\subsection{Outras funções de utilidade}

Utilizamos aqui como função de utilidade a função identidade no resultado do contrato, tendo como único elemento aleatório o desempenho do contrato. Vemos a oportunidade de desenvolvimento da função de utilidade em três pontos:

1) A utilização de uma função de utilidade não linear no resultado do contrato, que reflita a propensão ou aversão ao risco por parte da instituição financeira. Algumas sugestões de funções de utilidade desse tipo podem ser encontradas em (Straub, 1988). 
2) A utilização da propensão à contratação conforme a taxa de juros. Contratos de alto risco cuja taxa de juros sugerida pela metodologia seja demasiado alta, espera-se que o contratante esteja pouco propenso a aceitar o contrato de crédito, preferindo outra instituição com uma taxa mais atrativa ou não utilizando o crédito. Da mesma forma, em se reduzindo a taxa de juros a contratos de menor risco, espera-se atrair maior número de clientes de baixo risco, aumentando a receita pelo volume de operações.

3) Taxa de juros como fator de risco: na metodologia proposta, o resultado depende da taxa de juros apenas na medida em que quanto maior a taxa, maior são os juros pagos em cada parcela. Por outro lado, espera-se também que quanto maior a taxa de juros, maior seja a probabilidade de um dado cliente se tornar inadimplente. Este fator é extremamente difícil de se medir, pois a taxa de juros tende a ser dada em função do próprio risco de crédito, introduzindo um efeito de confundimento na análise, que pode ser ilustrada com a pergunta: "a alta taxa de juros foi dada por causa do alto risco ou o risco tornou-se alto por causa da elevada taxa de juros?".

\subsection{Parâmetros para alocação de capital}

Recentemente, o Acordo da Basiléia (BIS II) faz exigências para que os investidores de uma instituição financeira tenham parte de seu capital alocado, de modo a diminuir riscos de insolvência da instituição. Esta alocação de capital é feita de acordo com parâmetros de perda esperada e perda inesperada. O conceito da perda esperada é baseado na esperança da perda, e o conceito de perda inesperada é baseado no pior cenário que se obtém com $\mathrm{P} \%$ de probabilidade (normalmente usa-se $\mathrm{P}=99$ ).

\subsubsection{Perda esperada}

Segundo o BIS II, a perda esperada deve ser obtida através do produto de três parâmetros: PD (probability of default), EAD (Exposure at Defalut) e LGD (Loss Given Default).

De modo a utilizar a metodologia apresentada para alocação de capital, devemos ter o evento de desempenho alinhado com o conceito regulamentar de default, e devemos estimar a distribuição de probabilidades do tempo até o Default (de modo que obtemos da tabela PRICE o saldo no Default). Condicional ao evento do Default, podemos obter a probabilidade de o grupo de desempenho evoluir para 3 (prejuízo), e estimar a 
distribuições de probabilidades do número de parcelas pagas até o prejuízo, ou até a quitação, dependendo do caso.

\subsubsection{Perda inesperada}

A perda inesperada tem um papel importante na alocação de capital regulatória que a instituição deve manter, regulatoriamente, para evitar insolvência. Normalmente a Perda Inesperada é obtida através de uma aproximação pela curva normal (Stolf, 2008), mas sabe-se também que esta não é uma boa aproximação.

Uma proposta alternativa de cálculo da perda inesperada utilizando a metodologia proposta é por simulações de Montecarlo, para obter o percentil desejado da distribuição da perda.

\subsection{Inferência bayesiana}

Em trabalhos futuros pretendemos construir a estimativa final do resultado através de inferência Bayesiana. A idéia básica é a mesma realizada em diagnóstico médico (Pereira, 1990), porém, utilizando no lugar do "teste de diagnóstico" do médico, os valores esperados para as probabilidades de desempenho de cada contrato. 


\section{APÊNDICE 1. Programas}

Neste apêndice colocamos alguns dos principais programas utilizados neste trabalho relacionados às simulações, cálculo de estatísticas e procedimentos computacionais como geração de gráficos importantes.

APÊNDICE 1.1. S Simulação dos dados

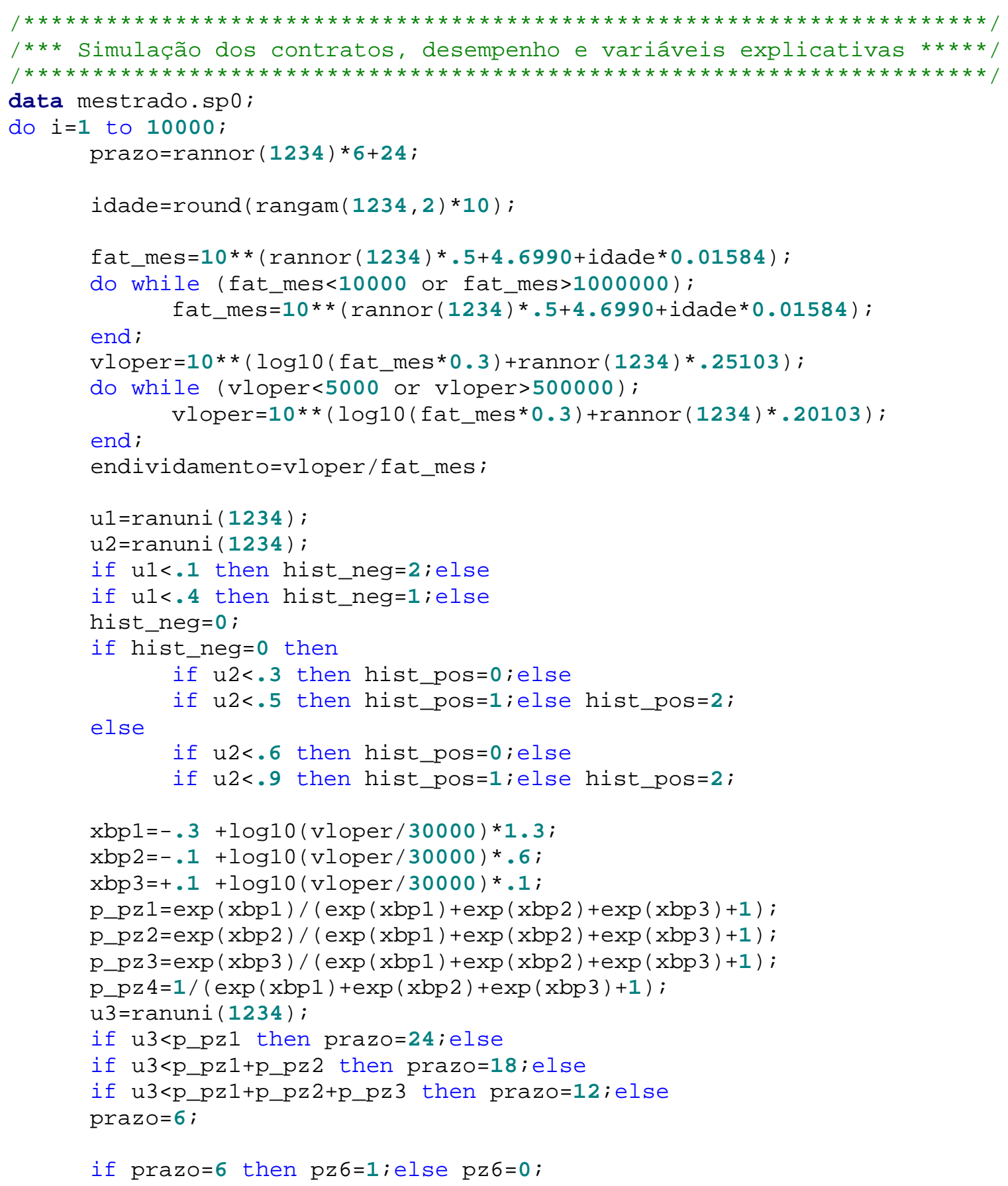


if prazo=12 then pz12=1; else pz12=0;

if prazo=18 then pz18=1; else pz18=0;

if prazo=24 then pz24=1; else pz24=0;

end;

output;

run;

APÊNDICE 1.2. S Simulação da situação de encerramento

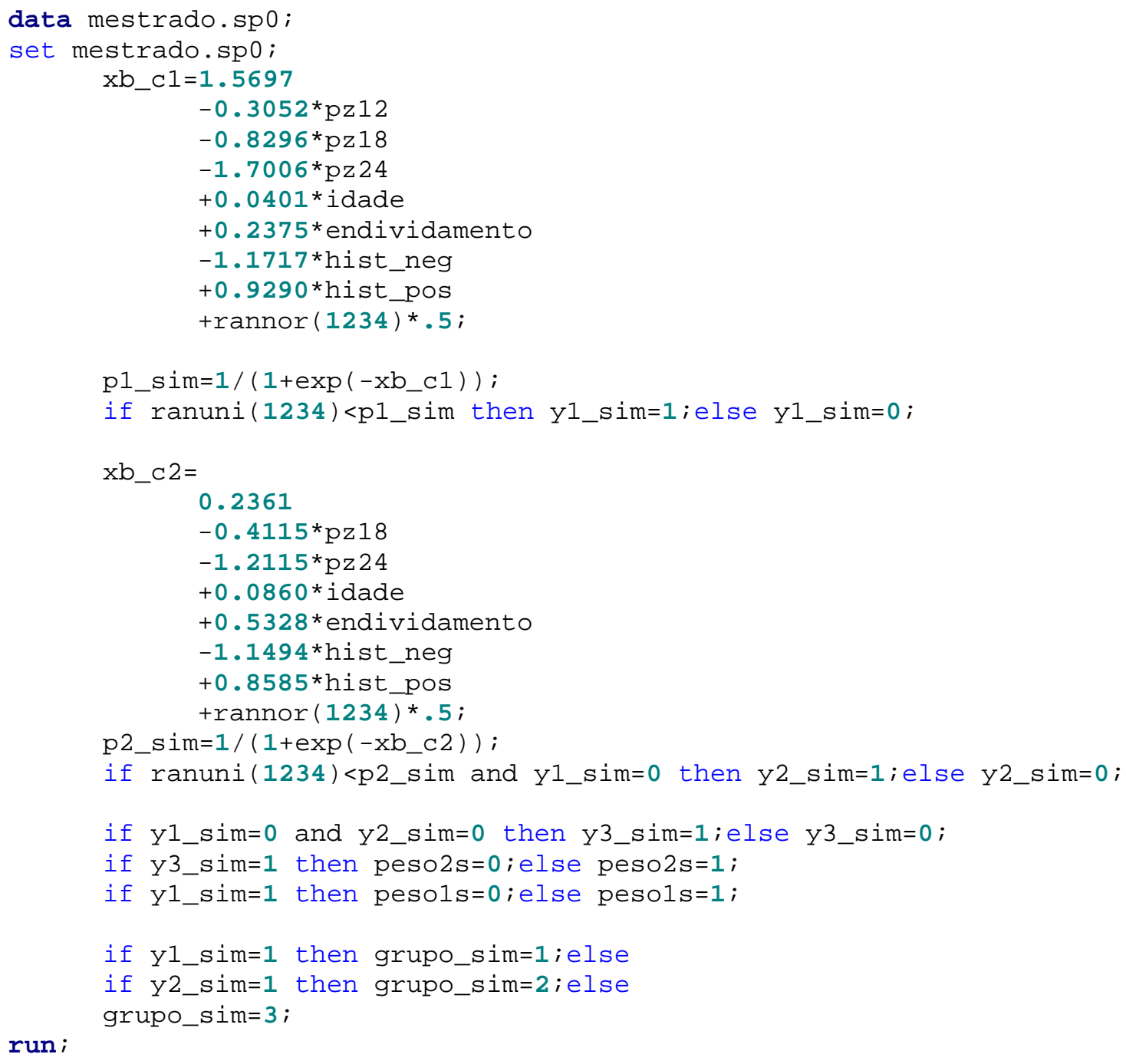


APÊNDICE 1.3. Simulação do tempo até evento

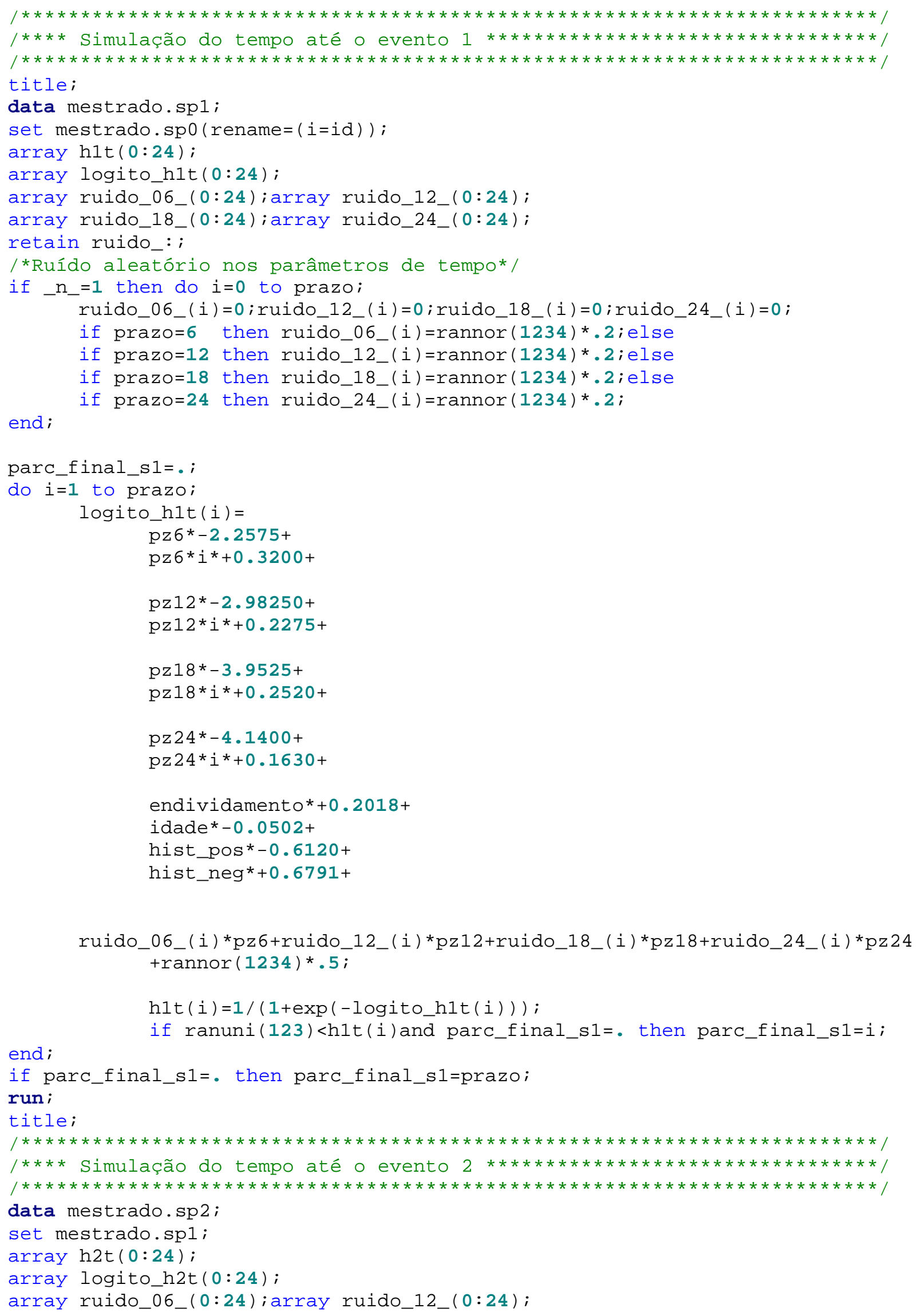


array ruido_18_(0:24); array ruido_24_(0:24);

retain ruido_:;

/*Ruído aleatório nos parâmetros de tempo*/

if _n_=1 then do $i=0$ to prazo;

ruido_06_(i)=0; ruido_12_(i)=0; ruido_18_(i)=0; ruido_24_(i) =0;

if prazo=6 then ruido_06_(i)=rannor $(1234) * .2$; else

if prazo=12 then ruido_12_(i)=rannor(1234)*.2; else

if prazo=18 then ruido_18_(i)=rannor (1234)*.2; else

if prazo=24 then ruido_24_(i)=rannor $(1234) * .2$;

end;

parc_final_s $2=$;

do $i=1$ to prazo;

logito_h2t $(i)=$

pz $6 *-5.9170+$

$p z 6 * i *+1.3050+$

$\mathrm{pz} 12 *-4.4410+$

$\mathrm{pz} 12 * i *+0.4390+$

$\mathrm{pz} 18 *-5.5410+$

pz18*i*+0.3490+

pz2 $4 *-4.9000+$

$\mathrm{pz} 24 * i *+0.1940+$

endividamento* $+0.7360+$

idade*-0.0110+

hist_pos* $-0.6120+$

hist_neg*-0.5791+

ruido_06_(i)*pz6+ruido_12_(i)*pz12+ruido_18_(i)*pz18+ruido_24_(i)*pz24

+rannor $(1234) * .5$;

h2t $(i)=1 /\left(1+\exp \left(-\log i t o \_h 2 t(i)\right)\right)$;

if ranuni(123) $<$ h2t (i) and parc_final_s2=. then parc_final_s2=i;

end;

if parc_final_s2=. then parc_final_s2=prazo;

run;

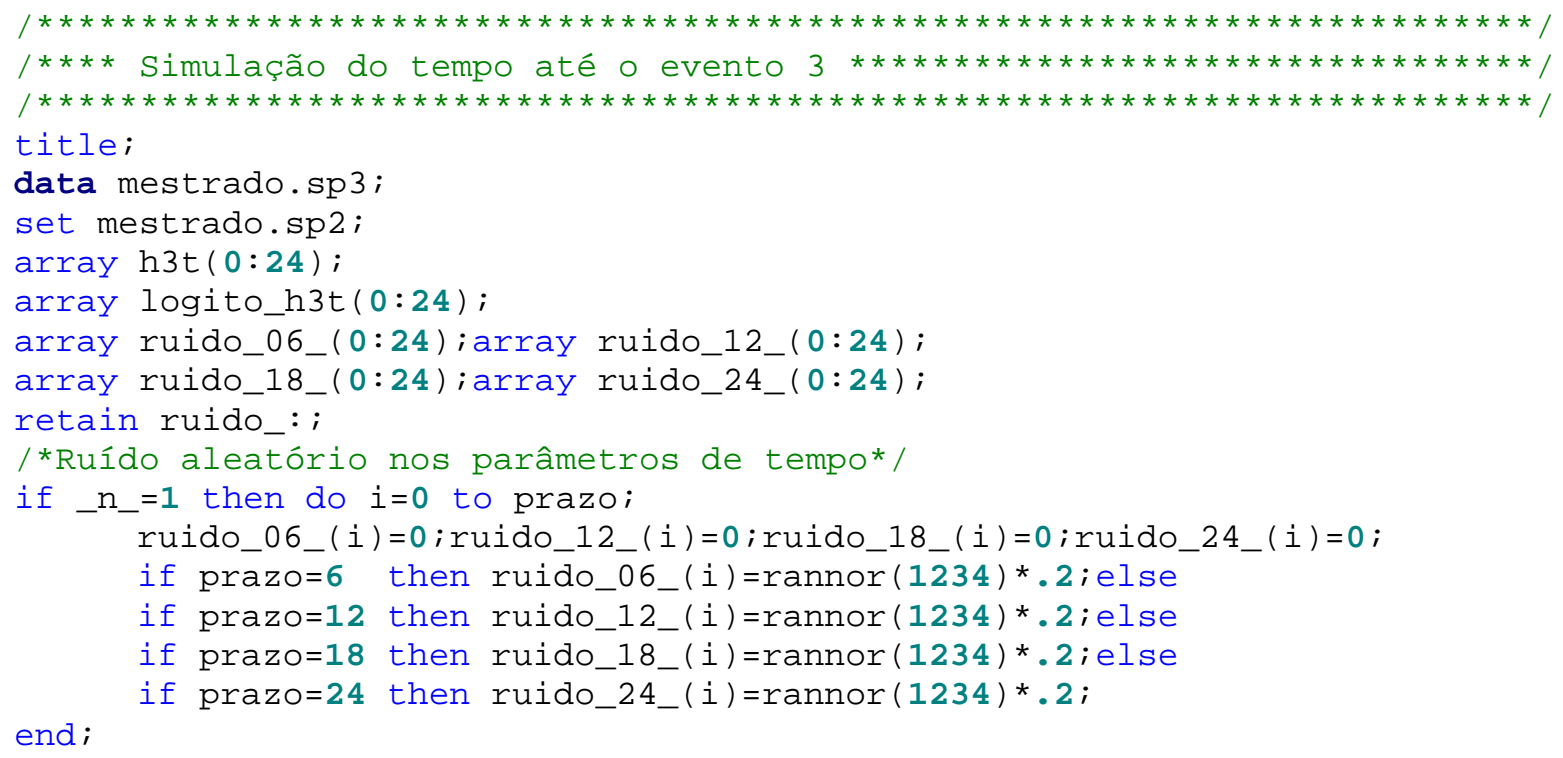




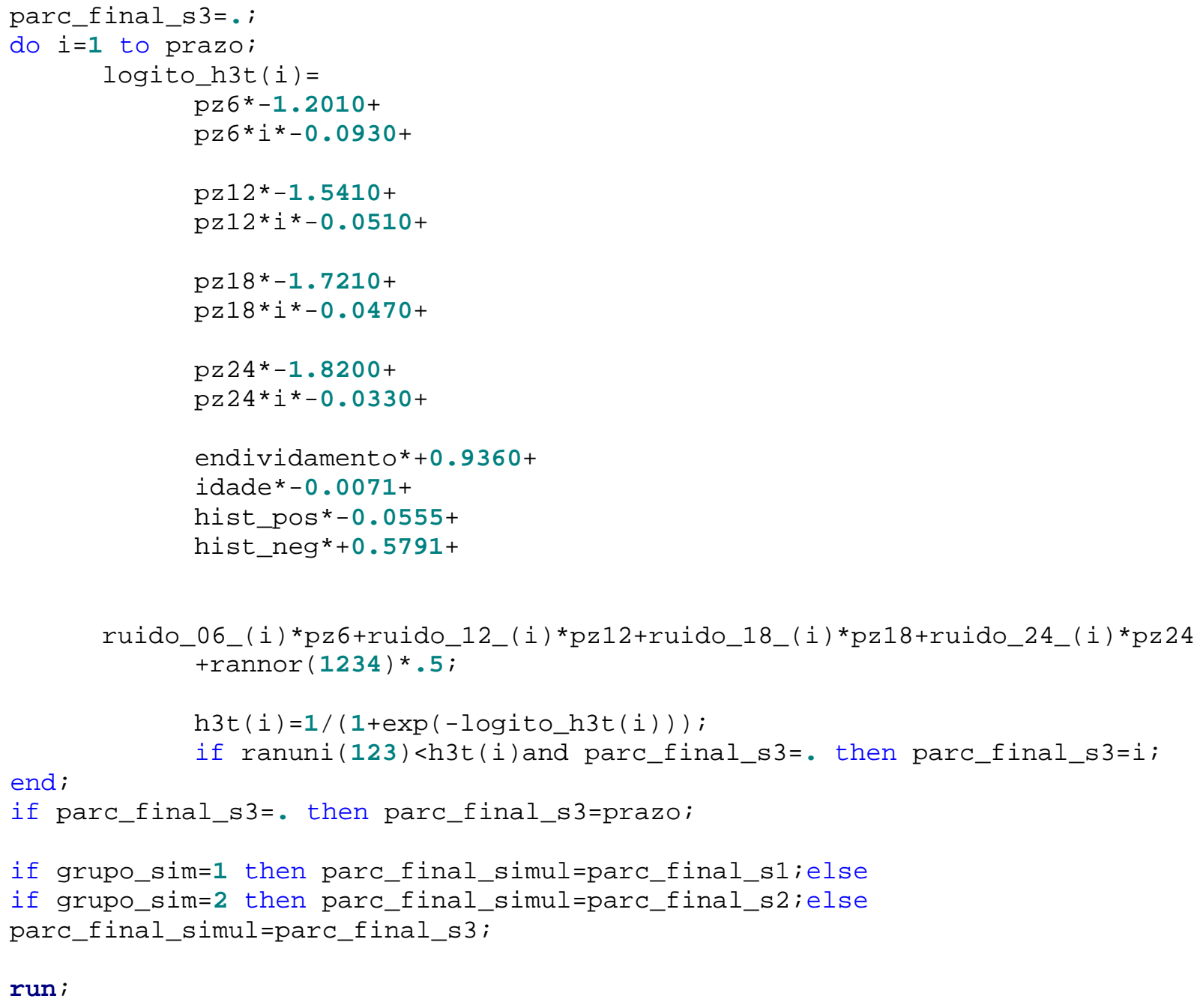

run;

APÊNDICE 1.4. Macro para categorizar variáveis por quantís

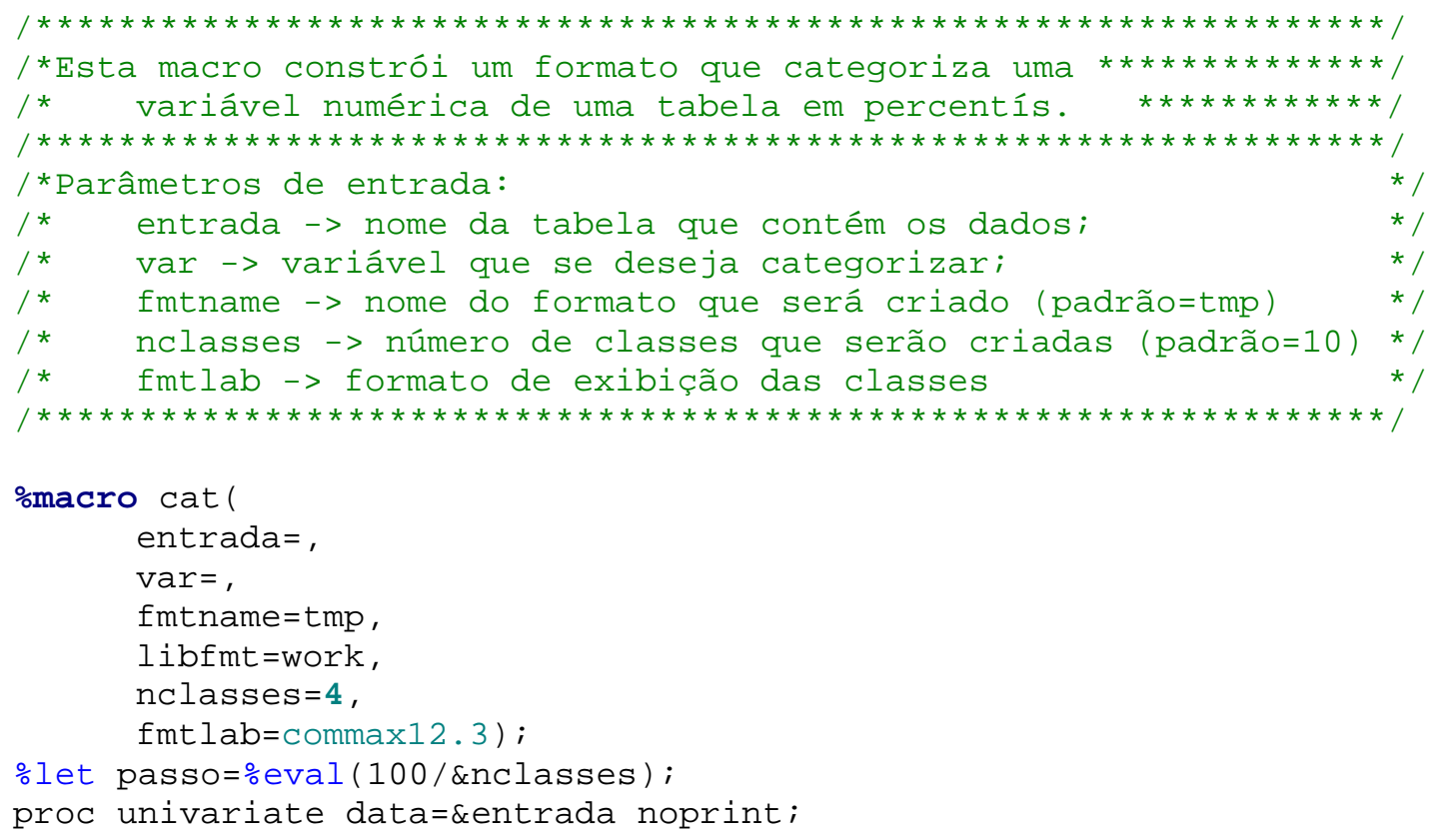


var \&var;

output out $=$ tmp pctlpre $=\mathrm{P}_{-}$pctlpts $=$

0 to 100 by \&passo;

run;

proc transpose data=tmp out=tmp_t;run;

proc sort data=tmp_t nodupkey; by collirun;

data cntlin;

set tmp_t end=fim;

retain type

' $N$ ' fmtname "\&fmtname" hlo ' ' sexcl ' $\mathrm{y}$ ' eexcl ' $\mathrm{n}$ ' start end .;

if $-n_{-}=$

1 then do;

$\min =\operatorname{col} 1$;

end;

else if ${ }_{n}$ - $=2$ then do;

$\max =\operatorname{col} 1$;

start $=$. ;

end $=\operatorname{col} 1$;

label=' low-|'! ! trim (left (put (end, \& fmtlab. )) );

$\mathrm{hlO}=$ ' 1 ';

output;

$\mathrm{hlo}=$ ' ';

$\min =\operatorname{col} 1$;

start $=\operatorname{col} 1$

end;

else if fim=1 then do;

$\max =\operatorname{col} 1$;

end $=$.;

label=trim (left (put (start, \&fmtlab.)) ) ! '-high' ;

$\mathrm{hlo}=$ ' $\mathrm{h}$ ';

output;

start =.; $\quad$ end=.; $\quad \min =. ; \quad \max =. ; \quad \mathrm{hlo=} \mathrm{o}^{\prime} ; \quad$ label='miss';

end;

output;

else do;

$\max =\operatorname{col} 1$;

end=col1;

label=trim (left (put (start, \&fmtlab. ) ) ) ! '-|'

! ! trim (left (put (end, \& fmtlab.)) ) ;

output;

$\min =\operatorname{col} 1$;

start $=\operatorname{col} 1$;

end;

run;

proc format library $=\& l i b f m t$ cntlin=cntlin; run;

omend; 
APÊNDICE 1.5. Estimação dos parâmetros de classificação

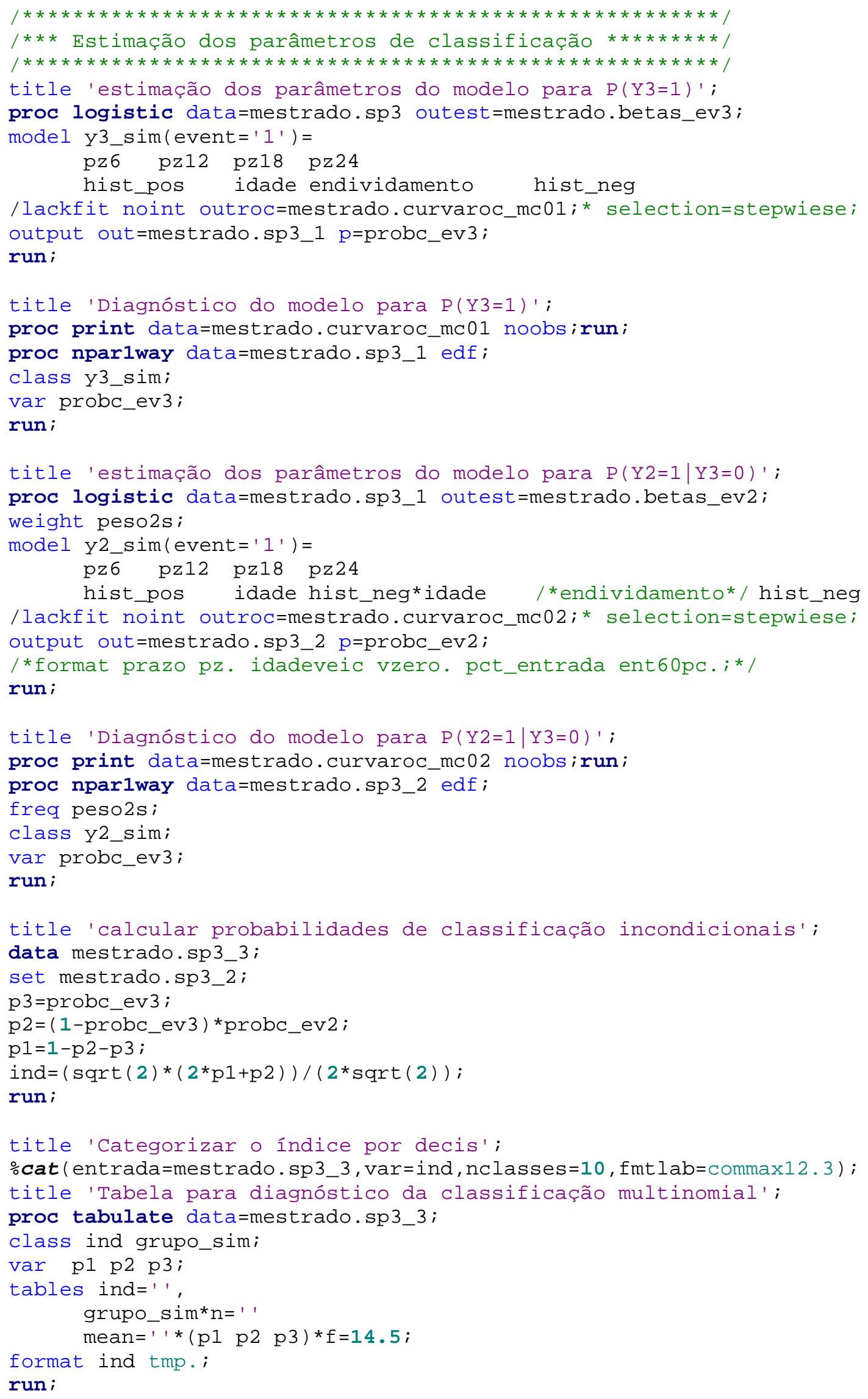


APÊNDICE 1.6. Estimação dos parâmetros de tempo até evento

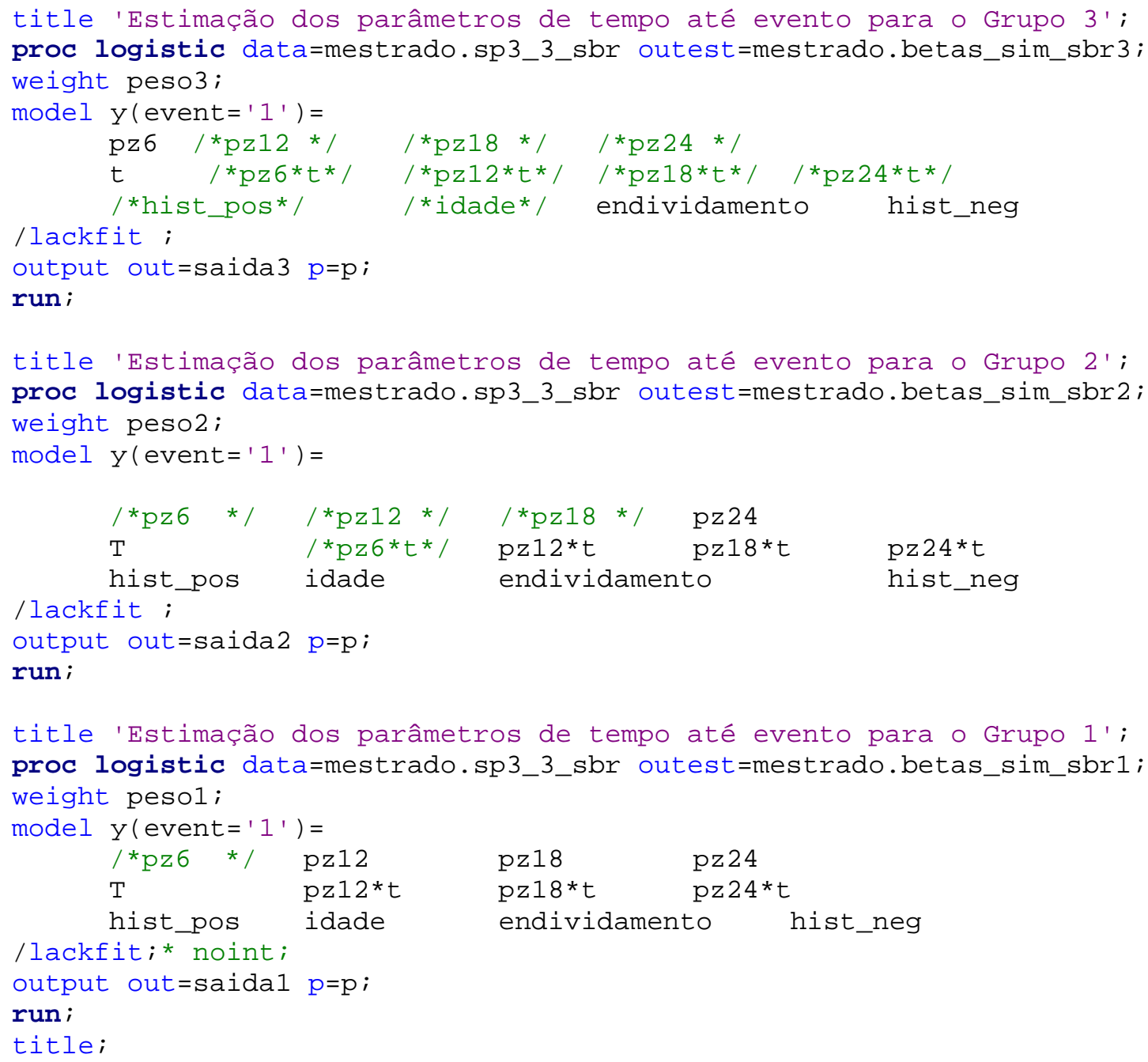




\section{APÊNDICE 2. Cálculos}

Neste apêndice estão dispostos com detalhes os cálculos realizados neste trabalho: as demonstrações, cálculos de probabilidades e verossimilhanças.

\section{APÊNDICE 2.1. Modelo multinomial condicionado}

Aqui mostraremos o desenvolvimento algébrico do modelo apresentado na Seção 3.1, referente à classificação de contratos em um de três grupos, dadas informações $\mathbf{X}=\left(\mathrm{x}_{1}, \mathrm{x}_{2}, \ldots, \mathrm{x}_{\mathrm{p}}\right)$ observáveis do indivíduo.

Os três grupos referidos são:

1) O contrato foi quitado sem despesas de cobrança;

2) O contrato foi quitado com despesas de cobrança;

3) O contrato foi lançado a prejuízo.

Sejam N indivíduos observados de uma amostra, definimos:

$$
\begin{gathered}
Y_{i j}=\left\{\begin{array}{l}
1 \text { se o contrato } \text { i pertence ao grupo } j \\
0 \text { caso contrário }
\end{array}\right. \\
\pi_{i j}=P\left(Y_{i j}=1\right) \\
N_{j}=\sum_{i=1}^{N} Y_{i j}
\end{gathered}
$$

Com $i=1, \ldots N$ e $j=1,2$ ou $3, Y_{i 1}+Y_{i 2}+Y_{i 3}=1$ e $\pi_{i 1}+\pi_{i 2}+\pi_{i 3}=1$, de modo que:

$$
Y_{i}=\left(Y_{i 1}, Y_{i 1}, Y_{i 1}\right) \sim M\left(\pi_{i 1}, \pi_{i 2}, \pi_{i 3}, 1\right) .
$$

Em que $M(a, b, c, n)$ representa a multinomial de parâmetros $a, b$ e $c$, e tamanho amostral $n$.

Definimos também:

$$
\theta_{i 2}=P\left(Y_{i 2}=1 \mid Y_{i 3}=0\right)
$$


Note que $\left(\pi_{i 1}, \pi_{i 2}, \pi_{i 3}\right)=\left(\left(1-\pi_{i 3}\right)\left(1-\theta_{i 2}\right),\left(1-\pi_{i 3}\right) \theta_{i 2}, \pi_{i 3}\right)$, além disso, $\pi_{i 3}$ e $\theta_{i 2}$ são de variação independente.

A seguir escreveremos a função de verossimilhança da multinomial na sua forma mais tradicional (em função de $\pi_{i 1}, \pi_{i 2}$ e $\pi_{i 3}$, com $\mathrm{N}$ observações), e em seguida, escreveremos esta verossimilhança em função de $\theta_{i 2}$ e $\pi_{i 3}$ :

$$
L(\mathbf{Y} ; \Theta)=\prod_{i=1}^{N} \pi_{i 1}^{Y^{i 1}} \pi_{i 2}{ }^{Y_{i 2}} \pi_{i 3}{ }^{Y_{i 3}}
$$

Substituindo $\left(\pi_{i 1}, \pi_{i 2}, \pi_{i 3}\right)$ por $\left(\left(1-\pi_{i 3}\right)\left(1-\theta_{i 2}\right),\left(1-\pi_{i 3}\right) \theta_{i 2}, \pi_{i 3}\right)$ temos:

$$
\begin{gathered}
L(\mathbf{Y} ; \Theta)=\prod_{i=1}^{N}\left[\left(1-\pi_{i 3}\right)\left(1-\theta_{i 2}\right)\right]^{Y_{i 1}}\left[\left(1-\pi_{i 3}\right) \theta_{i 2}\right]^{Y_{i 2}} \pi_{i 3}{ }^{Y_{i 3}} \\
L(\mathbf{Y} ; \Theta)=\prod_{i=1}^{N} \pi_{i 3}{ }^{Y_{i 3}}\left(1-\pi_{i 3}\right)^{Y_{i 2}+Y_{i 1}}{\theta_{i 2}}^{Y_{i 2}}\left(1-\theta_{i 2}\right)^{Y_{i 1}}
\end{gathered}
$$

Seja $G_{j}$ o conjunto de todos os indivíduos $i$ tais que $Y_{i j}=1$, podemos reescrever a verossimilhança como:

$$
L(\mathbf{Y} ; \Theta)=\prod_{i=1}^{N} \pi_{i 3}{ }^{Y_{i 3}}\left(1-\pi_{i 3}\right)^{Y_{i 2}+Y_{i 1}} \prod_{i \in G_{1} \cup G_{2}} \theta_{i 2}^{Y^{Y_{2}}}\left(1-\theta_{i 2}\right)^{Y_{i 1}}
$$

Conforme a equação (a.1), podemos fatorar a verossimilhança em uma parte dependente de $\pi_{i 3}$ e outra dependente de $\theta_{i 2}$. E por serem estas quantidades de variação independente, podemos estimá-las separadamente.

Definimos, então, os vetores de parâmetros: $\boldsymbol{\beta}_{2}=\left(\alpha_{2}, \beta_{21}, \ldots, \beta_{2 p}\right)^{\prime}$ e $\boldsymbol{\beta}_{3}=$ $\left(\alpha_{3}, \beta_{31}, \ldots, \beta_{3 p}\right)^{\prime}$ e estudar os parâmetros $\theta_{i 2}$ e $\theta_{i 3}$ como função das variáveis observáveis $\mathbf{X}_{\mathbf{i}}$, reescrevendo-nos da seguinte forma:

$$
\theta_{i 2}=\frac{1}{1+e^{\mathbf{X}_{\mathbf{i}} \boldsymbol{\beta}_{2}}} \text { e } \pi_{i 3}=\frac{1}{1+e^{\mathrm{X}_{\mathbf{i}} \boldsymbol{\beta}_{3}}}
$$

Os parâmetros $\theta_{i 2}$ e $\pi_{i 3}$ podem ser obtidos através das estimativas $\boldsymbol{\beta}_{3}$ e $\boldsymbol{\beta}_{2}$ que por sua vez podem ser obtidas através de métodos iterativos, tais que maximizam a 
verossimilhança da amostra em (a.1). Note que essa verossimilhança é equivalente à verossimilhança de uma regressão logística, de modo que as estimativas dos parâmetros podem ser obtidas com o auxílio dos pacotes estatísticos padrão, que possuam tal ferramenta.

\section{APÊNDICE 2.2. Modelo de tempo até evento}

Na Seção 2.4, definimos os três grupos de desempenho do contrato. A Seção 3.3 descreve uma metodologia para estudar a expectativa de em qual parcela se encerrará um determinado contrato, condicionando na ocorrência de cada um dos eventos.

A seguir, apresentaremos com maiores detalhes o desenvolvimento analítico do modelo utilizado na metodologia descrita na Seção 3.3.

\section{Definições básicas}

Consideremos a matriz de observações a seguir:

$$
\mathbf{Y}=\left[\begin{array}{cccc}
Y_{110} & Y_{111} & Y_{112} & Y_{113} \\
Y_{120} & Y_{121} & Y_{122} & Y_{123} \\
\vdots & \vdots & \vdots & \vdots \\
Y_{1 t_{1} 0} & Y_{1 t_{1} 1} & Y_{1 t_{1} 2} & Y_{1 t_{1} 3} \\
Y_{210} & Y_{211} & Y_{212} & Y_{213} \\
\vdots & \vdots & \vdots & \vdots \\
Y_{N t_{N} 0} & Y_{N t_{N} 1} & Y_{N t_{N} 2} & Y_{N t_{N} 3}
\end{array}\right]
$$

Aqui, $i=1, \ldots N$ indexa uma amostra de $N$ contratos, $t_{i}$ denota a primeira parcela que deveria ser paga quando do encerramento do contrato $i$.

$Y_{\text {itk }}$ são definidos como:

$$
Y_{i t 0}=\left\{\begin{array}{c}
1 \text { se o contrato } i \text { teve a parcela } t \text { paga normalmente e continuou ativo. } \\
0 \text { caso contrário }
\end{array}\right.
$$

$Y_{i t 1}=\left\{\begin{array}{c}1 \text { se o contrato } i \text { foi quitado sem despesas de cobrança, antes de pagar a parcela } t \\ 0 \text { caso contrário }\end{array}\right.$ $Y_{i t 2}=\left\{\begin{array}{c}1 \text { se o contrato } i \text { foi quitado com despesas de cobrança, antes de pagar a parcela } t \\ 0 \text { caso contrário }\end{array}\right.$

$$
Y_{i t 3}=\left\{\begin{array}{c}
1 \text { se o contrato i lançado a prejuízo, antes de pagar a parcela } t \\
0 \text { caso contrário }
\end{array}\right.
$$


Com $\sum_{k=0}^{3} Y_{i t k}=1 \mathrm{e}$, como os eventos são exclusivos mutuamente, temos que $Y_{i t k}=1$ somente para um único valor de $\mathrm{k}$ entre $1 \mathrm{e} 3$, e também somente quando $\mathrm{t}=\mathrm{t}_{\mathrm{i}}$ (ou seja, na última parcela observada do contrato).

A variável $G_{i}$ denota o grupo a que o contrato i pertence, sendo que:

$$
G=k \text { se } Y_{i t_{i} k}=1, k=1,2,3
$$

\section{Função de riscos:}

A função de riscos, $h_{\text {itk }}$, é definida como:

$h_{i t k}=P\left(Y_{i t k}=1 \mid Y_{i 10}=1, Y_{i 20}=1, \ldots, Y_{i(t-1) 0}=1 ; G=k\right)$

$\operatorname{com} i=1, \ldots N ; t=1, \ldots t_{i}$ e $k=1,2,3$.

Particularidades:

- Se o contrato $\mathrm{i}$ tem todas as suas parcelas pagas pontualmente, temos que $Y_{i t 1}=0$ para $t=1, \ldots$, prazo $i$ e $Y_{i t 1}=1$ para $t=$ prazo $_{i}+1-o$ único caso em que $j$ pode assumir valores maiores que o prazo do contrato. Dessa forma, o contrato é classificado no grupo 1.

- Observe que, dado o grupo a que o contrato pertence, $h_{i j k}=1$ para j=prazo e $k=2$ ou 3 .

\section{Modelo sobre a função de riscos:}

Definimos também as variáveis indicadoras de parcela

$$
\boldsymbol{D}_{i t}=\left(D_{i t 1}, D_{i t 2}, \ldots, D_{i t 24}\right)
$$

com:

$$
D_{i t l}=\left\{\begin{array}{c}
1 \text { se } t=l \\
0 \text { caso contrário }
\end{array}\right.
$$

Em que $\mathrm{i}$ indexa os contratos $(\mathrm{i}=1, \ldots, \mathrm{N})$, $\mathrm{j}$ indexa as parcelas $\left(\mathrm{j}=1, \ldots, \mathrm{j}_{\mathrm{i}}\right)$ e I varia entre 1 e ji para cada par $\mathrm{i}$, j, formando 24 variáveis indicadoras para cada parcela de cada contrato. 
Seja $\mathbf{X}_{\mathbf{i}}=\left(\mathrm{x}_{1}, \mathrm{x}_{2}, \ldots, \mathrm{x}_{\mathrm{p}}\right)$ o vetor de constantes observáveis de cada contrato. Para estudarmos $h_{i j k}$ dentre os perfis definidos pelos diferentes valores de $\mathbf{X}_{\mathbf{i}}$, escrevemos $h_{\mathrm{ijk}}$ em função dos parâmetros no vetor $\boldsymbol{\Theta}_{\mathbf{k}}=\left(\boldsymbol{\alpha}_{\mathbf{k}}, \boldsymbol{\beta}_{\mathbf{k}}\right)$, com $\boldsymbol{\beta}_{\mathbf{k}}=\left(\beta_{k 1}, \beta_{k 2}, \ldots, \beta_{k p}\right)^{\prime}$, que estarão relacionados às covariáveis $\mathbf{X}_{\mathbf{i}}$ e $\alpha_{k}=\left(\alpha_{k 1}, \alpha_{k 2}, \ldots, \alpha_{k 24}\right)^{\prime}$ que estarão relacionados à função de riscos de referência, que fornece o risco, quando todas as covariáveis são iguais a zero. Colocando em $h_{\mathrm{ijk}}$ um modelo logístico em função de $\mathbf{D}_{\mathrm{ij}}, \boldsymbol{\beta}_{\mathbf{k}}$ e $\mathbf{X}_{\mathbf{i}}$, temos:

$$
h_{i j k}=\frac{1}{1+e^{-\left(D_{i j} \boldsymbol{\alpha}_{k}+\boldsymbol{X}_{i} \boldsymbol{\beta}\right)}}
$$

Desenvolveremos $L_{k}\left(\mathbf{Y} ; \Theta_{\mathbf{k}}\right)$ a verossimilhança do modelo de tempo até evento condicionada aos contratos nela considerados pertencerem ao grupo k (descrito no capítulo 2.4).

Note que $P\left(Y_{i 1 k}=0, Y_{i 2 k}=0, \ldots, Y_{i j_{i} k}=1 \mid G=k\right)=P\left(J_{i}=j_{i} \mid G=k\right)$

Observe também que:

$$
P\left(J_{i}=j_{i} \mid \Theta ; \mathbf{X} ; \mathrm{G}=\mathrm{k}\right)=\left[\prod_{j=1}^{t_{i}-1}\left(1-h_{i j k}\right)\right] h_{i t k}=\prod_{j=1}^{t_{i}} h_{i j k} y_{i j k}\left(1-h_{i j k}\right)^{1-y_{i j k}}
$$

\section{Construção da verossimilhança:}

A seguir, $\mathrm{i}=1, \ldots, \mathrm{N}_{\mathrm{k}}$ denotam os $\mathrm{N}_{\mathrm{k}}$ contratos do grupo $\mathrm{k}$. Assim, verossimilhança de cada um dos três grupos tem a forma:

$$
L_{k}(\mathbf{Y} ; \Theta \mid \mathbf{X})=\prod_{i=1}^{N_{k}} P\left(\mathrm{~J}_{\mathrm{i}}=\mathrm{j}_{\mathrm{i}} \mid \Theta ; \mathbf{X} ; \mathrm{G}=\mathrm{k}\right)=\prod_{i=1}^{N_{k}}\left[\boldsymbol{h}_{i j_{i} k} \prod_{j=1}^{j_{i}-\mathbf{1}}\left(\mathbf{1}-\boldsymbol{h}_{i j k}\right)\right]
$$

E a função de verossimilhança pode então ser reescrita como:

$$
L(T ; \beta \mid X)=\prod_{i=1}^{N_{k}} \prod_{j=1}^{j_{i}} h_{i j k}^{y_{i j k}}\left(1-h_{i j k}\right)^{1-y_{i j k}}
$$

Temos, portanto, que a função de verossimilhança em (a.6) pode ser escrita com a mesma forma analítica que a verossimilhança de uma regressão logística, com cada 


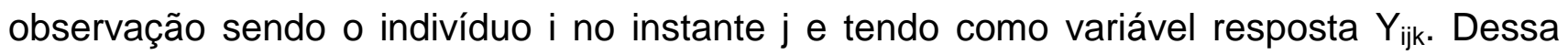
forma, os parâmetros $\Theta_{\mathbf{k}}=\left(\boldsymbol{\alpha}_{\mathbf{k}}, \boldsymbol{\beta}_{\mathbf{k}}\right)$ podem ser estimados em qualquer pacote estatístico que resolva a regressão logística.

Este modelo é um modelo longitudinal com resposta binária, em que cada indivíduo é observado diversas vezes até que o evento ocorra. Assim, para estimar os parâmetros do modelo descrito para o evento $k$, deve-se preparar a base de dados da seguinte forma:

1. Separar somente os contratos nos quais observou-se a ocorrência do evento k antes dos outros dois eventos;

2. Replicar na base de dados, ji vezes, cada linha correspondente ao contrato i, construindo as variáveis $D_{\mathrm{ijl}}$ e $Y_{\mathrm{ijk}}$, conforme a definição em 6.1.

Note que a estrutura de correlação entre as probabilidades de ocorrência do evento em cada tempo está contemplada na medida em que essas probabilidades são decompostas nos $h_{\mathrm{ijk}}$ 's através de probabilidades condicionais.

\section{APÊNDICE 2.3. Modelo de tempo até evento com riscos competitivos}

O modelo anterior descreve o tempo até evento condicionado à ocorrência do evento de um dos três tipos de evento. O modelo descrito a seguir considera os três riscos incondicionalmente, bem como casos de censura - quer seja porque o contrato foi encerrado por algum motivo não contemplado quer seja porque no momento da coleta dos dados o contrato ainda permanecera em aberto.

\section{Sejam:}

$$
Y_{i t 0}=\left\{\begin{array}{c}
1 \text { se o contrato } i \text { teve a parcela t paga normalmente e continuou ativo. } \\
0 \text { caso contrário }
\end{array}\right.
$$

$Y_{i t 1}=\left\{\begin{array}{c}1 \text { se o contrato } i \text { foi quitado sem despesas de cobrança, antes de pagar a parcela } t \\ 0 \text { caso contrário }\end{array}\right.$ $Y_{i t 2}=\left\{\begin{array}{c}1 \text { se o contrato } i \text { foi quitado com despesas de cobrança, antes de pagar a parcela } t \\ 0 \text { caso contrário }\end{array}\right.$

$$
Y_{i t 3}=\left\{\begin{array}{c}
1 \text { se o contrato i lançado a prejuízo, antes de pagar a parcela } t \\
0 \text { caso contrário }
\end{array}\right.
$$


Definimos também:

$T_{i k}-0$ número de parcelas pagas até que ocorra o evento k no contrato $\mathrm{i}$, com $\mathrm{k}=1$, 2, 3 e $T_{i 1} \neq T_{i 2}, T_{i 2} \neq T_{i 3}$ e $T_{i 1} \neq T_{i 3}$, pois é possível ocorrer apenas um evento em cada contrato, encerrando o processo.

$$
T_{i}=\min T_{i k}
$$

$K_{i}=K$ tal que $T_{i k}=T_{i}$

$c_{i}=\left\{\begin{array}{l}1 \text { se o contrato foi censurado } \\ 0 \text { caso contrário }\end{array}\right.$

A contribuição com a verossimilhança de um contrato encerrado pode ser escrita inicialmente como:

$$
P\left(T_{i}=t_{i} ; K_{i}=k_{i}\right)
$$

E a contribuição de um contrato não encerrado:

$$
P\left(T_{i}>t_{i}\right)
$$

Em uma análise de sobrevivência realizada anteriormente, a função de risco é definida como $h_{i j}=P\left(T_{i}=t_{i} \mid T_{i} \geq t_{i}\right)$, pois existe o risco de ocorrência de apenas um tipo de evento. Definiremos a seguir as funções de risco de cada tipo de evento:

$$
\begin{aligned}
& h_{i t 1}=P\left(T_{i}=t ; K_{i}=1 \mid T_{i} \geq t\right) \\
& h_{i t 2}=P\left(T_{i}=t ; K_{i}=2 \mid T_{i} \geq t\right) \\
& h_{i t 3}=P\left(T_{i}=t ; K_{i}=3 \mid T_{i} \geq t\right) \\
& h_{i t 0}=1-\left(h_{i t 1}+h_{i t 2}+h_{i t 3}\right)
\end{aligned}
$$

Note que $h_{\text {ito }}$ é a probabilidade de o contrato i não se encerrar na parcela t, dado que está ativo na parcela t-1. Vale lembrar que os eventos são disjuntos.

Podemos agora reescrever as probabilidades dos eventos observados na amostra que contribuirão com a verossimilhança, no caso não censurado e censurado da seguinte forma: 
Não censurado:

$$
P\left(T_{i}=t_{i} ; K_{i}=k\right)=\left[\prod_{t=0}^{t_{i}-1} h_{i i 0}\right] h_{i t_{i} k}
$$

Caso censurado:

$$
P\left(T_{i}>t_{i}\right)=\left[\prod_{t=0}^{t_{i}-1} h_{i t 0}\right]
$$

Combinando os dois modelos anteriores, temos que, a cada parcela de um contrato, ocorre um e somente um de quatro eventos:

0) A parcela é paga e o contrato permanece ativo;

1) O contrato é quitado sem a ocorrência de sinistro;

2) O contrato é quitado com ocorrência de sinistro;

3) O contrato é lançado a prejuízo, com apenas as parcelas anteriores.

Observe que no caso de o contrato não ser encerrado até a última parcela, o evento (0) terá probabilidade zero.

Dessa forma, podemos desenvolver as contribuições com as verossimilhanças:

Caso não censurado:

$$
P\left(T_{i}=t_{i} ; K_{i}=k\right)=\prod_{i=0}^{t_{i}} h_{i t 0}{ }^{Y_{i j 0}} h_{i t 1}{ }^{Y_{i j 1}} h_{i t 2}{ }^{Y_{i j 2}} h_{i t 3}{ }^{Y_{i j 3}}
$$

Note que a mesma equação vale para o caso censurado:

$$
P\left(T_{i} \geq t_{i}\right)=\prod_{t=0}^{t_{i}} h_{i t 0}{ }^{Y_{i j 0}} h_{i t 1}{ }^{Y_{i j 1}} h_{i t 2}{ }^{Y_{i j 2}} h_{i t 3}{ }^{Y_{i j 3}}
$$

Definimos agora as funções de riscos condicionais:

$$
\theta_{i t 3}=P\left(Y_{i t 3}=1 \mid Y_{i 10}=1, \ldots Y_{i(t-1) 0}=1\right)
$$




$$
\begin{gathered}
\theta_{i t 2}=P\left(Y_{i t 2}=1 \mid Y_{i 10}=1, \ldots Y_{i(t-1) 0}=1, Y_{i t 3} \neq 1\right) \\
\theta_{i t 1}=P\left(Y_{i t 1}=1 \mid Y_{i 10}=1, \ldots Y_{i(t-1) 0}=1, Y_{i t 3} \neq 1, Y_{i t 2} \neq 1\right) \\
\theta_{i t 0}=P\left(Y_{i t 0}=1 \mid Y_{i 10}=1, \ldots Y_{i(t-1) 0}=1, Y_{i t 3} \neq 1, Y_{i t 2} \neq 1, Y_{i t 1} \neq 1\right)
\end{gathered}
$$

E vamos escrever a verossimilhança dependendo dessas funções condicionais:

$$
\begin{aligned}
& L(Y ; \Theta)=\prod_{i=1}^{N} P\left(T_{i}=t_{i} ; K_{i}=k\right)^{1-c_{i}} P\left(T_{i}>t_{i}\right)^{c_{i}} \\
& L(Y ; \Theta)=\prod_{i=1}^{N} \prod_{t=1}^{t_{i}} h_{i t 3}{ }^{Y_{i t 3}} h_{i t 2}{ }^{Y_{i t 2}} h_{i t 1}{ }^{Y_{i t 1}} h_{i t 0}{ }^{Y_{i t 0}} \\
& =\prod_{i=1}^{N} \prod_{t=1}^{t_{i}} \times \begin{array}{c}
\theta_{i t 3}{ }^{Y_{i t 3}}\left(\theta_{i t 2}\left(1-\theta_{i t 3}\right)\right)^{Y_{i t 2}} \\
\times\left(\theta_{i t 1}\left(1-\theta_{i t 2}\right)\left(1-\theta_{i t 3}\right)\right)^{Y_{i t 1}} \\
\left(\left(1-\theta_{i t 1}\right)\left(1-\theta_{i t 2}\right)\left(1-\theta_{i t 3}\right)\right)^{Y_{i t 0}}
\end{array} \\
& =\prod_{i=1}^{N} \prod_{t=1}^{t_{i}} \theta_{i t 3}{ }^{Y i j 3}\left(1-\theta_{i j 3}\right)^{Y_{i j 0}+Y_{i j 1}+Y_{i j 2}} \theta_{i j 2}{ }^{Y_{i j 2}}\left(1-\theta_{i j 2}\right)^{Y_{i j 0}+Y_{i j 1}} \theta_{i j 1}{ }^{Y_{i j 1}}\left(1-\theta_{i j 1}\right)^{Y_{i j 0}} \\
& =\left[\prod_{i=1}^{N} \prod_{t=1}^{t_{i}} \theta_{i j 3}{ }^{Y i t 3}\left(1-\theta_{i t 3}\right)^{Y_{i t 0}+Y_{i t 1}+Y_{i t 2}}\right] \\
& \times\left[\prod_{i=1}^{N} \prod_{t=1}^{t_{i}} \theta_{i t 2}{ }^{Y_{i t 2}}\left(1-\theta_{i t 2}\right)^{Y_{i t 0}+Y_{i t 1}}\right] \\
& \times\left[\prod_{i=1}^{N} \prod_{t=1}^{t_{i}} \theta_{i t 1}^{Y_{i t 1}}\left(1-\theta_{i t 1}\right)^{Y_{i t 0}}\right]
\end{aligned}
$$

Podemos ainda definir os conjuntos de parcelas de modo a agrupar os eventos:

$P_{k}=\left\{(i, t)\right.$ tal que $Y_{i t 0}=k$ ou $\left.Y_{i t 0}=0\right\}$ com $\mathrm{k}=1,2,3$.

Então a verossimilhança pode novamente ser reescrita como: 


$$
\begin{aligned}
& L(Y ; \Theta)=\left[\prod_{P_{1}} \theta_{i t 3}{ }^{Y i t 3}\left(1-\theta_{i t 3}\right)^{1-Y_{i t 3}}\right] \\
& \times\left[\prod_{P_{2}} \theta_{i t 2}^{Y^{i t 2}}\left(1-\theta_{i t 2}\right)^{1-Y_{i t 2}}\right] \\
& \times\left[\prod_{P_{3}} \theta_{i t 1}^{Y^{i t 1}}\left(1-\theta_{i t 1}\right)^{1-Y_{i t 1}}\right]
\end{aligned}
$$

Podemos colocar em $\theta_{i t 1}, \theta_{i t 2} e \theta_{i t 3}$ um modelo logístico, escrevendo-os da seguinte forma:

$$
\theta_{i t k}=\frac{1}{1+e^{-\left(D_{1 i t} \alpha^{\prime}{ }_{k 1}+\cdots+D_{T i t} \alpha^{\prime}{ }_{k T}+X_{i 1} \beta^{\prime}{ }_{k 1}+\cdots+X_{i p} \beta^{\prime}{ }_{k p}\right)}}
$$

Uma vez que a verossimilhança pôde ser fatorada em três partes dependentes apenas de $\theta_{\mathrm{it} 1}, \theta_{\mathrm{it} 2}$, e $\theta_{\mathrm{it} 3}$, podemos estimá-los com algoritmos independentes. Além disso, os respectivos fatores de cada uma das três funções de risco são equivalentes a verossimilhanças de regressões logísticas. Assim, os parâmetros a e $\beta$ podem ser estimados através de algoritmos de estimação para modelos de regressão logística. 


\section{APÊNDICE 3. Técnicas estatísticas tradicionais}

Neste apêndice são discutidas algumas técnicas estatísticas consideradas mais tradicionais pelos autores, já apresentadas também em outros trabalhos.

\section{APÊNDICE 3.1. Teste de Hosmer \& Lemeshow}

O Teste de Hosmer \& Lemeshow (Hosmer \& Lemeshow, 1989) é um teste de adequabilidade de ajuste proposto para modelos cuja variável resposta é binária (por exemplo, a regressão logística), proposto especificamente para o caso o número de "perfis de covariáveis" (J) é muito próximo do tamanho da amostra (n). Ou seja, existe quase que uma combinação de variáveis explicativas $\mathbf{x}_{\mathbf{i}}$ (perfil de covariável) para cada indivíduo i dentro da amostra em que o teste será aplicado. Isto ocorrerá em modelos com pelo menos uma variável explicativa contínua (que é o caso dos modelos desta dissertação).

Descreveremos a seguir a forma mais comum (e recomendada pelos autores do teste) de construção do teste de Hosmer \& Lemeshow:

Agrupar as $n$ observações em $\mathrm{g}=10$ grupos, de acordo com os decis da probabilidade estimada de ocorrência do evento de interesse. Isto é, sejam $d_{1}, d_{2}, \ldots, d_{9}$ os decis calculados das probabilidades estimadas $\hat{p}_{i}(\mathrm{i}=1, \ldots, \mathrm{n})$. Cada indivíduo terá um grupo $g_{i}$ de modo que:

$$
g_{i}=\left\{\begin{array}{c}
1 \text { se } \hat{p}_{i} \leq \mathrm{d}_{1} \\
k \text { se } d_{k-1}<\hat{p}_{i} \leq \mathrm{d}_{\mathrm{k}}(k=2, \ldots, 9) \\
10 \text { se } \hat{p}_{i}>\mathrm{d}_{9}
\end{array}\right.
$$

A estatística $\hat{C}$ do teste é então definida como:

$$
\hat{C}=\sum_{k=1}^{g} \frac{\left(o_{k}-n^{\prime}{ }_{k} \bar{\pi}_{k}\right)^{2}}{n^{\prime}{ }_{k} \bar{\pi}_{k}\left(1-\bar{\pi}_{k}\right)^{\prime}}
$$

Em que $n_{k}^{\prime}$ é o número total de indivíduos no grupo $k$, e sendo $c_{k}$ denota o número de perfis de covariáveis no grupo $k$,

$$
o_{k}=\sum_{j=1}^{c_{k}} y_{j}
$$


É o número de ocorrências do evento dentro do grupo k, e

$$
\bar{\pi}_{k}=\sum_{j=t}^{c_{k}} \frac{m_{j} \hat{\pi}_{j}}{n^{\prime}{ }_{k}}
$$

É a média das probabilidades estimadas do grupo $\mathrm{k}$.

Foi verificado através de simulações (Hosmer, 1980) que, quando existe um perfil de covariável para cada observação, $\hat{C}$ tem distribuição aproximada qui-quadrado com $g$-2 graus de liberdade, sob $\mathrm{H}_{0}$ : o modelo estimado é adequado.

\section{APÊNDICE 3.2. Estatística de Kolmogorov \& Smirnov}

Kolmogorov e Smirnov propuseram uma metodologia de comparação de distribuições descrita em (Conover, 1999), que pode ser utilizada, em particular, para a comparação das distribuições de uma variável aleatória em duas populações.

Sejam os $\mathrm{N}$ indivíduos divididos em dois grupos, de tal forma que para o grupo 1 teremos $\mathrm{y}_{\mathrm{i}}=0$ e para o grupo $2 \mathrm{y}_{\mathrm{i}}=1$, com $\mathrm{i}=1,2, \ldots \mathrm{N}$. Dado um classificador $e$, sejam as funções de distribuição empíricas do classificador para cada um dos grupos:

$$
F_{0}(x)=\frac{\sum_{i=1}^{N} \mathbf{1}\left(y_{i}=0 ; e_{i} \leq x\right)}{\sum_{i=1}^{N} y_{i}} \quad \text { e } \quad F_{1}(x)=\frac{\sum_{i=1}^{N} \mathbf{1}\left(y_{i}=0 ; e_{i} \leq x\right)}{N-\sum_{i=1}^{N} y_{i}}
$$

A estatística do teste de Komlogorov e Smirnov se baseia na distância $D$ :

$$
D=\max _{x}\left|F_{0}(x)-F_{1}(x)\right|
$$

Essa medida distância indica o quanto as medidas do classificador são distintas entre os dois grupos. Ela varia entre zero e um, sendo zero quando as distribuições empíricas são idênticas e um quando são totalmente separadas (o mínimo de uma é maior que o máximo da outra). 


\section{APÊNDICE 3.3. Curva ROC}

Para um dado modelo binário, digamos, que estime a proporção de clientes pertencentes ao grupo 3 contra os demais, podemos classificá-los como pertencentes ao grupo 3 se a proporção dada pelo modelo for maior que $\mathrm{C}$, e como não pertencentes ao grupo 3 em caso contrário. Para cada valor de $\mathrm{C}$, a sensibilidade é definida como a probabilidade de um cliente ser classificado como sendo do grupo 3 , dado que ele realmente pertence ao grupo 3 , e a especificidade é definida como a probabilidade de 0 cliente não pertencer ao grupo 3 dado que ele realmente não pertence ao grupo 3 .

Conforme C varia no intervalo [0,1], a especificidade aumenta - mais clientes vão sendo classificados como sendo do grupo 3 , e a especificidade diminui - pois menos contratos vão sendo classificados como sendo do grupo 3. A curva ROC é obtida ao se construir um gráfico com todos os pontos formados por (especificidade, 1-sensibilidade) para cada possível valor de C.

Um bom modelo fornecerá uma curva ROC com valores elevados de especificidade combinados com baixos valores de (1-sensibilidade), ou seja, para os clientes pertencentes ao grupo 3 teríamos altas taxas de classificação correta, e para os contratos não pertencentes ao grupo 3 , poucos deles seriam classificados erroneamente no grupo 3 . 


\section{Bibliografia}

Alves, M. C. (2008). Estratégias para o desenvolvimento de modelos de Credit Score com inferência de rejeitados. São Paulo, Brasil: Dissertação de Mestrado. Instituto de Matemática e Estatística - Universidade de São Paulo.

Conover, W. J. (1999). Practical nonparametric statistics. New York: Wiley.

Glantz, M. (2003). Managing Bank Risk: An Introduction to Broad-Base Credit Engineering . Londres: Academic Press.

Hosmer, D. W. (1980). A goodness-of-fit test for the multiple logistic regression model. Communications in Statistics, A10, 1 043-1069.

Hosmer, D. W., \& Lemeshow, J. S. (1989). Applied logistic regression. New York: Willey.

Hosmer, D. W., \& Lemeshow, J. S. (1999). Applied survival analysis : regression modeling of time to event data. New York: John Wiley.

Martinez, E. Z., Neto, F. L., \& Pereira, B. d. (2003). A curva ROC para testes diagnósticos. Caderno Saúde Coletiva, Rio de Janeiro, p. 7-31.

Moraes, D. d. (2008). Modelagem de Fraude em Cartão de Crédito. São Carlos, Brasil: Dissertação de Mestrado. Departamento de Estatística - Universidade Federal de São Calros.

Neter, J., Kutner, M. H., Nachtsheim, C. J., \& li, W. (2004). Applied linear regression models 4ed. New York: Irwin.

Pereira, C. A. (1990). Influence Diagrams and Medical Diagnosis. In: R. M. Smith, Influence Diagrams, Belief Nets and Decision Analisys (pp. 351-358). New York: John Wiley and Sons.

Pompeu, J. N., \& Hazzan, S. (2007). Matemática Financeira - 6a. ed. São Paulo: Saraiva. 
Porteous, B. T., \& Tapadar, P. (2006). Economic Capital and Financial Risk Management for Financial Services Firms and Conglomerates. New York: Palgrave Macmillan.

Rosa, P. d. (2000). MODELOS DE "CREDIT SCORING": REGRESSÃO LOGÍSTICA, CHAID E REAL. São Paulo, Brasil: Dissertação de Mestrado. Instituto de Matemática e Estatística - Universidade de São Paulo.

Singer, J. D., \& Willet, J. B. (1993). It's About Time: Using Discrete-Time Survival Analysis to Study Duration and Timming of Events. (H. U. Statistics, Ed.) Journal of Educational Statistics , 18, 155-195.

Stern, J. M., \& Shieli, J. S. (2001). The EVA challenge: implementing valueaddedchange in an organization. New York: John Wiley \& Sons.

Stolf, W. A. (2008). Quantificação do risco de crédito: Um estudo de casos utilizando o modelo Creditrisk. Piracicaba, Brasil: Universidade de São Paulo - Escola Superior de Agricultura.

Straub, E. (1988). Non-life Insurance Mathematics. Zürich: Springer-Verlag Berlin Heidelberg and Associations of Swiss Actuaries.

Tomazela, S. M. (2007). Avaliação do desempenho de modelos de Credit Score ajustados por Análise de Sobrevivência. Brasil: Dissertação de Mestrado. Instituto de Matemática e Estatística - Universidade de São Paulo.

Vieira Sobrinho, J. D. (2006). Matematica financeira . São Paulo: Atlas.

Vuk, M., \& Curk, T. (2006). ROC Curve, Lift Chart and Calibration Plot. Metodoloski zvezki, vol. 3, No. $1,89-108$. 